Linköping Studies in Science and Technology

Dissertations, No. 1864

Stimulating the diffusion of environmental technologies through export

Wisdom Kanda

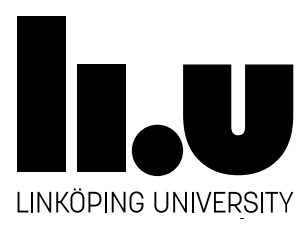

Linköping, 2017

Environmental Technology and Management

Department of Management and Engineering

Linköping University, SE-581 83 Linköping, Sweden

www.liu.se 


\section{Cover page}

The conceptual figure on the cover page is an attempt to synthesise the core message of the thesis. The export of environmental technologies is conceptualised to be influenced by five main elements which are discussed throughout the thesis. Actors interested in the overarching topic of stimulating the diffusion of environmental technologies through export should aim to analyse these elements for a comprehensive understanding of the subject.

(C) Wisdom Kanda, 2017

Stimulating the diffusion of environmental technologies through export Linköping Studies in Science and Technology

Dissertations, No. 1864

ISSN: 0345-7524

ISBN: 978-91-7685-495-2

Printed in Sweden by LiU-Tryck, Linköping, 2017

Distributed by:

Linköping University

Department of Management and Engineering

SE-581 83 Linköping, Sweden

Phone: +4613281000 
"...to be a successful academic...you need the strength of a horse, the hide of an elephant, and the work ethic of a honey bee."

- Sir J. Fraser Stoddart (The Nobel Prize winner in Chemistry, 2016) 



\begin{abstract}
Contemporary environmental problems represent complex societal challenges, and as these problems become increasingly global, the international diffusion of environmental technologies is essential. One way to diffuse technologies internationally is through export. Despite the potential benefits from the adoption of environmental technologies, their export is stifled by externalities and free-rider problems.
\end{abstract}

From this background, the aim of this thesis is to analyse how to stimulate the diffusion of environmental technologies through export. This aim is operationalised using four research questions, which focus on governmental initiatives to promote environmental technology export and their perceived effectiveness among targeted firms, obstacles to and drivers for export among municipally owned companies, the use of international city networks to facilitate environmental technology export and components of business concepts for environmental technology export. These questions are explored in the Swedish context using document analyses, interviews and internet surveys in a compilation thesis which consists of a cover essay and an appendix of five scientifically peer-reviewed and published journal articles.

The conclusions are that governmental export promotion initiatives are often generic for all kinds of exporters, including environmental technologies, and comprise financial support, information provision, education and training, and trade and mobility-related programs, often with little incorporation of the specific characteristics of environmental technologies which many exporters perceive as ineffective. Municipally owned companies experience different barriers to and drivers for engaging in international activities compared to privately owned companies, and are often involved in international projects which are not always commercial export. International city networks serve as important arenas for bi-directional information sharing and learning regarding market characteristics, environmental challenges and potential solutions, building legitimacy for technologies and their suppliers. Regarding components of business concepts for the export of environmental technologies, regulation, legitimacy and private-public partnership are identified as particularly important based on the complexity and systemic nature of environmental technologies.

Altogether, this thesis makes a contribution by conceptualising the export of environmental technologies with emphasis on technology characteristics, the technology supplier including their business concepts, obstacles to and drivers for export, technology adopters and their characterisation, communication channels and the diffusion context. For policy makers, a dynamic approach to environmental technology export promotion, in which specific attributes of environmental technologies and their suppliers are considered along their international business development, is suggested as a complement to existing generic initiatives. The possibility to provide such support should be reconciled with resource effectiveness, heterogeneity among companies and the complementary role of governmental interventions to market initiatives. Finally, partnerships between publicly and privately owned companies are suggested as particularly relevant since they build on the long-term experience, functioning proof-of-concept and legitimacy of publicly owned companies together with the competitiveness and flexibility of privately owned companies. These attributes could help overcome the liabilities of foreignness and newness, as well as resource constraints which challenge environmental technology export. 


\section{Sammanfattning}

De stora miljöproblemen innebär komplexa samhällsutmaningar och allt eftersom miljöproblem globaliseras ökar behovet av en internationell spridning av miljöteknik. Export är ett sätt att sprida teknologier internationellt, men trots de potentiella fördelarna med miljöteknikexport stöter det ofta på hinder. Exempel på sådana hinder är externa effekter som att miljönytta inte tillfaller det exporterande företaget, och att konkurrenter åker snålskjuts på de företag som tar de initiala stegen.

Utifrån denna bakgrund syftar den här avhandlingen till att analysera hur miljöteknikexport kan stimuleras ytterligare. För att besvara syftet har fyra frågeställningar utformats som fokuserar på statliga initiativ för att främja export av miljöteknik och hur deras effekter uppfattas bland företag i målgruppen; hinder och drivkrafter för export hos kommunala bolag; internationella nätverk mellan storstäder som arenor för att underlätta export av miljöteknik; samt affärsmodeller för att exportera miljöteknik. Frågeställningarna utforskas i ett svenskt sammanhang genom dokumentanalys, intervjuer och enkäter. Avhandling bestående av en sammanfattande "kappa" och fem publicerade vetenskapliga artiklar.

Resultaten från avhandlingen visar att statliga initiativ för att främja export oftast är generiska för olika typer av exportörer inklusive miljöteknikföretag. Initiativen inkluderar vanligtvis finansiellt stöd, information, utbildning samt stöd för marknadsbesök och mobilitet. Dock tas ingen större hänsyn till de särskilda egenskaperna hos miljöteknik vid utformandet av stödet. Stödet uppfattas dessutom av många miljöteknikexportörer som ineffektivt. Kommunala bolag har andra hinder och drivkrafter än privata företag för att engagera sig internationellt och är oftast involverade i projekt som inte är direkta exportaktiviteter. Internationella nätverk mellan städer kan fungera som arenor för informationsutbyte och lärande mellan olika aktörers marknadsegenskaper, miljöproblem och potentiella lösningar samt bidra till legitimitet för tekniken och dess leverantörer. När det gäller utveckling av affärsmodeller för att exportera miljöteknik framstår lagstiftning, legitimitet, och samarbete mellan privata och offentliga aktörer som särskilt viktigt att beakta på grund av miljöteknikens komplexitet och systemiska natur.

Sammanfattningsvis bidrar avhandlingen till en konceptualisering av miljöteknikexport genom att fokusera på teknikens egenskaper, dess leverantörers affärsmodeller, hinder och drivkrafter för export, de som köper tekniken och deras egenskaper, kommunikationskanaler samt sammanhang där spridningen sker. En rekommendation är att politiska beslutsfattare borde stödja export av miljöteknik på ett dynamiskt sätt där specifika egenskaper hos miljöteknik och dess leverantörer beaktas i takt med deras internationella affärsutveckling. En dynamisk ansats kan vara ett bra komplement till många befintliga generiska statliga initiativ för att främja export av miljöteknik. En sådan ansats bör ta hänsyn till resurseffektivitet, olikheter mellan företag, samt vara komplementär till de icke-statliga initiativ som redan finns på marknaden. Slutligen föreslås samarbeten mellan offentliga och privatägda företag, vilket anses högst relevant eftersom offentliga företag kan bidra till att kombinera den mångåriga erfarenheten av miljötekniska lösningar samt den legitimitet som sådana företag kan ha med privata företags styrkor så som konkurrenskraft och flexibilitet. Dessa förslag kan bidra till att minska de exporthinder som har att göra med att miljöteknik ofta är ny och främmande, samt miljöteknikföretagens ofta begränsade resurser. 


\section{Acknowledgements}

There is a traditional African proverb which goes like this: "It takes a village to raise a child." At this stage of my Ph.D. research education, this proverb makes particular sense to me because I have found a community of family, friends and colleagues who have provided essential support and guidance for me throughout my research education.

To my supervisors, thank you very much for giving me the opportunity to work with you. You did not only give me a life-changing opportunity, but you have also dedicated an important part of your own careers to train me to become a researcher. I am forever grateful! To Olof, thank you for meticulously reading each and every manuscript that I have written and for being always available for discussions and feedback. To you, Dzamila, I always appreciate your comments and feedback which challenge me to broaden my perspectives out of my comfort zone. I have also enjoyed our conversations on a range of different topics during many of our research project trips abroad.

To my co-authors, I sincerely appreciate your openness and willingness to listen to me every time I approached with an idea for a manuscript. Santiago Mejiá-Dugand, Tomohiko Sakao, Kajsa Kairento and Marcus Nygårds, thank you for your various contributions and I wish you all the best in your individual endeavours and hope we can find common interests to work together again. I also want to say a special thank you to Dr. Pablo del Río, from the Spanish National Research Council, for providing constructive comments and feedback on an earlier version of the thesis during my final internal seminar. Also to Professor Stefan Anderberg, thank you for taking time off your busy schedule and research trips to read and discuss the thesis in detail with me. Your efforts have really helped to improve the thesis. A special thank you also goes to Johannes Matschewsky and Santiago Mejiá-Dugand for providing feedback on the earlier version of the thesis while it was still under development.

I am sincerely grateful to the organizations which funded the different research projects upon which this thesis is based: The Swedish Innovation Agency (VINNOVA), Tekniska verken i Linköping AB's Industrial Ecology Research Programme, Eco-innovera through The Swedish Research Council (Formas), The Swedish Energy Agency (Energimyndigheten), The Swedish International Centre for Local Democracy (ICLD), and The European Union Regional Development Fund. To all the companies who took part in my studies through interviews, responding to surveys and participating in workshops, I appreciate your time and efforts and I hope you find some use of the results in your export ambitions.

To my colleagues at the division of Environmental Technology and Management, you have been of tremendous support, both in and outside the university. To all those who read the thesis and provided written comments and feedback (Mats, Sara, Jonas, Tom, Raphael...), I appreciate your time and efforts. To my current and previous office mates (Paul, Sophia, Roozbeh, Amir), we have engaged in various discussions and collaborations which I deem very fruitful in my development. To you, Maria Eriksson, you have been an essential support for all the administrative processes and also for helping me practise my Swedish. Tack ska $d u$ har! To all other colleagues, thank you for the coffee breaks (fika), an important moment to relax and talk about other important issues in life apart from research. 
Finally, a special thank you goes to my parents and siblings (Edwin, Winfred and Pearl). You have been my backbone and supported me in every endeavour I undertook, even deciding to pursue my academic ambitions in the faraway land of Sweden. To Anders, Marie, Samuel and Johanna and Tina (of blessed memory), you have been my extended family here in Sweden. To my new family, thank you Agnes for your love and hard work in supporting our family and making sure that everything is in order. To you, Serena, if you are reading this, it means you have come of some age and I challenge you to achieve even more than this, "for the greatest benefit to mankind".

To everyone, mentioned here or not, who has contributed in diverse ways through their encouragement and support (Yaw, Andrews, Mesfin, Marianna...), I say a big thank you. This long and winding journey seems to be ending, only for other goals and ambitions to begin.

It always seems impossible until it's done

- Nelson Mandela (1918-2013). 


\section{Preface}

The objective of writing this preface is to give readers an insight into my experiences of the Ph.D. research education process at Linköping University, Sweden. This preface is thus fundamental to fully comprehend the content and appreciate the contribution of this thesis.

This Ph.D. thesis is the outcome of approximately four years of full-time research education at Linköping University, Sweden. A Ph.D. research education at Linköping University is composed of mainly two parts, participating in (i) scientific research education and (ii) institutional duties.

I fulfilled the scientific research education part of my training by participating in different local, national and international research projects and also completing Ph.D. education courses. My participation in these research projects was through empirical data collection, analysis, co-creation of knowledge and dissemination through scientific journal articles, international conferences, project reports and interactions with practitioners. For the Ph.D. education courses, a doctoral student has the freedom to choose certain courses, while others are mandatory for a particular research education subject area. The courses that I chose to study were inspired by two main reasons (i) to broaden my knowledge base and competence into other subjects, e.g. basic statistics and entrepreneurship; and (ii) to deepen my understanding in the subject of environmental technology and management, which was the core of my master's education in Energy and Environmental Engineering. The mandatory courses are intended to form a foundation from which a Ph.D. student can progress in his or her scientific knowledge development. The mandatory courses which I took fall broadly under the subject area of environmental engineering and environmental management, and include corporate environmental management, industrial symbiosis, and environmental systems analysis.

On the other hand, I have participated in institutional duties by teaching, examination, organising field trips, seminars and supervision at the graduate and undergraduate level. These activities are to develop the Ph.D. student as a potential researcher who, in addition to developing scientific knowledge, is also capable of sharing this knowledge with society at large through education, teaching and co-creation activities.

The aim of this thesis is to analyse how to stimulate the diffusion of environmental technologies through export. This is undertaken in a cover essay (known in Swedish as a Kappa) based on five scientifically peer-reviewed and published journal articles. These articles are interrelated and complementary to each other, but also serve as independent scientific articles which address specific research questions in-depth.

In writing this thesis, I have engaged with privately and municipally owned companies from different perspectives in an attempt to comprehensively address the overarching aim and develop scientific knowledge of relevance for theory and practice. In addition to studying the topic of this thesis as an "outsider", I have also actively participated in a four-year project as an "insider" with industry practitioners where the focus was on the actual design, construction and operation of a potential environmental technology system - a waste recycling facility in Botswana, Southern Africa. Altogether, these experiences and the thesis writing culture at the Division of Environmental Technology and Management shape the outcome of my doctoral thesis. 


\section{List of appended scientific articles}

\section{Article 1:}

Kanda, W., Hjelm, O., \& Mejía-Dugand, S. (2016). Promoting the export of environmental technologies: An analysis of governmental initiatives from eight countries. Environmental Development, 17, 73-87.

\section{Article 2:}

Kanda, W., Mejía-Dugand, S., \& Hjelm, O. (2015). Governmental export promotion initiatives: awareness, participation, and perceived effectiveness among Swedish environmental technology firms. Journal of Cleaner Production, 98, 222-228.

\section{Article 3:}

Kanda, W., Hjelm, O., Kairento, K., \& Nygårds, M. (2016). Export of environmental technologies by publicly owned companies: approaches, drivers and obstacles among Swedish municipal companies. European Planning Studies, 24(12), 2175-2196.

\section{Article 4:}

Mejía-Dugand, S., Kanda, W., \& Hjelm, O. (2016). Analyzing international city networks for sustainability: a study of five major Swedish cities. Journal of Cleaner Production, 134, 61-69.

\section{Article 5:}

Kanda, W., Sakao, T., \& Hjelm, O. (2016). Components of business concepts for the diffusion of large scaled environmental technology systems. Journal of Cleaner Production, 128, 156-167. 


\section{Definitions}

In this section, I will attempt to briefly describe the use of some key terms in the context of this thesis. Furthermore, some of the terms are elaborated on in the text, including alternative definitions when used.

Technology: I understand technology in a broad sense as encompassing material and immaterial objects - both hardware and software that can be used to solve real-world problems and also technical knowledge embodied with the physical artefact.

Environmental technology: The definition provided by the Swedish Ministry of Environment is adopted: "goods, systems, processes and services that offer clear environmental advantages in relation to existing or alternative solutions, seen from an ecocycle perspective."

Invention: In this thesis, an invention constitutes the first development of a scientifically or technically new or improved technology from the perspective of the adopter.

Innovation: In this thesis, an innovation is something new with a high level of originality for customers or others for whom it may benefit, that breaks into (or obtains foothold in) society, often via the market.

Diffusion: In this thesis, diffusion refers to the planned and/or spontaneous spread of environmental technologies.

Export: The sale of technologies to international markets.

Internationalisation: A process of business development whereby a company becomes increasingly committed to and involved in international business operations.

Municipally owned company: A company wholly owned by one or several municipalities. 


\section{Table of Contents}

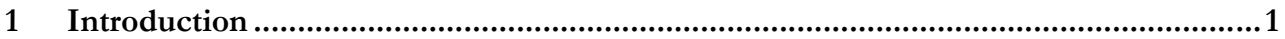

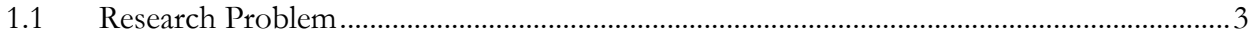

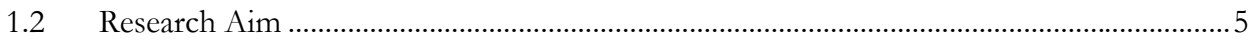

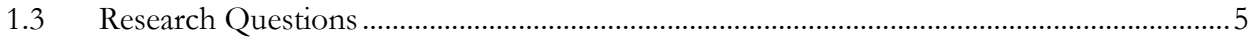

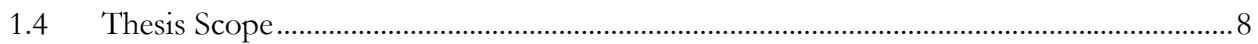

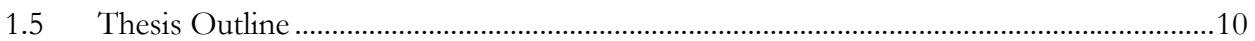

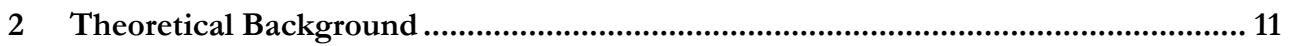

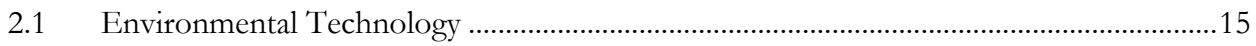

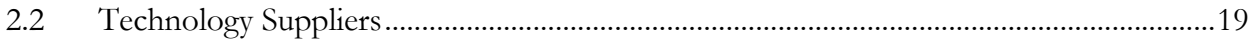

2.2.1 The Swedish Environmental Goods and Services Sector ...........................................19

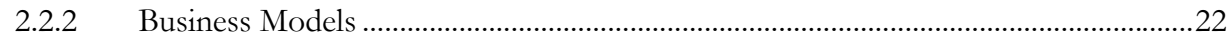

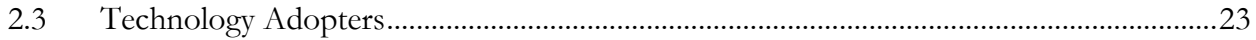

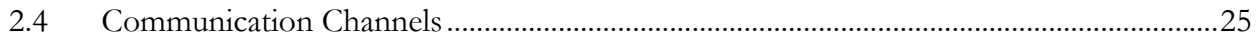

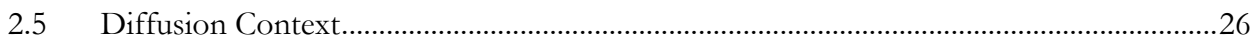

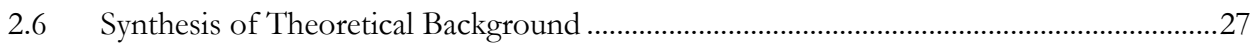

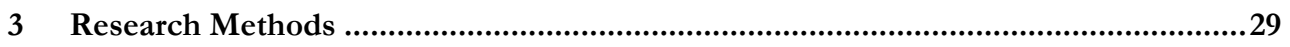

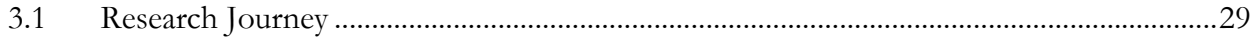

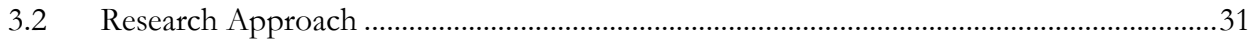

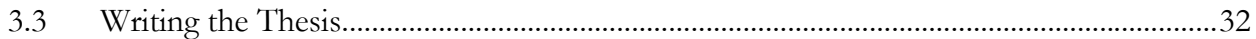

3.4 Overview of Research Methods ............................................................................................34

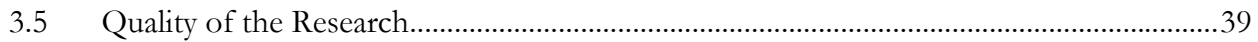

3.6 Reflexivity and Problematisation...................................................................................... 42

3.6.1 Implications of Research Design and Methods ......................................................... 42

3.6.2 Reflection on some key Assumptions and Theories ..................................................43

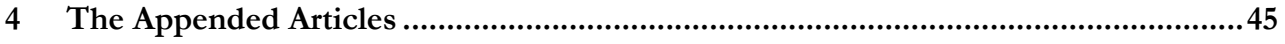

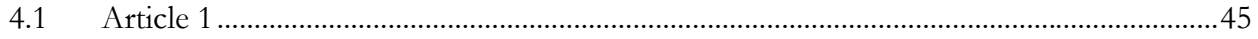

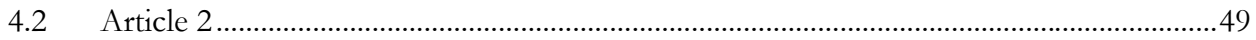

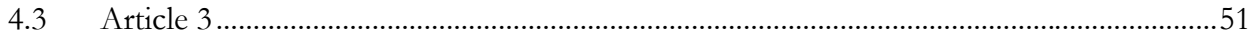

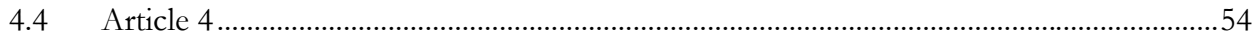

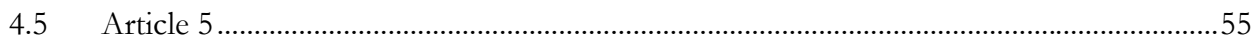

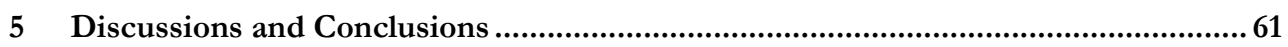

5.1 Governmental Export Promotion Initiatives and their Perceived Effectiveness ............61 
5.2 Obstacles to and Drivers for Environmental Technology Export among Municipally Owned Companies.

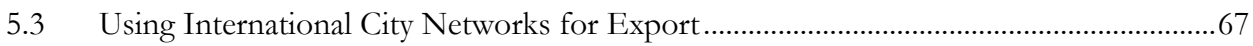

5.4 Components of Business Concepts for Environmental Technology Export ...................70

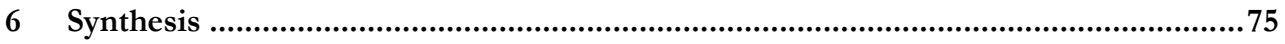

6.1 An attempt to Conceptualise the Diffusion of Environmental Technologies through

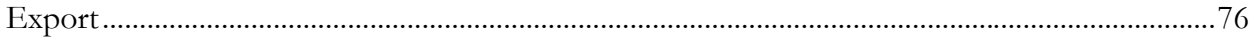

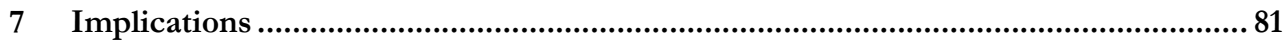

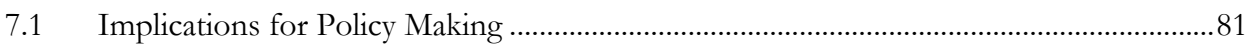

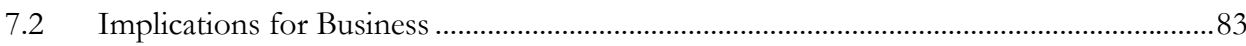

7.3 Implications for Further Research .................................................................................. 85

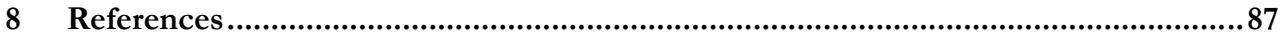




\section{List of Figures}

Figure 1: Adopter categorisation based on innovativeness (Rogers, 2003)......................................24

Figure 2: Connections between main elements in the research process............................................32

Figure 3: Governmental initiatives and implementation options for promoting environmental

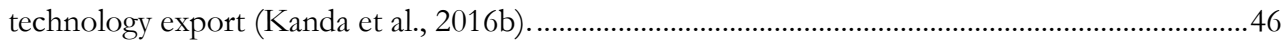

Figure 4: Awareness, participation and perceived effectiveness of governmental initiatives (Kanda

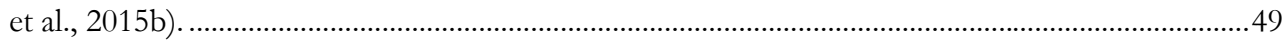

Figure 5: Frequency of mentioned challenges in export (Kanda et al., 2016a)................................52

Figure 6: Frequency of mentioned drivers for export (Kanda et al., 2016a)......................................53

Figure 7: Synthesis of components of business concepts for environmental technology export

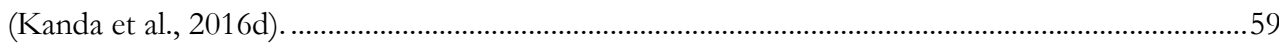

Figure 8: A conceptual model of the diffusion of environmental technologies through export....77 


\section{List of Tables}

Table 1: Overview of the environmental goods and services sector in Sweden (compiled from Statistics Sweden)

Table 2: Relation between research questions, appended articles and research methods...... . .33

Table 3: Pronounced characteristics of environmental technologies which could influence its export.

Table 4: Main elements in the diffusion of environmental technologies through export... . .77 


\section{Introduction}

This chapter starts broadly by highlighting some environmental problems which motivate the writing of this doctoral thesis. The chapter then narrows down to different approaches for addressing these environmental problems, and pinpoints potential gaps in scientific knowledge relating to one such approach - the diffusion of environmental technologies. This is followed by the aim and research questions, anchored in the knowledge gap together with the scope and outline for the entire thesis.

Environmental problems such as climate change, biodiversity loss, pollution, and natural resource depletion represent complex societal challenges. These environmental problems are complex because they are deeply interlinked with each other, have multiple causes, transcend several societal sub-systems such as the economy, culture, technology, ecology and institutions, and persist through several geographic and time scales (Grin et al., 2010). The complexity of these environmental problems demand approaches which are long-term focused, far-reaching in scope, deep structured and systemic, involving multiple actors and goals (Rennings, 2000).

As a response to these environmental problems, several initiatives continue to be propounded and implemented on different societal levels. These include the recent intergovernmental initiative to foster global development through the Sustainable Development Goals (UN General Assembly, 2015), international agreements to tackle climate change (e.g. UNFCCC, 2015), national and regional strategies towards a circular economy (e.g. European Commission, 2016), degrowth paradigms (e.g. Jackson, 2009), and industrial transformations through eco-innovation (e.g. OECD, 2009), but to mention a few. Even though these initiatives sometimes do differ in focus, temporal and geographical scope, stakeholders involved and the required institutional conditions, their overarching goal is often to reconcile economic development with environmental and social welfare.

In this regard, changes are needed in current socio-technical systems including technologies, institutions, infrastructure, lifestyles, and business models. These changes are even more pressing given the recent economic and social crises in certain parts of the world which reveal several challenges with the current short-term profitability strategies, policies and actions of individuals and firms (Boons et al., 2013). Albeit not sufficient, technological change is one of the essential requirements for tackling environmental problems (Del Río, 2009). Tackling environmental problems with technological change can be attributed to the double-edged-sword nature of technology with regards to environmental problems. This means that, in general, technological development and the increasing use of technology ${ }^{1}$ is one of the factors linked to the environmental burdens from economic activities and second, that certain types of technologies can as well reduce the environmental burdens from economic activities (Chertow, 2000a; Del Río, 2009). In this context, environmental technologies ${ }^{2}$, i.e. technologies that offer clear environmental advantages in relation to existing or alternative solutions, are relevant seen from a

\footnotetext{
${ }^{1}$ In line with Bergek et al. (2008), I understand technology in a broad sense as encompassing material and immaterial objects - both hardware (e.g. products, tools, and machines) and software (e.g. procedures, processes and digital protocols) - that can be used to solve real-world problems and also technical knowledge either in general terms or embodied with the physical artefact.

${ }^{2}$ See Subchapter 2.1 in Chapter 2 for a discussion of the term environmental technology.
} 
life-cycle perspective. The development and diffusion of environmental technologies continue to gather support as an essential component of approaches to tackle global environmental problems (Rennings, 2014).

However, technological solutions are no magic bullets, and thus are not the only way to address environmental problems. Indeed, even though energy and material resource efficiency has continuously increased throughout history, largely due to technological innovations, absolute environmental pressures related to primary energy and raw material use have continued to rise (Font Vivanco et al., 2015). This paradox is captured in the IPAT equation (Chertow, 2000b), which describes environmental impact (I) as a product of population (P), affluence (A), and technology $(\mathrm{T})$. The equation suggests that, the pressing environmental problems that the earth and its inhabitants face are a manifestation of the fact that technological improvements have not been able to offset the pressures from increases in population and affluence (Chertow, 2000a). The rationale that improvements in technological efficiency can induce increased consumption is coined as the environmental rebound effect (Font Vivanco et al., 2015). To this effect, nontechnological solutions such as changes in lifestyles and consumption patterns, e.g. autonomous downsizing of consumption, the consumption of alternate goods and services that do not induce environmental degradation - degrowth (see Jackson, 2009), can be environmentally desirable. However, the existence of rebound effects should not hinder the development and diffusion of technologies aimed at addressing environmental problems, but rather shed light on which innovation areas have the potential to achieve absolute decoupling (Font Vivanco et al., 2015).

Technological change (including environmental technology change) can be characterised by three major stages: invention, innovation and diffusion (Del Río, 2009). An invention represents the first development of a scientifically or technically new or improved product or process (ibid). Frankelius (2009) defines an innovation as something new with a high level of originality for customers or others for whom it may benefit, that breaks into (or obtains foothold in) society, often via the market. Diffusion as defined by Rogers (2003 p.5) refers to "the process in which an innovation is communicated through certain channels over time among members of a social system" or simply put, the adoption and use of an innovation over time. And even though these three major stages of technological change are presented as conceptually distinct, in practise they interact with each other through iterations, overlaps and feedback loops as emphasised in the systemic model of innovation; e.g. post-adoption technical challenges motivate further innovation activity (Del Río, 2009). The complexity presented by the wide temporal and geographic scope of environmental problems such as climate change, biodiversity loss and natural resource depletion means that, some environmental problems are no longer local but also global. Within the context of technological change, one approach for addressing such global environmental problems is the international diffusion of environmental technologies (Rennings, 2014).

Despite potential benefits from the adoption and use of environmental technologies, their diffusion is stifled by both market and system failures (cf. Jaffe et al., 2005). This means that the diffusion of environmental technologies (or at least some types, e.g. front-of-pipe solutions) can be particularly slow (since they have to be integrated into existing processes compared to end-ofpipe solutions, which can simply be add-ons), even though they could contribute to tackling climate change, pollution and resource depletion challenges (Institute for Prospective 
Technological Studies, 2004). The international diffusion of environmental technologies can be undertaken using interrelated approaches such as export, international aid projects, foreign direct investment and technology transfer. Due to structural and strategic flexibility (e.g. the ability to adapt the foreign market entry modes), relatively minimal resource requirements, and lower risks involved (Leonidou et al., 2011), and the opportunity to tackle environmental problems as business opportunities, create employment opportunities for the local workforce, contribute to public funds through additional tax revenues and generate foreign revenue (Dean and McMullen, 2007), export of environmental technologies is an increasingly desired activity among companies and governments (The Swedish Government, 2013). The prominence of export in the current public discourse on global environmental sustainability and economic development, relative to the other alternatives for environmental technology diffusion, predominantly explains the focus of this thesis on export. However, exporting is a challenging business activity as reflected by the numerous and diverse obstacles with varying frequency, intensity and significance that could hinder it (Leonidou, 1995).

This thesis explores the diffusion of environmental technologies through export from complementary perspectives - governmental export promotion initiatives, obstacles to and drivers for export, international city networks and components of business concepts for export. The starting point for the analysis is the perspective of the technology supplier, focusing particularly on municipally and privately owned companies. The knowledge gaps addressed in this thesis in relation to the export of environmental technologies are presented in the next section, paving way for the aim and research questions guiding this thesis.

\subsection{Research Problem}

The motivation for writing this doctoral thesis stems from both societal challenges and gaps identified in the scientific literature. From a societal perspective, environmental technologies need continued international diffusion to be able to contribute to addressing urgent contemporary environmental problems (Rennings, 2014). For example, substantial investments are needed for renewable energy technologies to diffuse at a pace that can limit the irreversible consequences of climate change (UNFCCC, 2009). Despite potential economy-wide benefits from the development and diffusion of environmental technologies, activities of international organizations, national governments, firms and local groups suggest the need for continued efforts to stimulate their diffusion (Carrillo-Hermosilla et al., 2009). As Fichter and Clausen (2016 p.31) put it "from a sustainability perspective, we are not confronted primarily with a problem of innovation, but a problem of diffusion."

From a scientific perspective, there is a need for reflections and constructive criticism to the diffusion of innovation literature in general (Rogers, 2003). This is to advance the current discourse and to ask questions which have been ignored, creating new paths and covering ground which might have been overlooked in previous research. In his book, "Diffusion of Innovations", four major criticisms of diffusion research are discussed by Rogers (2003) (i) the pro-innovation bias - the notion that an innovation should be diffused and adopted by all members of a social system; (ii) the individual (adopter) blame bias - the tendency to hold an individual unit responsible for their problems (e.g. rejection of a potentially beneficial innovation), rather than the system of which the individual is part of; (iii) the recall problem, 
which emphasises the challenges of depending on self-reported recall data from respondents about their adoption of innovations; and (iv) the issue of equality, which details how diffusion scholars have overlooked how the socio-economic benefits of innovations are distributed among individuals in a social system.

This thesis particularly contributes to addressing the individual blame bias. In effect, the thesis moves away from the dominant focus of many diffusion studies - technology adopters - and focuses on an often less emphasised actor, technology suppliers and the wider context within which the diffusion of environmental technologies occurs. With an individual blame bias, adopters who chose not to adopt an innovation are often labelled as laggards, irrational and lacking knowledge or resources. As Rogers (2003) puts it if the shoe does not fit, there is something wrong with your foot - not the shoemaker. The diffusion of environmental technology literature is extant with contributions focused solely on the adopter and why they adopt or reject a technology. Questions such as determinants and barriers to environmental technology adoption (Del Río, 2005), the impact of policy instruments on adoption (Jaffe and Stavins, 1995), and challenges environmental technology adopters face (Mignon and Bergek, 2016) have been extensively explored. The role of other important elements of the diffusion process such as the business aspects, the communication channels, and technology suppliers has either been less investigated or studied in isolation, which is important for depth, but sometimes falls short in providing a comprehensive understanding of the environmental technology diffusion process. Though recent contributions taking an integrated perspective are beginning to emerge particularly as doctoral dissertations (e.g. Mejía-Dugand, 2013, 2015b; Mignon, 2016), the attention adopters have received in the diffusion of innovation literature compared to suppliers is simply unmatched. Thus, scientific knowledge continues to emerge in the diffusion of innovations literature on (i) how public policy influences the diffusion activities of environmental technology suppliers compared to the adoption decisions of adopters, and (ii) the characteristics of environmental technologies which influence their diffusion compared to the characterisation of different types of adopters.

Further on, potential gaps exist in the literature as a result of the empirical coverage of some previous contributions. Some contributions on the diffusion of environmental technologies focus on a few cases studies or studies within individual sectors (Fichter and Clausen, 2016). Even though such scope of studies allows for targeted conclusions and recommendations for specific actors, it may not particularly yield robust generalisations. In addition, the international dimension of technology diffusion including export is emphasised as a research trajectory which needs further attention (Del Río, 2009; Rennings, 2014). Thus, the empirical data presented in this thesis covers both privately and municipally ${ }^{3}$ owned companies in Sweden which belong to the environmental goods and services sector. These categories of companies represent a significant share of the Swedish environmental goods and services sector, and are increasingly encouraged by different stakeholders including the national government, to engage in export. These companies offer systems, products, processes and services which can be labelled as

\footnotetext{
${ }^{3}$ In this thesis, municipally owned companies refer to companies wholly owned by one or several municipalities. This definition reflects the cases studied in this thesis, even though there are other forms of municipal company ownership based on partnerships between private actors and municipalities. See Subchapter 2.2.1 in Chapter 2 for elaboration on the term municipally owned company.
} 
potential environmental technologies. This broad empirical basis allows for sector-wide generalisations, as well as actionable recommendations.

From the research problem description, one overarching aim and four research questions are formulated. The aim and research questions are purposively abstracted to a level to make them potentially relevant for research outside the empirical context but also grounded enough to reflect the empirical context within which they were explored. The specific questions, the motivations for asking them and the unit of analysis for their operationalisation are presented in the forthcoming subchapters on the research aim and research questions.

\subsection{Research Aim}

The aim of this thesis is to analyse how to stimulate the diffusion of environmental technologies through export.

The aim of the thesis can be approached using different analytical perspectives. This is due to the fact that, the diffusion of technologies in general is influenced by numerous factors which are difficult if not impossible to analyse in their entirety (Montalvo and Kemp, 2008). In particular, export is influenced by different factors such as foreign market characteristics, firm size and ownership, networks, organisational culture, business strategy and public support. These factors vary in relevance and intensity, depending on the particular context and case (Zou and Stan, 1998).

To operationalise the aim and research questions, I synthesize five main elements which influence diffusion of innovations in general based on the previous literature (e.g. Fichter and Clausen, 2016; Rogers, 2003; Wejnert, 2002) and then contextualize these elements with the specificities of environmental technology export. These five main elements are (i) the technology and its characteristics, (ii) technology suppliers and their characterisation, (iii) technology adopters and their categorisations, (iv) communication channels, and (v) the diffusion context. These five main elements are elaborated on in Chapter 2, Theoretical Background, and used further as a framing to respond to the thesis aim and research questions.

\subsection{Research Questions}

1. How do governments promote environmental technology export and what is the perceived effectiveness of such initiatives among private environmental technology companies?

Several governments have identified export from the environmental technology sector as a potential source of renewed economic development (WWF, 2014). To this end, there are numerous governmental initiatives and agencies operating with the aim to promote the export of environmental technologies from their respective countries (see e.g. Swentec, 2008a, b). Even though export promotion initiatives are expected to differ across countries based on their specific political, economic and historic idiosyncrasies, the overarching aim of export promotion is to tackle market and system failures and thus ultimately enhance companies' export (Lederman et al., 2010). However, the effectiveness of export promotion initiatives is not only contingent on the formulation of such initiatives, but more so on how they are implemented and received by the target companies (Kumcu et al., 1995). This research question explores export promotion initiatives in eight selected countries across Asia, Europe and North America as a starting point, 
and narrows down to the perceived effectiveness of such governmental export promotion initiatives among private Swedish environmental technology companies. Though perceived effectiveness of governmental export promotion initiatives influences firms' participation in such initiatives and is thus an important evaluation criterion, additional criteria could be used to evaluate the effectiveness of governmental export promotion and their initiatives, such as the effects of their organisational structure, strategies, resources and activities on national export as presented by Lederman et al. (2010). However, addressing the question of perceived effectiveness provides firm level insights to further develop export promotion initiatives compared to the aggregate insights from other evaluation criteria. Governmental export promotion is an essential complement to companies' internal strategies such as networks and business models (Leonidou et al., 2011).

\section{What are the obstacles to and drivers for environmental technology export among municipally owned companies?}

As argued in the research problem description, the export of environmental technologies is not only stifled by adopters' categorisations according to risk aversion and innovativeness, but also potentially by technology suppliers and their particular characteristics. To discuss such characteristics, this research question addresses the obstacles to and drivers for environmental technology export among municipally owned companies in export. This research question is operationalised based on the experiences of exporting and non-exporting Swedish municipally owned companies engaged with environmental technologies. Obstacles to export relate to factors which prevent companies from commencing export and also the difficulties encountered by companies already engaged in export. Drivers for export on the other hand relate to all factors triggering the decision of a company to initiative and develop export activities (Leonidou et al., 2007). Even though some of the obstacles and drivers identified are specific to municipally owned companies and their experiences in environmental technology export, some of them are also applicable to environmental technology suppliers in general irrespective of size, ownership, and offering type as will be presented in the discussions. An analysis of such obstacles and drivers is a fundamental input for action plans to stimulate the export of environmental technologies, since initiatives can be formulated both to overcome the obstacles and encourage the drivers. Swedish municipally owned companies represent a relevant context to operationalise this question because they have a history of developing and operating environmental technologies to take care of the environmental pressure from the inhabitants of their municipalities. Furthermore, municipally owned companies are increasingly encouraged to be commercial and export oriented. This presents the opportunity to uncover both successful and failed cases but also to develop actionable scientific knowledge. An understanding of the obstacles and drivers among municipally owned companies, characteristics of the large technical systems they develop and cities often as their potential customers in export gave reasoning to the third research question, which deals with how such companies can use international city networks for environmental technology export. 


\section{How could municipally owned companies use international city networks to facilitate environmental technology export?}

The importance of interpersonal connections and communication in facilitating the diffusion of innovations is well established in the innovation literature (Baptista, 2001). The experiences of municipally owned companies regarding obstacles to and drivers for export differ in some aspects from that of their private counterparts. Partly as a result of the scale and purpose of large technical systems, municipally owned companies often have other cities, governments and publicly owned companies as potential customers. International city networks provide an important arena for such actors to meet with technology suppliers to share knowledge and experiences about particular technologies as well as environmental problems. Thus, communication channels such as international city networks for sustainability are given particular attention in the operationalisation of Research Question 3 and how municipally owned companies can use such networks to facilitate environmental technology export. By focusing on five Swedish cities and the international city networks for sustainability they belong to, the main argument in addressing this research questions is that municipally owned companies can take advantage of the local, regional and international positioning of their owner municipalities in city networks to facilitate environmental technology export.

\section{Which components could be considered in business concepts for environmental technology export?}

Research Question 4 focuses on the internal strategies (an elaborate and systematic plan of action) of both municipally and privately owned environmental technology companies to export. This research question builds on insights from the previous three questions regarding governmental initiatives, obstacles and drivers, and international city networks for export. Research Question 4 purposively focuses on components of business "concepts" for export because the studied companies were in their initial stages of export, and thus were experimenting with different export business alternatives, which implied that various specific aspects of a functioning business "model" such as cost structure, revenue streams, and customer relations could not be described at such early phases based on facts but speculation. Nonetheless, the discussions on components of business concepts are inspired by approaches for describing business models for products, combined products and services offerings, and large technical systems, which are reviewed in Chapter 2, Theoretical Background. As Research Question 1 suggests, governmental export promotion initiatives are in theory supposed to complement market initiatives, and thus cannot be expected to tackle every market and system failure. The business model represents a company's strategy to create, deliver and capture value relevant in tackling some market and system challenges. However, challenges with business model development have been identified as one of the significant barriers to the diffusion of environmental technologies (Cerin et al., 2007). Furthermore, business model development offers the opportunity for firms to plan export including gathering relevant resources (e.g. market information, partnerships), identifying key stakeholders and incorporate particular characteristics of environmental technologies into their strategies. This could assist exporters to identify potential bottle necks at early stages and reduce the risks of failure. The business model is also particularly relevant for environmental technologies and their suppliers since their characteristic potential to deliver environmental benefits is not necessarily an inherent property of particular technologies, but also influenced by how the technologies are developed and utilised throughout 
their life cycle. This research question is operationalised on selected Swedish municipally and privately owned environmental technology companies engaged in export. The analysis abstracts from specific company cases and offering types relevant components to consider in business concepts for environmental technology export in general.

Altogether, these research questions provide support to operationalise the research aim. However, important choices and delimitations made in order to make this operationalisation possible are elaborated on in the next subchapter.

\subsection{Thesis Scope}

The focal unit of analysis in this thesis is environmental technology suppliers. To comprehensively analyse how to stimulate environmental technology diffusion through export, a complementarity approach was adopted. This approach adopts a systemic view of diffusion in which the activities of technology suppliers' influence and are influenced by other elements of diffusion generally (i) the technology and its characteristics, (ii) innovation adopters and their categorisations, (iii) communication channels, and (iv) the diffusion context. These main elements of the diffusion process including their specificities regarding export of environmental technologies are discussed in detail in Chapter 2, the Theoretical Background.

Furthermore, the empirical data analysed in this thesis was collected in Sweden and covered particular types of environmental technology suppliers - Small and Medium-sized Enterprises $\left(\mathrm{SMEs}^{4}\right)$ and municipally owned companies. What makes Sweden in general, and SMEs and municipally owned companies in particular, a compelling context to operationalise the research aim and questions are discussed below.

\section{What makes Sweden an interesting empirical context?}

Sweden as a country has been consistently ranked among the top ten global leaders in the development of environmental technologies (see e.g. WWF, 2012, 2014). However, with regard to commercialisation (including export) of such technologies, Sweden lags behind other topranked countries (e.g. Denmark, Israel). Furthermore, the domestic market size for environmental technologies is relatively small and could saturate and even decline for some environmental technology types, e.g. end-of-pipe technologies (cf. Saeedi, 2017). This challenge has been recognised nationally, and several initiatives and recommendations have been drawn up to boost the performance of the environmental goods and services sector as a whole and exports in particular (Swentec, 2008a, b; The Swedish Government, 2011, 2013). However, governmental efforts to boost environmental technology exports are not exclusive to Sweden and several initiatives can be found in Denmark, the USA, Japan, Norway and the other countries. The highlighted conditions in Sweden (top eco-innovator, small and potentially shrinking domestic market and government interests in export of environmental technologies) suggest that there is an interest in enhancing environmental technology export, both at the firm and national level.

\footnotetext{
${ }^{4}$ There is no universally accepted definition for the small and medium-sized enterprise. The U.S. Department of Commerce defines an SME as a company with 500 employees or less. In Canada, an SME has up to 300 employees. The European Union defines SMEs based on a combination of staff headcount and either turnover or balance sheet total. Medium-sized enterprises have less than 250 employees, small companies have less than 50 employees while less than 10 employees represent a micro-enterprise. This footnote is based on Etemad et al., (2001).
} 
This interest to stimulate the export of environmental technologies ties into a fundamental argument brought forth in the introduction: that technological change is a necessary component of approaches to tackle contemporary global environmental problems. Thus, the Swedish context provides a good opportunity to analyse leading environmental technology companies and governmental initiatives geared toward export which could generate potential learning outcomes for other countries and related scientific knowledge.

\section{Why privately owned small and medium-sized enterprises?}

To answer Research Question 1, an internet survey was conducted among 693 privately owned Swedish environmental technology firms with a $25 \%$ response rate. The final list of companies among which the survey was conducted was dominated by small and medium-sized companies (less than 250 employees). Organisations such as consultants and business hubs not directly engaged with export as well as municipally owned companies were excluded from the survey, since they are not the target of public-funded export promotion initiatives. The predominance of SMEs is based on the characteristics of the environmental technology sector in Sweden, which is made up of about $90 \%$ SMEs (ITPS, 2008) and also the fact that SMEs are often the target of governmental export promotion initiatives (European Commission, 2007). SMEs experience sizerelated challenges in export such as lack of resources (finance, time, and personnel), lack of knowledge about foreign markets and challenges to meet customer demands, but to mention a few. Despite these particular challenges, SMEs also represent an engine for economic growth in many countries, and have thus been the focus of many governmental initiatives to promote export (European Commission, 2007). The dominant position of SMEs in the environmental technology sector, their specific challenges in export, and the particular attention they receive from governmental initiatives makes these companies an important focus for analysing the diffusion of environmental technologies through export.

\section{Why municipally owned companies?}

Municipally owned companies were selected as cases for responding to Research Questions 2, and 3 and were part of the cases for Research Question 4. In general, public-affiliated organisations have been identified as key stakeholders when it comes to fostering environmental sustainability, due to the public good nature of the environment and externalities involved (cf. Kivimaa, 2014). They differ from traditional private organisations, whose activities are typically profit-driven. For example, municipally owned companies have different stakeholders and business logic compared to private companies, which often have to create financial value for shareholders. Thus, motivations such as contributing to environmental sustainability could be more significant for municipally owned companies than financial priorities, particularly in export (cf. Estrin, 2012). Furthermore, Swedish municipally owned companies have been responsible since the 1970s for addressing the environmental pressure from their own municipalities through the development and operation of environmental technologies in waste management, district heating, renewable energy systems, and water supply (SKL, 2013b). As an outcome of this long history of responsibility, many municipally owned companies have technical expertise on environmental technologies, which has been apparently limited to the boundaries of their municipalities (Kairento and Nygårds, 2014). However, with the rising global challenges of environmental sustainability, increasing commercial competition and globalisation, publicly 
owned companies in many parts of the world (including Sweden) have become more internationally-oriented and commercial-minded (cf. Furlong, 2016). Thus, analysing Swedish municipally owned companies presents an opportunity to uncover new scientific insights based on their long-term experience with developing and applying environmental technologies, their increasing orientation towards commercial and international markets, and their different stakeholder expectations and business logic compared to privately owned companies. In addition, the context of Swedish municipally owned companies also offers the opportunity to investigate both successful and failed cases, since these companies have actively begun to export in recent years.

\subsection{Thesis Outline}

This subchapter presents an outline for Chapters 2-7 of the cover essay.

In Chapter 2, Theoretical Background, key concepts and theoretical perspectives which guide the thesis are presented. In the cover essay, the theoretical background presents an abstraction and further development of the various theoretical backgrounds discussed in the appended articles, with the objective to holistically synthesise a framework for understanding the export of environmental technologies.

In Chapter 3, Research Methods, two broad themes inspired by the thesis writing culture at the Division of Environmental Technology and Management are addressed. The first theme details the progress from the different research projects I was involved in, culminating with this thesis. The second theme pays particular attention to the scientific approach used to write the cover essay, together with methods used to collect and analyse empirical data in the appended articles. The chapter ends with a critical reflection and problematisation of some key assumptions and research methods underlining this thesis.

In Chapter 4, the appended articles are presented with a particular focus on their findings. To minimise repetition between various parts of the thesis, Chapter 4 mimics a typical "results" section in an academic writing, presenting findings from the appended articles which strictly contribute to answering the guiding research questions.

In Chapter 5, Discussions and Conclusions, the guiding research questions are in focus with an attempt to provide a comprehensive discussion and concise conclusion for each of the research questions.

In Chapter 6, the synthesis chapter, an attempt is made to address the overarching aim of the thesis. Thus, discussions on the research questions are abstracted to provide a conceptualisation relevant for the overarching thesis aim.

In Chapter 7, the conclusions and synthesis from the thesis are brought into a wider context, discussing their implications for policy makers, managers and researchers. 


\section{Theoretical Background}

This chapter discusses key concepts and theories from two fields namely, internationalisation and the diffusion of innovations, which form a basis for the collection and analyses of empirical data presented in this thesis.

The theories of internationalisation of the firm and the diffusion of innovations play complementary roles in analysing the export of environmental technologies. The synergy achieved by the combination of these two fields in understanding the export of environmental technologies may not be possible by using either of them. For example, on a general level, internationalisation theories often have the firm as a primary focus, while the innovation and it's adopters are given central attention in the diffusion of innovations literature. Despite the different foci in both fields, they both recognise aspects external and internal to their unit of analysis, which influences export. These aspects include: government policy, business models, business networks, technology characteristics, the diffusion context and even entrepreneurial characteristics.

Internationalisation is a broad concept which is defined and understood differently by different international business scholars (Saeedi, 2017). Some scholars consider internationalisation as a pattern of foreign direct investment (Dunning, 1988), a process of incremental commitment to international markets (Johanson and Vahlne, 1977) and network of business relationships (Johanson and Vahlne, 2009). Despite these different definitions, there is some argumentation for inward internationalisation and outward internationalisation as the two main types of internationalisation of the firm (Fletcher, 2001). Typically, internationalisation is outward-driven, and the firm's international revenue is realised through different outward modes such as direct and indirect export, outward licensing, franchising and strategic alliances. On the other hand, Fletcher (2001) argues that firms can also become internationalised by inward activities such as importing, becoming a licensee for a foreign firm, or being a joint partner with an overseas firm in its domestic market. Exporting is regarded as one of the initial steps towards internationalisation (Johanson and Vahlne, 2009). This thesis focuses on outward internationalisation in the form of environmental technology exports.

There exist a variety of theories developed to analyse the internationalisation of firms (Saeedi, 2017). These theories mainly attempt to provide answers to two questions - how firms internationalise and factors influencing firm internationalisation (Fletcher, 2001). One of the most important (Andersson and Wictor, 2003), and frequently applied (Andersson, 2004), models in the field of internationalisation is the so-called Uppsala Model developed by Johanson and Vahlne (1977). In the Uppsala Internationalization Model, internationalisation is viewed as a process of increasing experiential knowledge marked by linear incremental commitment to foreign markets (Andersson, 2004). In operation, the model has been used to describe the sequence of foreign market entry and the pattern of increasing commitment to a single market. According to the model, firms initially focus on their national markets to avoid unnecessary risks, and then make incremental commitment to foreign markets with close "psychic distance" (Johanson and Vahlne, 1977). Psychic distance refers to such factors preventing the flow of information between firm and market, e.g. differences in language, culture, political systems, levels of education, and levels of industrial developments (Andersson and Wictor, 2003). Thus, in the beginning there are no regular export activities, thereafter export 
takes place via independent representatives, later through subsidiaries and eventually a manufacturing subsidiary is established (Johanson and Vahlne, 1977).

This stepwise view of internationalisation has lived in constant criticism (Andersson, 2004). Some critics have pointed to the deterministic nature of the model, arguing that internationalisation does not necessarily follow a linear path (Andersson, 2003). On the contrary, the rapid globalisation of markets in recent times has yielded new international ventures with a global market focus soon after their inception (Bell et al., 2003). Other critics have restricted the validity of the model to the early stages of internationalisation, where resources and market knowledge remain constraints (Andersson, 2004). In spite of the criticism, the model is considered one of the most popular in internationalisation studies, and several empirical works have corroborated its validity in different countries especially in the 1970s and 1980s (Andersson, 2004). In a revision to the Uppsala Model in light of changes in business practises and theoretical advances after three decades, Johanson and Vahlne (2009) stipulate the current business environment to be viewed as a web of relationships, a network rather than the neoclassical view with independent suppliers and customers. Outsidership in relation to the relevant network, rather than psychic distance, is the source of uncertainty (Johanson and Vahlne, 2009).

In recent years, a number of studies have demonstrated the growing importance of business networks in the internationalisation of firms (Saeedi, 2017). These studies have demonstrated that business network relationships have an impact on foreign market selection, modes of entry (Johanson and Vahlne, 2009) and international performance (Saeedi, 2017). Johanson and Mattsson (2015) consider business networks as the relationship a firm has with its customers, distributors, suppliers, competitors and governments. These relationships seem to develop essentially through social exchange processes by means of cumulative knowledge and trust building, leading to increasingly greater commitments (Johanson and Vahlne, 2009). When some of these actors are involved in international activities then the connections take firms into international markets, either intentionally or unplanned, with or without leaving home (Etemad et al., 2001). By internationalisation, the firm creates and maintains relationships with counterparts in other countries (Chetty and Holm, 2000). This occurs in different ways: first, by forming relationships with counterparts in countries that are new to the firm (international extension), second, by increasing commitment in already established foreign networks (penetration), and third, by integrating their positions in networks in various countries (international integration). An underlining assumption of the network model is that, a firm requires resources controlled by other actors, which can be obtained through its network position (Chetty and Holm, 2000).

An explicit emphasis on the internal resources, capabilities and competencies of a firm as the source of its sustained competitive advantage in internationalisation is linked to the resourcebased view of the firm (Peng, 2001). The resource-based view, often attributed to the scholarly contributions of Barney (1986), Wernerfelt (1984), among others, seeks to explain why firms in the same industry might differ in their competitiveness based on their internal resources, capabilities and competence such as in-house knowledge, customer relationships, financial reserves, physical resources, reputation, motivation, top management commitment, human resources, personal contacts and networks (Peñasco et al., 2017). The central proposition of the theory is that, if a firm is to reach a state of sustained competitive advantage (acquire or develop attributes that allows a firm to outperform its competitors), it must acquire and control resources 
and capabilities with the so-called VRIN characteristics, i.e. valuable $(\mathrm{V})$, rare $(\mathrm{R})$, inimitable $(\mathrm{I})$, and non-substitutable $(\mathrm{N})$, in addition to the ability to absorb and apply them (Kraaijenbrink et al., 2010). A firm does not need to own all these different resources in-house, but through different forms of co-operation and networking, firms can acquire complementary resources essential for internationalisation. The lack of suitable resources and the management skills to manage available resources appropriately is one of the barriers to internationalisation (Frankelius et al., 2011). Thus, when discussing the barriers to internationalisation among cleantech firms, aspects of the firm's internal resources, such as the amount of available and suitable resources, together with managerial skills to organise and utilise these resources effectively, are important to consider (Frankelius et al., 2011). However, the resource-based view of the firm is often criticised for largely ignoring the firm's surroundings, such as market conditions and institutional contexts and their related dynamics which provide a context for competition among industries. This criticism suggests the need to complement the resource-based view of the firm with other theories which pay particular attention to the context of the firm as a basis for explaining its innovation activities (Peñasco et al., 2017).

As the drivers for globalisation are breaking down the walls which traditionally segmented the competitive environment between small and large-sized companies (Etemad et al., 2001), symbiotic small-large firm arrangements are evolving internationalisation for the mutual benefit of both parties. Small firms in recent times may neither have the prerequisite resources to internationalise nor the luxury of unlimited time in which to acquire them. Collaboration between small and large firms is a significant means to acquire these resources and get products into global markets quickly and at a lower cost than independent expansion (see Öhrwall Rönnbäck, 2010).

A new breed of SMEs is emerging with international ambitions right from their inception. These firms do not build their way slowly into international markets; on the contrary, they are born global. Andersson and Wictor (2003 p. 254) define a born global as "a company that has achieved [a] foreign sales volume of at least $25 \%$ within 3 years of its inception and that seeks to drive significant competitive advantage from the use of resources and the sale of outputs in multiple countries." A distinctive internal characteristic of such firms remains that the majority of them are formed by entrepreneurs with extensive local and international experience and personal networks. They view the world as a market-place from the onset, benefiting from supplementary competences from local and international networks. The offerings of born globals typically involve substantial value addition and are intended for industrial use (Andersson and Wictor, 2003). Within the firm's environment, several factors have been linked to such a global outlook. The increasing role of niche markets; advances in process technology; advances in communication technology; inherent advantages of small companies such as quicker response time, flexibility and adaptability; and the trends towards global networks.

Focusing on export as an initial step towards internationalisation, different foreign market entry modes are discussed in the related literature (Canabal and White, 2008). A foreign market entry mode is an institutional arrangement which facilitates the entry of a company's offerings into foreign markets (Albaum et al., 2008). At least four major alternatives of structural arrangements are available for foreign market entry - direct sales, licensing, joint ventures and wholly owned subsidiaries (Osland et al., 2001). With direct sales, a company's final or intermediate export offering is manufactured in the home market and subsequently transferred to the target 
customers. Licensing covers contractual agreement with another company which is active in international markets to use some or all the exporting company's patents, trademarks, name, technology, and/or business methods at an agreed upon fee. Joint ventures and wholly owned ventures, on the other hand, are established to engage in export on behalf of the parent company involving financial, technology and human resource contributions from each partner, and can be located in the home or target market.

From the internationalisation (including export) literature, it is apparent that important attention is given to the firm including its business networks, resources, capabilities, competencies and entrepreneurial characteristics. To complement this view, the diffusion of innovation literature is used to lay emphasis on other aspects which potentially influence export but are latent in the internationalisation literature, such as the characteristics of environmental technologies, technology adopters and their characterisation, and the diffusion context. The use of the term "diffusion" with reference to technological innovations varies throughout the literature. Some scholars (e.g. Baas, 2007) restrict the use of the term diffusion to the spontaneous unplanned spread of new ideas while using the term "dissemination" for the directed and managed spread of ideas. In this thesis, I use the term diffusion in a broad sense to include both the planned and spontaneous spread of environmental technologies, first to connect to the use of the term in previous literature (see Fichter and Clausen, 2016; Mejía-Dugand, 2013; Mignon, 2016; Rogers, 2003) and second to reflect on both the planned and unsolicited nature of export activities that this thesis covers.

The diffusion of innovation research paradigm began over seventy years ago, when mainly sociologists studied the adoption of agricultural innovations (hybrid seed corns) among rural farmers (Valente and Rogers, 1995). In recent decades, diffusion of innovation research has been undertaken in different fields including social psychology, communication, public relations, advertising, marketing, consumer behaviour, public health, economics and rural sociology (Karakaya et al., 2014). There are numerous theories and models of innovation diffusion, which Sarkar (1998) categorises into three dominant groups. The first group, epidemic models is characterised by the assumption that, the number of potential adopters of a technology increases as non-adopters get in contact with and gather information from those who have already adopted the technology. Potential adopters are assumed to be passive, as they do not actively seek information about the particular technology. The second group, neoclassical equilibrium models is characterised by consecutive shifts in equilibria due to given stimulus and the consequent adjustments of adopters. This group of models postulates that, decision makers are infinitely rational. The third group, evolutionary disequilibrium models, regards diffusion as a process in which competitive advantages of different technologies, the behaviour of adopters, and the economic and institutional context determine the diffusion of technologies.

Everett Rogers, largely regarded as one of the founding fathers of diffusion research (see Fichter and Clausen, 2016), defines diffusion as "the process in which an innovation is communicated through certain channels over time among members of a social system.” (Rogers, 2003 p.5). For others, diffusion describes the aggregate adoption decision by a population of potential adopters over time (Kemp and Volpi, 2008), or simply put, diffusion is the adoption and use of an innovation over time (Jaffe et al., 2002). Diffusion comprises the period after the first successful 
implementation or after market introduction (Fichter and Clausen, 2016). In this regard, export can be considered as one approach to technology diffusion.

Export as an approach to diffusion is influenced by a variety of factors which need to be analysed complementarily to reach a comprehensive understanding. Starting with the literature on the diffusion of innovations in general and with particular attention to environmental technologies (e.g. Beise and Rennings, 2005; Mejía-Dugand et al., 2013; Mignon and Bergek, 2016; Rogers, 2003; Wejnert, 2002), five main elements appear to define technology diffusion processes. These elements are (i) the technology and its characteristics, (ii) characteristics of technology suppliers, (iii) technology adopter and their categorisations, (iv) communication channels, and (v) the diffusion context. Though these main elements are potentially relevant for the diffusion of innovations in general, their discussion and use in this thesis focuses on the export of environmental technologies in particular. These five elements are presented as separate entities mainly for the purpose of conceptual distinction. In practise, however, a sharp distinction between some of these elements may be difficult to establish. Furthermore, other elements could be more relevant for a particular diffusion process, and the elements highlighted in this thesis could have different levels of significance in any particular export case. This notwithstanding, the conceptual synthesis provides a comprehensive overview for understanding the different aspects in the export of environmental technologies. The elaboration below gives particular attention to the aspects which have been given particular attention in this thesis.

This synthesis of these five main elements characterising the diffusion process provides the opportunity to anchor the thesis in the diffusion of innovation literature and highlight key aspects of environmental technologies and their export which might otherwise be overlooked using only the internationalisation literature, which allows for a more sensitive understanding of the export of environmental technologies. In essence, situating this thesis in the diffusion of innovation literature highlights the dynamic nature of the diffusion process, the relevance of the particular technology and its characteristics, the importance of the diffusion context, categorisations of technology adopters and the characteristics of technology suppliers (one of the under-researched elements of the diffusion process). On the other hand, the internationalisation literature also enriches the analysis presented in this thesis with the business aspects of diffusion, which is particularly important in exports within the business-to-business (B2B) contexts. In fact, the business aspect is largely silent in many diffusion studies (cf. Fichter and Clausen, 2016; Kemp and Volpi, 2008).

\subsection{Environmental Technology}

The term "environmental technology" is subjected to several contestations. With no internationally agreed upon definition, the term environmental technology has several meanings and understandings throughout the literature. The term has been used in diverse contexts and with different connotations that may eventually reduce its practical value to a panacea for all environmental problems. The term is used synonymously with other terms such as "environmentally sound technology”, "cleantech", "greentech", "green technology", "sustainable technology", and "low carbon technology" (Guziana, 2011). Several attempts have been made to define environmental technology, and Box 1 provides a compilation of some of the dominant definitions. I acknowledge that insights from the definition to other related terms such as eco- 
innovations and sustainable innovation can be relevant for the understanding of the term environmental technology, and this possibility is explored in this thesis particularly while discussing the various definitions of the term environmental technology.

Box 1. Definitions of environmental technology from the literature

Shrivastava (1995 p.185) - "production equipment, methods and procedures, product designs, and product delivery mechanisms that conserve energy and natural resources minimise the environmental load of human activities, and protect the natural environment."

Kemp (1997 p.11) - "technique, process or product which conserves or restores environmental qualities."

Ramarkrishnan (2004 p.48) - "technologies that provide improvements in environmental quality."

Etap/EU (2004 p.2) - "all technologies whose use is less environmentally harmful than relevant alternatives. They encompass technologies and processes to manage pollution (e.g. air pollution control, waste management), less polluting and less resource-intensive products and services and ways to manage resources more efficiently (e.g. water supply, energy-saving technologies)."

Kuehr (2007 p.1320) - "Environmental Technologies (ET) contain four different categories: measuring, cleansing, cleaner, and clean technologies differing in their ecological effectiveness. ET reduce pollution at least in one environmental medium, only accepting the transformation of emissions into another form or into another medium as a short-term measure in order to cope with harmful pollutants. Thus, ET implements the continuous improvement of processes, products and services by the conservation of raw materials and energy and by the reduction of toxic substances, waste and emissions within the production cycle."

DEFRA (UK) - They are any technology that, when compared to other similar technologies, does the same thing but with a low environmental impact.

SWENTEC/SCB (Sweden) - Any technology that directly or indirectly contributes to a better environment. Environmental technology comprises products, systems, processes and services which provide clear environmental advantage compared to current or alternative solutions, from a life cycle perspective.

Source: based on (Guziana, 2011). 
Despite the different definitions and understandings of the term, the defining characteristic of environmental technologies remains its potential environmental benefits with or without initial intention (Del Río et al., 2016; Mejía-Dugand, 2015b). Specifically, the diffusion and adoption of environmental technologies is expected to yield reductions in the environmental impacts of consumption and production activities. The various definitions of the term (see Box 1) highlight certain attributes of environmental technologies which need to be considered carefully for a comprehensive understanding.

One such attribute is the realised versus the intended environmental benefits of developing and adopting environmental technologies. A challenge with focusing on the realised environmental benefits is concluding which technologies, in practise, actually reduce the environmental impacts of products and production. Analysing the realised environmental benefits of technologies using approaches such as life cycle assessment and environmental systems analysis does not always produce objective and unequivocal results due to contextual issues such as the types of impacts included, quality of inventory data, methodological choices and uncertainties (Finnveden, 2000). There are also challenges with a definition focused solely on the environmental intentions of technology suppliers. For example, it is challenging to delimit the collective environmental intention of technology suppliers, and these environmental intentions may increasingly become entangled with other intentions such as financial gains as the industry moves from end-of-pipe technologies to integrated technologies (Carrillo-Hermosilla et al., 2010).

A further discussion is the "relativeness" of such environmental benefits compared to relevant alternative technologies. This attribute can undermine the robustness of the term, since any technological innovation with incremental improvements which yields higher environmental benefits can be argued as environmentally friendlier when compared to previous models of the same technology.

The discussions above highlight the challenges of defining and operationalising the term environmental technology. Even though a sharp and rigid definition might be relevant academically, in practise it might be unnecessarily limiting and difficult to operationalise. In this thesis and in the appended scientific articles, I adopted the definition for environmental technology proposed by The Swedish Ministry of the Environment (2005) - "goods, systems, processes and services that offer clear environmental advantages in relation to existing or alternative solutions, seen from an ecocycle perspective." This definition was adopted because it has a broad and inclusive scope which covers the different types of technologies studied in this thesis. Furthermore, the definition was also familiar to the technology suppliers who were interviewed as part of data collection, and served as a relevant starting point for discussions. Finally, this definition is also used by the national statistics agency of Sweden to collect, analyse and report data on the environmental goods and services sector to which the studied companies belong.

Departing from these contextual issues, the adopted definition in itself offers particular analytical advantages to investigate the diffusion of environmental technologies through export. First, the scope of technologies means that I am not only interested in the hardware aspect of technology and its associated services, but equally in the software aspects including embodied knowledge. Second, the life cycle perspective offers important insights into the environmental performance 
of such technologies. This suggests that the export of environmental technologies could potentially go beyond sales to implementation, operation and end-of-life management, yielding new value creation opportunities for technology suppliers and their customers.

Environmental technologies are a subset, and share several characteristics with innovations in general. However, environmental technologies also have specific attributes which influence their diffusion through export and require particular attention. An essential element which influences the diffusion is the characteristics of the technology. In fact, Rogers (2003) argues that the perceived attributes of an innovation is one important explanatory factor for its rate of diffusion. He further identifies five attributes of innovations that influence their diffusion which have been corroborated in many diffusion studies (e.g. Fichter and Clausen, 2016; Jacobsson and Johnson, 2000; Meade and Islam, 2006). These are relative advantage, compatibility, complexity, trialability, and observability.

- Relative advantage is the degree to which an innovation is perceived as being better than the idea it supersedes.

- Compatibility is the degree to which an innovation is perceived as consistent with the existing values, past experiences, and needs of potential adopters.

- Complexity is the degree to which an innovation is perceived as relatively difficult to understand and use.

- Trialability is the degree to which an innovation may be experimented with on a limited basis.

- Observablity is the degree to which the results of an innovation are visible to others.

Though these five attributes are also relevant for environmental technologies (see Del Río, 2009), additional characteristics of environmental technologies have been highlighted as influential in their diffusion. These additional characteristics stem from the fact that environmental technologies provide other relative advantages (e.g. potential environmental benefits) for adopters apart from economic profitability and social prestige. This attribute of better environmental performance is to some extent determined by how a technology is developed and used, and is not necessarily an inherent property of a given technology. This requires adaptability, which entails how easily both the hard and soft dimensions of technologies can be adjusted to fit the local context within which they are diffused (Mejía-Dugand, 2015b). Furthermore, though an adopter may bear a significant part of the cost in adopting a particular environmental technology, some of the benefits from the adoption can spill over to others who do not directly bear any part of the cost, a phenomenon often referred to as externalities (Jaffe et al., 2005). The phenomenon of externalities associated with both the development and diffusion of environmental technologies - the "double externality problem" - leads to a very important role for regulations in the diffusion of environmental technologies (particularly end-of-pipe solutions). From the above discussions, two additional characteristics emerge, adaptability and double externalities of environmental technologies which have potential influence on their export. 


\subsection{Technology Suppliers}

In this thesis, technology suppliers refer to actors in contact with potential adopters with the intention to persuade them to adopt a particular technology. The technology supplier can thus be the original innovator of the technology, or an intermediate actor between the original innovator and a potential adopter. In the diffusion of innovation literature, technology suppliers can include individual experts, households, companies, and governmental agencies.

Compared to the characterisation of technology adopters, the characteristics of technology suppliers and their role in the diffusion of technologies have received less research attention. It appears as though some scholars hinge the entire diffusion of technologies on the categories of potential adopters (innovators, early adopters, early majority, later majority and laggards), which determines their propensity to adopt or reject an innovation. The technology suppliers considered in this thesis are privately and municipally owned companies which develop and/or operate environmental technologies. Environmental technology suppliers can among other dimensions be characterised by their business models, their drivers for and their obstacles to export, which in turn influence their export activities. These three attributes of technology suppliers are contingent on their ownership type and size, their approach to export and also the type of environmental technologies they offer. As pointed out in the scope, the choice of which technology suppliers to analyse is partly linked to the characteristics of the environmental goods and services sector in Sweden.

\subsubsection{The Swedish Environmental Goods and Services Sector}

Statistics Sweden (the Swedish National Statistics Agency) adopts the definition promulgated by the Swedish Ministry of Environment to define environmental technologies, which is the same definition I have adopted in this cover essay and the appended articles. According to Statistics Sweden, the Environmental Goods and Services Sector - EGSS (also referred to as environmental sector), "is one of the prime sources of environmental technologies and [...] consists of activities which produce goods and services to measure, prevent, limit, minimise or correct environmental damage to water, air, and soil as well as problems related to waste, noise and eco-systems. This includes cleaner technologies, products and services which reduce environmental risk and minimise pollution and resource use." This definition is the basis for Statistics Sweden's collection, analyses and reporting of sectoral data both nationally and internationally.

This sector consists of nine environmental areas: renewable energy; recycled materials; waste management; wastewater management; heat/energy saving; environmental consultants; sustainable agriculture and fisheries; sustainable forestry; air pollution control; soil and ground water; education, research and monitoring; other resource management (including eco-tourism) and, noise and vibration. Table 1 provides an overview of the environmental goods and services sector in Sweden between 2006 and 2015, including number of establishments, turnover, exports and the percentage of turnover coming from exports. 
Table 1: Overview of the environmental goods and services sector in Sweden (compiled from Statistics Sweden).

\begin{tabular}{|l|r|r|r|r|r|r|r|r|r|r|}
\hline & $\mathbf{2 0 0 6}$ & $\mathbf{2 0 0 7}$ & $\mathbf{2 0 0 8}$ & $\mathbf{2 0 0 9}$ & $\mathbf{2 0 1 0}$ & $\mathbf{2 0 1 1}$ & $\mathbf{2 0 1 2}$ & $\mathbf{2 0 1 3}$ & $\mathbf{2 0 1 4}$ & $\mathbf{2 0 1 5}$ \\
\hline Establishments & 13624 & 14317 & 14772 & 15195 & 16044 & 15869 & 16849 & 16481 & 16186 & 15904 \\
\hline $\begin{array}{l}\text { Gainfully } \\
\text { employed }\end{array}$ & 69473 & 72108 & 73639 & 71347 & 71283 & 70749 & 71986 & 71854 & 71204 & 69473 \\
\hline $\begin{array}{l}\text { Turnover } \\
\text { (million SEK) }\end{array}$ & 198234 & 210873 & 247184 & 220517 & 251517 & 257708 & 231666 & 227170 & 224956 & 224942 \\
\hline $\begin{array}{l}\text { Export (million } \\
\text { SEK) }\end{array}$ & 31503 & 36066 & 46719 & 40206 & 40015 & 42737 & 42343 & 37692 & 37563 & 38359 \\
\hline $\begin{array}{l}\text { Export/Turnover } \\
\text { (\%) }\end{array}$ & 15,9 & 17,1 & 18,9 & 18,2 & 15,9 & 16,6 & 18,3 & 16,6 & 16,7 & 17,1 \\
\hline
\end{tabular}

The sector is reported to consist of about $90 \%$ small and medium-sized enterprises (with less than 250 employees and at most $€ 50$ million turnover), while the remaining $10 \%$ is composed of publicly owned and some large-sized companies. Furthermore, the area of renewable energy which is dominated by municipally owned companies and other large private energy companies has historically contributed the largest part of the sector's turnover (over 80 billion SEK in 2014) (Statistics Sweden, 2015). With regard to export, as can be seen in Table 1 above, the percentage of total turnover coming from export ranges between 15 and 19\%. All the companies analysed in this thesis (both privately and municipally owned) belong to this sector.

When discussing statistics, particularly regarding environmental technology, Statistics Sweden points out the lack of definitions and methodology that can be used to produce regular and comparable statistics. Statistics Sweden further argues that the confusion between the environmental goods and services sector and the environmental technology sector partly stems from the definitions of the two sectors, which largely cover the same things (Statistics Sweden, 2016). Thus, environmental technology companies, as referred to in this thesis, are most likely a subset of the environmental goods and services sector, but it is also possible that environmental technology companies are found outside the boundaries of the environmental goods and services sector. This thesis focused on identifying environmental technology companies from the environmental goods and services sector as there is readily available data on the sector since 1998, in addition to the sector being an important source of environmental technologies.

\section{Municipally owned companies}

In Sweden, the concept of municipalities was introduced in 1862 (SKL, 2013a). Municipalities have the obligation to follow national regulations as well as the freedom to make independent decisions and levy taxes from their inhabitants. There are a number of commitments from municipalities towards their inhabitants, such as the provision of social amenities including elderly care, educational services, public transport, water and wastewater systems, sanitation and waste management. Swedish municipalities fulfil these responsibilities through public procurement, providing these services by themselves or by engaging municipally owned companies which can have a monopolistic right for providing such services within their jurisdiction, e.g. as with household waste management. 
A municipally owned company refers to a company fully owned by one or several municipalities. Swedish municipalities and their companies have been at the forefront of taking care of the environmental pressure from their inhabitants since the 1970s through the development and operation of environmental technologies related to waste management, renewable energy, and district heating. However, Swedish municipally owned companies are embedded in a complex mix of rights and constraints, some of which are fundamental to understanding their business logic and export activities (cf. Corvellec et al., 2012).

Municipalities follow the municipalities' law (Kommunallagen in Swedish) which stipulates their rights and responsibilities. The law specifies that the main objective for municipalities and their companies lies within their geographical area and the interests of their inhabitants (SFS, 1991:900). In 2009, amendments were made to the law which gave municipalities the authority to conduct certain activities outside those prescribed in the municipalities' law. One such activity is the export of knowledge and experience within the current municipal services which must be conducted at low risk and secured by some guarantee or insurance (SFS, 2009:47).

Furthermore, municipally owned companies are subject to political control (ägardirektiv in Swedish), which implies that their board of directors is composed of politically appointed members, and a change in political majority in a municipality can have profound strategic implications for the company (Corvellec et al., 2012). Though municipally owned companies are constructed for public purposes, they resemble private companies in the way they are organised and governed (Thomasson, 2009). Their governance structure, with an owner, a board of directors and a managing director resembles that of private companies. Furthermore, it is not uncommon for municipally owned companies to conduct services on the market besides public services. However, there is also an open-ended legal controversy both at the national and European Union level between national governments, the private sector and municipally owned companies which threaten the entire business logic and operations of municipally owned companies. The central discourse is that municipally owned companies specifically those engaged with waste management, must derive only a marginal share of their income (broadly understood as less than 20\%) from customers outside their own jurisdiction to safeguard their monopolistic right to process household waste within their owner territory (Corvellec et al., 2012). This institutional context of rights and constraints defines the conditions under which Swedish municipally owned companies operate, and is essential in understanding their export activities.

Finally, municipally owned companies are not limited to Sweden and similar forms of organisations are identifiable worldwide. For example, in certain cities, such companies are responsible for generating energy for transportation, supplying drinking water in Canada (Furlong, 2015), Zurich (Lieberherr and Truffer, 2015), solid waste management in Botswana (Taye et al., 2014), and providing telephony, drinking water and sewage treatment in Colombia (Mejía-Dugand, 2015a). 


\subsubsection{Business Models}

Business models have received increasing scholarly attention over the last 15 years, with several definitions and approaches for describing business models being propounded in the related literature (Dentchev et al., 2015). Osterwalder and Pigneur (2010 p.14) present the business model as "the rationale of how an organization creates, delivers and capture value." Amit and Zott (2001 p.494) states that "a business model depicts the content, structure, and governance of transactions designed so as to create value through the exploitation of business opportunities." On the other hand, Magretta (2002) puts it openly, as a business model should tell a good story about how enterprises work. It should answer the following questions: Who is the customer? What does the customer value? How does the business obtain revenue? Despite these different perspectives on the definition of business models, overall, most scholars agree that the business model underscores a systemic and holistic approach to understanding how a firm creates and captures value (Dentchev et al., 2015).

Osterwalder and Pigneur (2010) present a generic canvas for describing the business model for different kinds of businesses and their offerings, whereas other scholars describe business model frameworks that are limited to (i) a particular industry segment, e.g. heat energy generation (Okkonen and Suhonen, 2010); (ii) an offering type, e.g. integrated product-service offerings (Lay et al., 2009), and (iii) company ownership, e.g. municipally owned waste management companies (Corvellec and Bramryd, 2012). Approaches to describe business models which are of relevance for addressing Research Question 4 - Which components could be considered in business concepts for environmental technology export? - are elaborated on below.

A popular tool for mapping business models is the business model canvas (Osterwalder and Pigneur, 2010). The business model canvas presents a practical guide for generating the business model of an organisation (Osterwalder and Pigneur, 2010). The business model canvas consist of nine building blocks: customer segments, value proposition, channels, customer relationships, revenue streams, key resources, key activities, key partnerships, and cost structure. To create, deliver and capture value, these nine building blocks of the business model canvas should be explored synergistically.

Mason and Spring (2011), identify three core elements of business models for products. These are (i) technology, (ii) market offering, and (iii) network architecture. By exploring the theoretical roots of each of these core elements, multiple dimensions are identified. Technology refers to technologies that make up the product/service offering, its delivery and management. They suggest business model analysis needs to take into account four classes of technology, namely product, process, core, and infrastructure technology. Process technologies are used to manufacture products or deliver services; core technologies underlie the particular product technology a firm innovates, and infrastructural technologies are those that enable connection. The second core element, market offering, concerns what is actually offered to the customer and how, focusing particularly on the nature of the producer-user interaction, rather than any particular feature of a product or service. Network architecture refers to the configuration of buyers and suppliers that make the market offering possible. 
With regards to combined products and service offerings, Lay et al. (2009) offer a morphological box of important parameters and optional features to describe business concepts. The main parameters are ownership during and after the use phase, responsibility for manufacturing and maintenance, location of operation, number of operating customers and payment model. Each parameter has several options, a combination through which different business concepts can be generated.

Corvellec and Bramryd (2012) present a business model based on case studies of two Swedish municipally owned waste management companies. In their conceptualisation, they argue these municipally owned companies are exposed to four different but related markets: a political market in which their legitimacy as an organisation is determined, a waste-as-material market where they compete for raw material input, a technical market where these companies decide how to process the waste using different available technical options, and finally a commercial market where their products or services are sold. These four markets differ in nature, involve complex dynamic interrelations, and influence revenue from both input (e.g. gate fees) and output (e.g. selling heat, electricity and materials) activities.

From the review above, it is evident that the components of business models are often determined by the empirical context (e.g. the firm and its networks, technologies, business offerings and sectors) and theoretical roots (e.g. technology and innovation studies, industrial marketing, operations strategy, and evolutionary economics) from which they are conceptualised. This thesis synthesises six basic components from the reviewed business models and incorporates additional components based on the specific characteristics of environmental technologies studied (see Research Question 4 in cover essay and appended Article 5).

\subsection{Technology Adopters}

Technology adopters and their characteristics are some of the most studied elements in diffusion research. The literature is extant with research on factors that influence adopter decisions to adopt or reject a technology (Del Río, 2005; Mejía-Dugand et al., 2013), adopter categorisation (Rogers, 2003), adopter motives and barriers to technology adoption (Mignon and Bergek, 2016) among others. As Fichter and Clausen (2016) point out, besides other diffusion elements, adopter-related factors play an important role in the diffusion of innovations.

The time dimension of the diffusion process allows for categorisation of adopters based on when they choose to adopt or reject an innovation. The adoption of an innovation ideally, but not always, follows a normal distribution when plotted over time on a frequency basis, as depicted in Figure 1 below (Rogers, 2003). Another model often used to depict the technology diffusion process is the S-shaped curve. This model describes the cumulative number of adopters of an innovation over time in a population. Attributed to Everett Roger's seminal work in diffusion studies, the epidemic model proposes a diffusion curve based on normal distribution in which technology adopters are categorised according to how long it takes them to adopt a technology. As depicted in Figure 1, first there are only a few adopters of an innovation, then a few more and then the number of adopters increases to a peak, after which it starts to level off following widespread adoption and technology maturation. Consequently, substitute technologies emerge following a similar diffusion pattern. 
These diffusion curves describe how a market segregates upon the introduction of a new technology, as depicted in Figure 1 below. The first group of adopters (also labelled as "innovators") are more eager to accept new technologies. The next group, the early adopters, buy into the technology because they understand and appreciate the benefits of the new technology. The first two groups of customers (innovators and early adopters) represent a minority in terms of number, and thus the quantities of units sold in aggregate are often small. Reaching the early majority and late majority is where technologies can achieve high commercial success. Finally, the last segment, the laggards, avoids the new technology. The criterion for adopter categorisation is based on innovativeness, the degree to which a potential adopter is relatively earlier in adopting an innovation than the other members of the population. This categorisation is rather conceptual and aids in the understanding of adopter behaviour particularly in a complete adoption by a population. However some information is lost as individual adopters are put into groups, nonadopters are not explicitly considered and incomplete adoption poses a challenge to this categorisation.

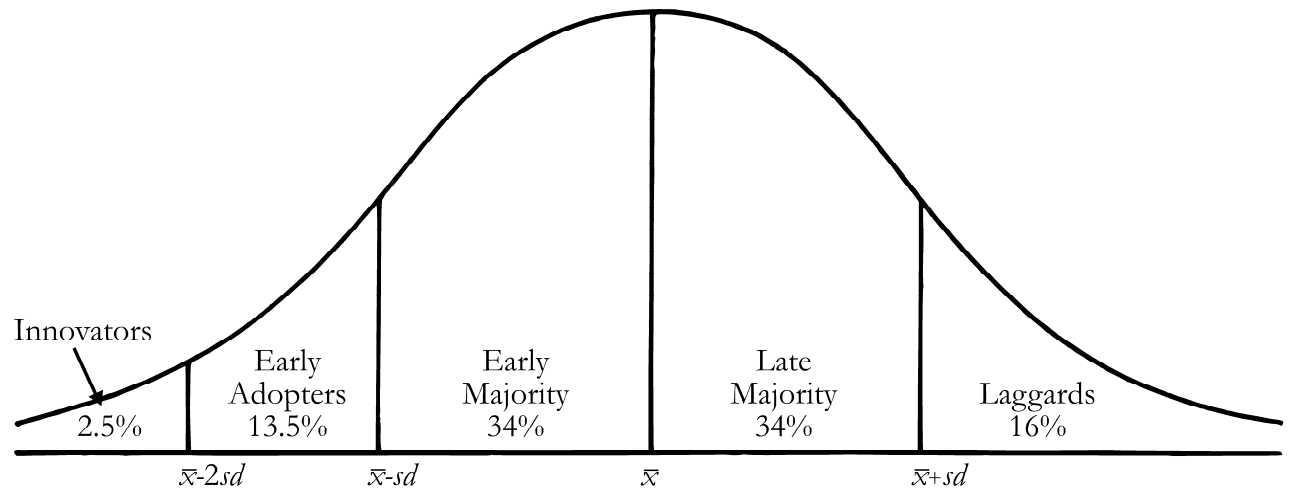

Figure 1: Adopter categorisation based on innovativeness (Rogers, 2003).

The diffusion of innovation model suggests that the adopter group of "innovators" plays a crucial role in market introduction and early diffusion of innovations, both for individuals and organisations (Fichter and Clausen, 2016). However, fundamental differences seem to occur between private individuals and business adopters regarding the adoption decision process. In businesses, adoption decisions are often (but not always) made collectively with emphasis on function, quality and cost-effectiveness. In the case of individuals, high price is often a constraint independent of cost-effectiveness, due to relatively limited debt-paying ability (ibid). 


\subsection{Communication Channels}

Diffusion can be understood as a special type of communication among members of a social system over time (Valente and Rogers, 1995). Participants in the communication process create and share information with each other to reach a mutual level of understanding about particular innovations and the problems they can potentially address. In its basic form, communication revolves around (i) the innovation, (ii) the unit that has knowledge of the innovation, (iii) the unit that does not yet have knowledge about the innovation, and (iv) a communication channel (Rogers, 2003).

A communication channel is the medium through which information moves from one unit to another. Based on the characteristics of the four basic elements of communication mentioned above, different communication channels are relevant for the diffusion of innovations. These include mass media channels such as radio, television, newspapers, internet and interpersonal channels such as personal networks. Conclusions from different diffusion studies suggest that potential adopters sometimes do not evaluate innovations on the basis of scientific evidence, but rather depend on subjective evaluations conveyed to them from other adopters within their networks (Rogers, 2003). This dependence on the experience of peers underpins the social nature of diffusion, which involves the creation and maintenance of interpersonal communication relationships (see e.g. Keiner and Kim, 2007). As such, diffusion networks such as local groups, international city networks, and technology clusters are expected to provide arenas for information sharing regarding innovations.

Diffusion in such networks is not only facilitated by interactions between similar adopters, but more importantly between adopters that are different from each other regarding certain attributes, e.g. innovativeness or risk aversion. For example, interactions between opinion leaders, lead users, and laggards are expected to further facilitate the scope of diffusion compared to interactions between only lead users. Interactions between adopters who are similar in certain attributes are often common in diffusion, since communication between them is more likely to be effective. However, heterophilous communication between individuals that have different meanings, beliefs and understandings may cause cognitive nuisance, since individuals are exposed to messages that are inconsistent with their existing knowledge. It is, however, such heterophilous interactions and communications that further the diffusion of innovations beyond close-knit networks (Rogers, 2003).

In this regard, one such milieu for interaction between different kinds of actors is international city networks. International city networks represent arenas where cities and their stakeholders with different attributes (technological competence, resources, goals, experiences and environmental challenges) can communicate and share knowledge, resources and experience potentially relevant for the export of environmental technologies. This builds on a widely-agreed upon notion in the innovation literature that diffusion is facilitated through the creation and maintenance of personal connections (Baptista, 2001; Simmie, 2003). Additional potential benefits from participation in such city networks include entering two-way information flows (Batten, 1995) where technology providers and potential adopters learn from each other (Cooke et al., 2002), finding common grounds for sustainability challenges and maximising the network value of innovations (Cooke et al., 2002), which are relevant for the diffusion of innovations in 
general including the export of environmental technologies. Furthermore, international city networks are regarded as an effective way to solve environmental and social problems (Keiner and Kim, 2007) through cooperation built on complementarity, communication and interactive construction of collective goals (Batten, 1995).

\subsection{Diffusion Context}

Adopter contexts considered in diffusion research include adopter norms, beliefs, the roles of opinion leaders, institutional frameworks, governance tools such as public policy, and how the social structure influences the innovation diffusion. With regard to diffusion through export, governmental intervention is particularly relevant for environmental technologies, due to the double externality problem highlighted as characteristic in the development and diffusion of environmental technologies (see Bleda and Del Río, 2013; Jaffe et al., 2005; Rennings, 2000).

The different policy instruments used by governments to support the diffusion of environmental technologies include governmental push and pull activities, and lead market policies. Strong reasons are often needed to justify governmental intervention to support private ventures, in this case for governmental initiatives to promote private firms' export. The rationale for such governmental support can be grouped into two categories: rationales based on societal desires from the success of such ventures, and rationales based on challenges faced by private ventures (Norrman, 2008).

However, the underlining theoretical rationale for governmental intervention can be different, depending on which academic field one subscribes to. The economic justification for government intervention to promote export is based on the theories of externalities and market failures associated with export (Lederman et al., 2010). In export, spillovers exist regarding the collection of foreign market information related to consumer preferences, laws, regulations, and business opportunities. Private exporters would hesitate to undertake such market research all by themselves, as the cost involved is significant and their competitors could benefit from their investment. Pace-setters in export who make ground-breaking investments to open foreign markets, establish contacts, develop distribution links, and engage in other costly undertakings that could benefit their rivals also face a similar dilemma (Lederman et al., 2010). In addition, political and economic risks of buyer default have been used to justify the promotion of exports by governments (Lederman et al., 2010). In the face of such market failures, a government's concern is to design and implement strategies that correct such irregularities and create a level playing field for exporters (European Commission, 2007).

However, in the innovation systems literature, the market failure justification for governmental intervention has almost been rejected as insufficient and incomplete, and rather a system failure approach is often preferred (Bergek et al., 2008). In this regard, the development and diffusion of innovations are governed by complex interactions between multiple socio-economic agents whose activities and interactions are governed not only by market forces, but to a large extent by non-market institutions. Thus, policy interventions are much needed for co-ordination of the interactions between the various socio-economic agents in a broader institutional context, a move from top-down to network setting (Bleda and Del Río, 2013). 


\subsection{Synthesis of Theoretical Background}

To synthesise, the theoretical background serves as a frame of reference through which to explore the overarching aim and research questions guiding the thesis. Specifically, the different theories serve as "a pair of glasses" with which I observe the phenomenon of environmental technology export. By analysing environmental technology export with these theories, certain aspects of the phenomenon are given particular attention, while others are blurred to the background due to the inherent attributes of the theories.

Anchoring the thesis in the diffusion of innovation literature presents several analytical possibilities and challenges. First, export is understood as an approach to diffusion, and thus environmental technology export is influenced by general innovation diffusion factors as well as specific export dimensions. Furthermore, the theoretical background highlights a systemic and complementarity approach which suggests that, the diffusion of environmental technologies through export can be comprehensively analysed with a combination of different perspectives and disciplines. Aspects which influence environmental technology export, such as the technology and its characteristics, are given particular attention that otherwise could have been ignored in traditional international business literature. On the other hand, the diffusion of innovation literature sometimes restricts the importance of suppliers and the business aspects of diffusion, two dimensions emphasised in the international business literature.

These limitations of both the diffusion of innovation and the international business literature are tackled by adopting a complementary approach emphasising the technology supplier, the characteristics of environmental technologies, the diffusion context and also business models for the diffusion of environmental technologies. This offers a systemic understanding of the subject at hand, recognising the different aspects and elements in the export process which might be overlooked in the two disciplines.

Narrowing down, the discussion on the definition of "environmental technology" highlights the challenges that emerge with the use of the term. The various definitions and their contestations reveal the challenges not only with defining the terminology, but more so with its operationalisation. Though the definition adopted for environmental technologies in this thesis, as "goods, systems, processes and services that offer clear environmental advantages in relation to existing or alternative solutions, seen from an ecocycle perspective" is rather broad, its operationalisation had to be delimited in the empirical context. The classifications provided for collecting and reporting data for the Environmental Goods and Services Sector (also referred to as the environmental sector) served as a useful boundary within which to identify companies engaged with the export of environmental technologies. Outside the boundaries of this sector, there are several sectors within which environmental technologies can emerge e.g. information technology sector.

Furthermore, theories of market failures are often used in the economic literature as an underlining justification as to why governments intervene through export promotion. In the diffusion of innovation literature and in particular innovation systems, the market failure view is expanded upon with the complex evolutionary nature of the innovation process, which cannot 
only be explained by market factors but also non-market institutions such as public policy and interactions among multiple socio-economic agents (see Bleda and Del Río, 2013).

Altogether, the conceptualisation of five main elements of the diffusion process (i.e. the technology and its characteristics, technology suppliers and their characteristics, technology adopters and their categorisation, communication channels and the diffusion context) can be used in different ways, depending on the purpose. For example, in this thesis, the central focus is on environmental technology suppliers while remaining sensitive to the other elements and their interactions which influence the export. Other scholars have focused on technology adopters, while considering the relevance of other diffusion elements either explicitly or implicitly (see e.g. Mejía-Dugand, 2013; Mignon, 2016).

Finally, the elements synthesised in this chapter are characteristic of several diffusion studies. Thus, similar synthesis with different theoretical underpinnings can be found in the diffusion literature to explore a particular research question (see e.g. Beise and Rennings, 2005; Fichter and Clausen, 2016). 


\section{Research Methods}

This chapter of the thesis focuses on two themes inspired by the doctoral thesis writing traditions at the Department of Management and Engineering, Linköping University. The first theme describes my research journey through the various research projects I have participated in leading up to this thesis. The second theme focuses on the scientific methods I used to identify, gather and analyse the empirical data upon which this thesis is based.

\subsection{Research Journey}

The foundations of my interest to pursue a doctoral study on the subject of technological change can be linked to my experiences as an undergraduate student. While studying for my undergraduate degree in Agricultural Engineering at the Kwame Nkrumah University of Science and Technology, Ghana, a dominant focus was put on mechanising traditional agriculture through the application of modern technology. This was my first vivid encounter with technological change from labour-intensive agricultural practices to more mechanised practices. Outside my formal education, an observation that intrigued me was how several international donor agencies came to Ghana, implemented technological solutions (e.g. bore holes, irrigation and electrification projects) and left, only to find out upon their return that their technological solutions were broken or not being used. These personal experiences informed my interest in the international diffusion of technology and how that could be effectively undertaken. Upon enrolling for my master's degree in Energy and Environmental Engineering at Linköping University, Sweden, I got the opportunity to explore another dimension of technologies - i.e. their potential to contribute to environmental sustainability. It was through a combination of my experiences and future ambitions that I developed keen interest in the export of environmental technologies.

Often (but not always), a Ph.D. position at Linköping University is based on externally funded research projects, and the scientific articles upon which this thesis is based are an outcome of my participation in such projects. My doctoral position emerged from a research project titled "Megatech" funded by VINNOVA, the Swedish Innovation Agency. The project focused on analysing megacities (cities with more than 10 million inhabitants) - specifically Cairo and Mexico City - as arenas for the diffusion of environmental technologies. This project was conducted mainly from the technology adopter perspective (cities, their decision makers, businesses and inhabitants). As an outcome of the Megatech project, there emerged some knowledge gaps, particularly regarding environmental technology suppliers and how they were supported by governments in their export activities. This was my first research task, and the main focus was to synthesise governmental export promotion for environmental technology suppliers, including the perceived effectiveness of such initiatives among target companies. The outcomes of this research were presented in a report (Kanda et al., 2012), a conference paper (Kanda et al., 2015a), and two scientific articles which are appended to this thesis (Kanda et al., 2016b; Kanda et al., 2015b).

After the Megatech project I was involved in a subsequent project, "BMEX" - Business Models for Market Expansion of Swedish Municipal Companies, funded by Tekniska verken i Linköping AB's Industrial Ecology Research Programme. This project focused on developing business models to support municipally owned companies (including their subsidiaries and spin-offs) in 
the export of environmental technologies. The project focused on how the specific characteristics of environmental technology systems such as district heating, waste management, and renewable energy solutions can be considered in business models for their export. A related project with a more or less similar focus to BMEX was commissioned by Avfall Sverige (the Swedish Waste Management Association) with a nationwide target on municipality owned companies to understand their challenges, drivers, key stakeholders and conditions which influence their export activities. The outcomes from my participation in these two projects were presented in a report to the funding agency (Kanda et al., 2013), and in two scientific articles - one on business concepts, the other on obstacles to and drivers for export - which are appended to this thesis (Kanda et al., 2016a; Kanda et al., 2016d). Insights from this project, particularly regarding the challenges to and drivers for the export of environmental technologies among municipally owned companies led to a smaller follow-up study on international city networks as arenas for export of environmental technologies. This follow-up study was focused on how international city networks could be used to assist export by serving as arenas for knowledge sharing among technology suppliers and potential adopters. The results from this study were presented in a conference paper (Mejía-Dugand et al., 2014) which was further developed into a scientific article appended to this thesis (Mejía-Dugand et al., 2016). Altogether, results from the projects described above and their respective scientific articles form the empirical basis for my doctoral thesis.

Nonetheless, my Ph.D. research education has been much broader than the projects and articles presented above. I have been involved in other research projects and scientific publications which directly or indirectly shape my understanding of and discussion on the export of environmental technologies. These include the European Union research project "SHIFT" Support systems for Sustainable Entrepreneurship and Transformation, funded by Formas (The Swedish Research Council), which focused on public support for the innovation of environmental technologies in Finland, Germany and Sweden. Another project, "Interbio" Internationalisation of Swedish biogas knowledge and technology for sustainable cities, funded by Energimyndigheten (the Swedish Energy Agency), focused on developing improved types of offerings and activities to potentially increase the export of biogas-related technology from Sweden. I also participated in a four-year implementation project "GTARS" - Gaborone Transfer and Recycling Station, funded by ICLD (Swedish International Centre for Local Democracy), which was focused on the design, construction and operation of a potential environmental technology system, a waste recycling facility in Gaborone, Botswana. Finally, I am currently participating in the on-going research project "SUPER" - Supporting eco-innovations towards international markets, funded by the European Union Regional Development Fund, which takes a combined look at the supply and demand side of public support from the development to the internationalisation of environmental technologies in several European regions.

These additional projects have also yielded interesting empirical findings, in some cases scientific articles and conference papers. The findings from these additional projects discuss relevant topics for this thesis such as the interaction between the innovation and diffusion phases of environmental technologies - the SUPER project, drivers for and challenges to export among privately owned companies within a particular branch, i.e. biogas - the Interbio project, and the 
use of intermediaries in supporting the development of environmental technology - the SHIFT project. Even though these discussions could be connected in some ways to the subject of this thesis, I have actively pursued to keep a coherent focus (both in terms of empirical scope and topic) for this doctoral thesis, with the inclination to make a sharper and more robust scientific contribution.

\subsection{Research Approach}

The overarching research approach for this thesis was exploratory (cf. Yin, 2008). An exploratory approach is appropriate in situations when the topic under investigation is in its early phase and also provides fundamental knowledge from which to narrow the research for further investigations (Babbie, 2013). An exploratory approach was appropriate for this thesis since the subject of environmental technology export is an emerging research topic. However, I acknowledge that the subject is not entirely in its infancy, and that some previous scholarly contributions on internationalisation in general including export (e.g. Johanson and Vahlne, 1977; Johanson and Vahlne, 2009) can in one way or another be related to the export of environmental technologies. In addition, the exploratory approach is particularly relevant as the research questions guiding this thesis are of a "how" and "what" nature (cf. Yin, 2008). The entire research process evolved organically, with initial findings providing guidance for subsequent exploration including iterations. As a result of the organic nature of the research process coupled with the nature of the scientific publication process, the ordering of the articles appended to this thesis does not strictly follow the chronology in which they were written, but does pursue potential connectivity including overlaps between them.

The first article that I wrote was on a review of different governmental initiatives to promote the export of environmental technologies (Article 1 in this thesis). Conclusions from this article suggested that the success of export promotion does not only depend on the formulation of such initiatives, but also their implementation and how the initiatives are perceived as effective by target firms. The outcomes of Article 1 provided input to the design of the survey and empirical data collection on the awareness, participation and perceived effectiveness of governmental export promotion initiatives among target firms (Article 2 in this thesis). The analyses from these two articles suggested that participation in governmental promotion alone does not guarantee successful export, particularly among companies that are not internally driven to engage in export. Thus, a complementarity perspective to government support and firm perception was sought after to understand the export of environmental technologies.

The focus was put on municipally owned companies (including their subsidiaries and spin-offs) since in addition to SMEs, municipally owned companies represent key actors in the Swedish environmental technology sector. We explored their drivers, approaches and obstacles in the export of environmental technologies which resulted in Article 3. After developing an understanding of the characteristics of the environmental technologies municipally owned companies developed, their potential customers, and their drivers for and obstacles to export, we investigated international city networks for sustainability as arenas for sharing knowledge and experiences which could potentially facilitate the export of environmental technologies from municipally owned companies (Article 4). Altogether, insights from these four scientific articles 
gave a foundation for exploring business concepts for the export of environmental technologies among municipally and privately owned companies as presented in Article 5.

In reality, the emergence of many of the results and scientific publications overlap with each other, which allowed me to revise data collection methods and to be flexible; thus, the research results and scientific publications cannot be sharply differentiated on a timeline. An attempt is made in Figure 2 below to present the development of the research process. As can be seen, different perspectives have been adopted to analyse various types of environmental technology suppliers using a combination of different research methods. Figure 2 also shows the relationship between the various articles and how they come together to form this doctoral thesis.

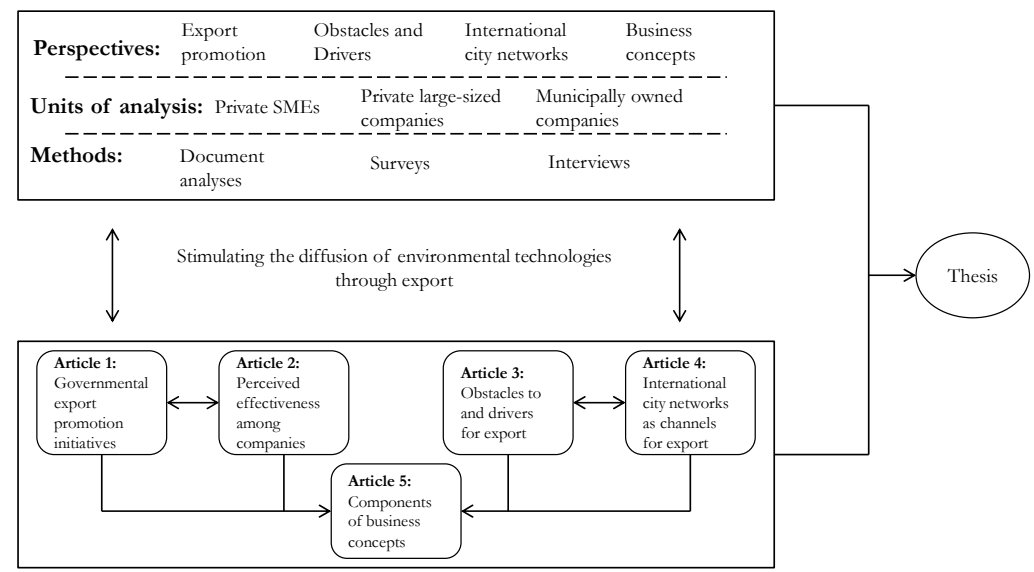

Figure 2: Connections between main elements in the research process.

\subsection{Writing the Thesis}

A doctoral thesis may be written as a monograph or a compilation (cover essay and appended articles). Both approaches have their strengths and weaknesses, and can also be linked to particular subject areas. For example, a thesis based on a compilation of scientific articles offers the Ph.D. candidate the chance to submit his/her work to international scholars for scrutiny in terms of quality (this is however not exclusive to a compilation thesis). The monograph, on the other hand, allows the scholar to develop an idea or arguments in considerable length and detail. This thesis is written as a compilation largely in adherence to the traditions at the Division of Environmental Technology and Management, where the Ph.D. research education process encourages the Ph.D. candidate to write and publish scientific articles.

The writing of the cover essay has been iterative between the various chapters, from the beginning to the end. I proceeded by abstracting one overarching aim and four research questions based on the specific results in the appended articles. Then, to explore the aim and research questions, a synthesis of key concepts and theoretical background was provided which served as frame of reference for the entire thesis. The different research methods used in the appended articles were then described, including a reflection on alternative methods and theories 
which could have been applied. The results from each of the appended articles were then presented and discussed in light of the theories and key concept in an attempt to address the research aim and questions. Finally the conclusions from the thesis were brought to a wider audience with potential implications for policy, businesses and further research.

The relation between the research questions, the appended articles and the research methods are presented in Table 2. The research methods used in each article are thematically elaborated on below.

Table 2: Relation between research questions, appended articles and research methods.

\begin{tabular}{|c|c|c|c|c|}
\hline Research question & \begin{tabular}{|l|} 
Contributing \\
Article's number
\end{tabular} & Unit(s) of analysis & $\begin{array}{l}\text { Main data } \\
\text { collection } \\
\text { method(s) }\end{array}$ & $\begin{array}{l}\text { Main data } \\
\text { analysis } \\
\text { method(s) }\end{array}$ \\
\hline $\begin{array}{l}\text { 1. How do governments } \\
\text { promote environmental } \\
\text { technology export and } \\
\text { what is the perceived } \\
\text { effectiveness of such } \\
\text { initiatives among private } \\
\text { environmental technology } \\
\text { companies? }\end{array}$ & $\begin{array}{l}1 \text { (Governmental } \\
\text { export } \\
\text { promotion } \\
\text { initiatives) } \\
\\
2 \text { (Perceived } \\
\text { effectiveness } \\
\text { among firms) }\end{array}$ & $\begin{array}{l}\text { Export credit } \\
\text { and export } \\
\text { promotion } \\
\text { agencies } \\
\text { - Private SMEs } \\
\text { and large-sized } \\
\text { environmental } \\
\text { technology } \\
\text { companies }\end{array}$ & $\begin{array}{l}\text { - } \begin{array}{l}\text { Document } \\
\text { analyses }\end{array} \\
\text { - Survey }\end{array}$ & $\begin{array}{l}\text { - Thematic } \\
\text { analysis }\end{array}$ \\
\hline $\begin{array}{l}\text { 2. What are the obstacles } \\
\text { to and drivers for } \\
\text { environmental technology } \\
\text { export among } \\
\text { municipally owned } \\
\text { companies? }\end{array}$ & $\begin{array}{l}3 \text { (Obstacles, } \\
\text { drivers among } \\
\text { municipal } \\
\text { companies) }\end{array}$ & $\begin{array}{l}\text { Municipally owned } \\
\text { environmental } \\
\text { technology } \\
\text { companies }\end{array}$ & $\begin{array}{ll}\text { - } & \text { Interviews } \\
\text { - } & \text { Survey }\end{array}$ & $\begin{array}{l}\text { - } \begin{array}{l}\text { Keyword } \\
\text { coding }\end{array} \\
\text { - } \begin{array}{l}\text { Thematic } \\
\text { analysis }\end{array}\end{array}$ \\
\hline $\begin{array}{l}\text { 3. How could municipally } \\
\text { owned companies use } \\
\text { international city } \\
\text { networks to facilitate } \\
\text { environmental technology } \\
\text { export? }\end{array}$ & $\begin{array}{l}\mathbf{4} \text { (International } \\
\text { city networks for } \\
\text { sustainability) } \\
5 \text { (Components } \\
\text { of business } \\
\text { concepts) }\end{array}$ & $\begin{array}{l}\text { - } \begin{array}{l}\text { Municipally } \\
\text { owned } \\
\text { environmental } \\
\text { technology } \\
\text { companies }\end{array} \\
\text { - } \begin{array}{l}\text { Cities and their } \\
\text { networks }\end{array}\end{array}$ & - Interviews & $\begin{array}{l}\text { - Thematic } \\
\text { analysis }\end{array}$ \\
\hline $\begin{array}{l}\text { 4. Which components could } \\
\text { be considered in business } \\
\text { concepts for } \\
\text { environmental technology } \\
\text { export? }\end{array}$ & $\begin{array}{l}\mathbf{5} \text { (Components } \\
\text { of business } \\
\text { concepts) }\end{array}$ & $\begin{array}{l}\text { Privately and } \\
\text { municipally owned } \\
\text { companies }\end{array}$ & - Interviews & $\begin{array}{l}\text { - Thematic } \\
\text { analysis }\end{array}$ \\
\hline
\end{tabular}




\subsection{Overview of Research Methods}

Both qualitative and quantitative data were collected as a basis for addressing the research aim and questions. This approach is referred to by some scholars as mixed methods research (Bryman, 2015). Qualitative methods are often used to understand the development, meaning, and characteristics of a phenomenon, whereas quantitative methods emphasise the use of numeric data to establish correlations and causalities. Many scholars advocate a combination of both qualitative and quantitative approaches. In a similar argumentation, Del Río (2009) suggests that qualitative and quantitative approaches or mixed methods should be used complementarily to analyse environmental technological change, since by doing so the researcher can derive synergies which are difficult to achieve with either approach.

Case studies based on interviews and other data sources are able to capture the details of environmental technological change at the local level, which might be overlooked by aggregate quantitative methods which tend to adopt a top-down approach (Del Río, 2009). Though quantitative approaches are usually perceived as more rigorous and objective, they are less equipped to capture the local institutional and socio-economic context related to environmental technological change (ibid). Due to the advantages and drawbacks of each of these individual approaches, a combination of qualitative and quantitative data has been used in this thesis, as recommended by Bryman (2015), Del Río (2009), and Yin (2008), to yield a better understanding of environmental technological change. As shown in Table 2, a combination of different empirical data collection and analysis methods has been used in each of the appended articles including documentation analyses, surveys and interviews, which are described below.

The individual articles are based upon more empirical data than what is presented in the cover essay, and thus only methods of relevance for the results presented in the cover essay and the research questions guiding the thesis are discussed below. For a complete description of the methods used in each of the appended articles, kindly refer to their method sections.

\section{Document analyses}

Article 1 is based on document analyses. This entailed the extensive search for and critical analysis of both scientific and grey literature (informally published written material such as reports from government agencies) to answer part of Research Question 1 on how different governments promote the export of environmental technologies. In doing so, empirical data were collected from export promotion and export credit agencies on governmental initiatives that aim to promote the export of environmental technologies. This data was collected from the following purposely selected countries: Germany, the USA, and Japan - the top three exporters of environmental technology by number of patents and market surplus; Denmark, Sweden, Finland, and Norway - Scandinavian leaders in environmental technology innovation; and Austria - an emerging eco-innovator (WWF, 2012). These countries were purposively selected to uncover potential diversities and similarities in governmental approaches to environmental technology export promotion as well as good practices.

For each of these countries, information was collected from the official documentation of action plans, websites and reports aimed at supporting the export of environmental technologies issued by export credit and export promotion agencies. The names and websites of the studied agencies 
and titles of specific reports that were analysed are presented in Table 2 in Article 1 . The analysed empirical data also covered general export promotion which could be accessed by all kinds of exporters including environmental technology exporters. Recognising that governmental export promotion initiatives may be changed, abandoned or renewed over time, the documentation analyses covered a ten-year period from 2002 to 2012. This information was collected in spring 2012 .

The analysis of the collected empirical data itself took the form of repetitive reading and categorisation into various themes on how different governments support the export of environmental technologies. The various themes which were used to categorise the empirical data were informed both by previous literature, in particular Leonidou et al. (2011), and major themes which emerged from repeatedly reading and discussing the documents. To examine the theoretical justifications underlying such governmental export promotion activities and the kind of initiatives offered, theories of market failure and externalities related to export were used to analyse the empirical findings.

I deemed document analysis appropriate to answer part of Research Question 1, which focused on how governments promote the export of environmental technology, because governmental export promotion and its initiatives are vast, and using other research methodologies such as case studies through interviews would be constrained practically by time and cost. The documentation analyses offered an overview of governmental export promotion initiatives from which to develop more focused empirical data collection. Other advantages of studying such documents are that they have been carefully reviewed by governmental agencies before publication, and that they offer detailed information particularly about historic events. As Bryman (2015) cautions, however, documents should be viewed as texts written with distinct objectives, and not simply as reflections of reality. Though governmental documents may be written to positively portray the support activities of such agencies, they still provide a fundamental account of export promotion initiatives which, together with other complementary sources can provide an overview of governmental support for export.

Furthermore, I acknowledge that since the data collection focused on official governmental agencies engaged with export promotion (i.e. export promotion and credit agencies), other agencies such as cluster organisations, export networks, and government ministries, whose activities can be argued to promote export in one way or another, could have been overlooked. However, since the research question is directed at governmental initiatives, the scope of empirical coverage and the findings provided a sufficient overview from which to explore the perceived effectiveness among target recipients.

\section{Surveys}

Article 2 explores the second part of Research Question 1 regarding how environmental technology firms perceived the effectiveness of export promotion initiatives. The empirical data addressing this question were collected using an Internet survey directed towards environmental technology firms. Before conducting this internet survey, a database of Swedish environmental technology suppliers was compiled. This information was gathered from different sources such as company webpages, contacts with industrial and academic networks, and sector organisations. 
The information collected on these companies covered their area within the environmental goods and services sector (e.g. renewable energy, waste management, and air pollution control), their products or services, location in Sweden and contact information. The final list of environmental technology suppliers consisted of 693 entries after duplications; non-companies (e.g. investment and marketing agencies that do not directly export) were removed from the list.

The Internet-based survey was sent to the chief executive officers of 693 private Swedish environmental technology firms, with a notification to forward the survey to a person within the firm with appropriate knowledge to answer the survey questions if the initial recipient was not capable of completing the survey. The survey included questions about firm awareness, participation and the perceived effectiveness of governmental export promotion initiatives. The survey questions were sent in Swedish, with the ambition to reach a relatively higher response rate. In developing the survey, the questions were first formulated in English and then translated into Swedish. To ensure content validity, a researcher with proficient knowledge of both languages translated the questions back and forth between English and Swedish to ensure that the questions were consistent in both languages and to follow good practise (cf. Leonidou et al., 2015). In an attempt to increase the response rate, two reminders were sent (two weeks apart) to all companies in the database. A total of 172 companies answered the survey completely (a response rate of approximately 25\%). The survey was conducted during May 2012.

The use of an Internet survey was motivated by the ambition to cover a large scope of Swedish environmental technology companies. It would be time and financial resource intensive to cover such a large database of companies with other kinds of data collection methods such as interviews. More so, the questions being addressed by the study regarding perceived effectiveness of governmental export promotion initiatives were answerable using the survey method. The numeric data from the survey results were analysed for major trends and descriptive statistics using the survey tool, while responses to open-ended questions were analysed thematically by iteratively reading through the responses and categorising them into themes.

Article 3, which focuses on the obstacles to and drivers for export among municipally owned companies, also uses a survey. Before the survey was conducted, a database to identify cases of municipally owned companies relevant for the research aim was compiled. With a total of 290 municipalities in Sweden, the search for relevant cases took the form of an internet scan, reading from homepages, and company and industrial network reports. To be able to manage the volume of information generated from such searches, the scan was narrowed down to larger-size municipalities which have a higher likelihood of owning such municipal companies. A total of 75 municipally owned companies were found which were currently exporting, have been exporting or were planning to export. For each case, information on their export activities including target markets, environmental technology, revenue and number of employees was collected; see Table 1 in Article 3 for details. Out of these 75 companies, 12 had conducted export previously (and data was collected from them using face-to-face interviews), while 4 cases were inconclusive and thus not followed up. The remaining 59 had no export activity, and were reached with a survey to uncover obstacles which prevented them from participating in export. Non-exporters are an important group of companies, particularly with regard to expanding the reach of governmental export promotion initiatives. An online survey was sent to the chief executive officer in each of these companies with a response rate of $61 \%$ (36 respondents out of 59). 
While using survey methods has several benefits such as having responses from a large set of companies yielding the possibility to identify trends and generalisations, I also acknowledge some limitations of surveys. Survey questions could be misinterpreted by different respondents and do not always allow for follow-up questions, and in-depth probing. Furthermore, low response rates and the type of questions asked can limit the potential analysis of survey results. Recognising these challenges, surveys conducted were complemented with in-depth interviews when necessary to capture aspects which may have been overlooked.

\section{Interviews}

Articles 3, 4 and 5 used interviews to gather empirical data. For each of these articles, the process for selecting respondents, conducting the interviews, and analysing the empirical data are described below.

Article 3 focused on obstacles to and drivers for the export of environmental technologies among municipally owned companies. Among the 12 exporting companies, interviews were conducted regarding their obstacles to and drivers for export. A semi-structured interview guide was developed for face-to-face interviews with employees of these companies who have been directly involved in export activities and/or were in strategic-decision making positions regarding export activities, e.g. chief executive officers (see Table 1 in Article 3). General areas discussed during these interviews included experiences with export activities, the outcomes of export activities, and obstacles to and drivers for export. Two researchers conducted the interviews which encouraged diversity and follow-up discussions to the pre-defined questions on the interview guide. These two researchers were Master's thesis students who worked under my supervision, and though I was not physically present during the interviews, I was actively part of formulating the interview questions, reading the transcripts and analysing the empirical data. The interviews, which lasted between 60 and 90 minutes, were recorded and fully transcribed for further analysis.

To analyse the empirical data, both keyword coding and thematic analysis were used. For some researchers, a theme is more or less the same as a keyword. In this thesis, however, a theme transcends a keyword and is made up of several groups of (key)words - i.e. sentences. The keywords used to categorise the responses from the interviews were identified both from the literature on obstacles and drivers for export, and from the empirical data. Examples included gains, results, and expectations as keywords for export drivers and challenges, refrain, and discussing as keywords for obstacles to export. Since it was possible to miss out on some of the obstacles and drivers for export, the keyword coding was complemented by iteratively reading and categorising the empirical data to identify emerging themes around obstacles to and drivers for export.

Article 4 discusses, among other things, how municipally owned companies can utilise their owner city's membership in international city networks to facilitate the export of environmental technologies. For this study, the five largest Swedish cities were selected based on population size which is linked to membership in international city networks (cf. Keiner and Kim, 2007). The cities selected were: Stockholm, Gothenburg, Malmö, Uppsala, and Linköping. For each of these 
cities, a gross list of international city networks for sustainability they belonged to was compiled (see Table 2 in Article 4). We focused on international city networks for sustainability using keywords such as "sustainability", "environment", energy efficiency", "water management", "waste management" and "emission reduction". Follow-up interviews were conducted using a semi-structured interview guide to discuss issues about the city's involvement in international city networks (expected and perceived benefits from membership, assessment and monitoring of their activities, outcomes and the commitments involved in maintaining their membership in such networks) and how such networks can support the export activities of municipally owned companies. All interviews were recorded and transcribed for further analysis. A thematic and cross-case analysis was adopted in which the interview transcripts were read iteratively to identify main emerging themes, but these themes were also compared across the five cities for commonalities and differences. For each city, the international city networks to which they belonged to were noted, including an estimate of the total number of members as well as the geographical reach of such networks (global, European), which gave an indication of its diversity and reach of relevance for export. I acknowledge that there is the possibility of not detecting every single international city network that a city belongs to, but since the main objective was on how participating in such city networks can serve as arenas for export rather than assembling an exhaustive list of each city's networks, the information collected was judged as useful in addressing the research question.

Article 5 focuses on components of business concepts for the export of environmental technologies. The article uses interviews to gather primary data from selected municipally and privately owned environmental technology companies (see Table 1, Article 5). The companies were selected mostly based on their involvement in the export of environmental technology systems such as district heating, waste management, and renewable energy solutions. In administering the research instrument, a semi-structured interview guide was used for face-toface interviews in all the cases. This opened up the opportunity for respondents to speak freely and also add extra information which they deemed as exhaustive answers to a question. As two researchers conducted the interviews, the discussions were improved by increasing the possibility of follow-up questions to pre-defined questions in the interview guide. The respondents in each of the cases were purposively selected based on their involvement in export activities (see Table 1 in Article 5). The interviews lasted between one and two hours and were recorded and fully transcribed for analysis. The transcripts were also sent to the interviewees for corrections and clarifications if needed. The use of interviews in this case was motivated by the desire for a deeper, fine-grain understanding of the characteristics and specifics of environmental technology export.

The analysis of the empirical data from the interviews focused on important factors to consider when designing business concepts to support the export of environmental technologies. This analysis required synthesising previous literature on business models to identify relevant components (see Figure 6 in Article 5) and then extracting from the empirical data important characteristics of environmental technologies for business concepts. A feedback workshop was also held with some of the environmental technology companies to discuss the findings and make improvements to the proposed components of business concepts. 
In all the interviews conducted, care was taken when formulating the research questions not to be theory laden (but rather theory informed) and also to avoid very specific and leading interview questions; a rather open and free-flowing conversation was the goal. In addition, the interview guide was always sent to the respondents when scheduling the interviews to allow them time to prepare and gather relevant documentation rather than to rely entirely on their memory during the discussions. The thematic analysis of the interview transcripts followed a matrix-based method for ordering and synthesising the empirical data (see Bryman, 2015). A matrix of themes was constructed for the cases and filled with quotes from each case relevant for a particular theme. The themes are an outcome of thorough reading and re-reading of the interview transcripts, together with previous themes identified in the literature. By using themes and iterative reading of the interview transcripts, I developed a closer insight into cases and a deeper understanding of the phenomenon I was analysing.

\subsection{Quality of the Research}

There are different approaches to assess qualitative research (Bryman, 2015). One position is to assimilate reliability and validity, predominant criteria for assessing quantitative research into qualitative research with little change of meaning (Mason, 1996). While validity refers to whether the researcher is observing, identifying or measuring what they claim to be studying, reliability covers the consistency of a study's results (Field, 2013). Some scholars question the applicability of reliability and validity to qualitative research on the basis of the possibility of several accounts of social reality rather than a single absolute account, and therefore argue for the need to specify alternative terms and ways to assess qualitative research. Guba and Lincoln (1994) suggest four criteria adapted to assess qualitative research as credibility, transferability, dependability and confirmability. Even though these four aspects are presented as separate entities, they overlap with and reinforce each other.

\section{Credibility}

Credibility refers to the congruence between a researcher's findings and the reality they observe. As there are potentially several accounts of a social reality, it is the coherence of the account the researcher arrives at that will determine its credibility among other scholars. The techniques of respondent validation and triangulation have been used in this thesis to enhance its credibility. Respondent validation is a process whereby the researcher provides the interviewees with an account of his or her findings for corroboration (Bryman, 2015). In all the articles that involved interviews (i.e. Articles 3, 4 and 5), the full transcripts of the interviews were sent back to the interviewees for validation of the content and the possibility to make changes where necessary. Furthermore, the conclusions from these studies have also been presented to key stakeholders (i.e. interviewees, studied companies, funders and export networks) for their feedback on the congruence between their reality and the findings.

Triangulation entails the use of multiple observations, theoretical perspectives, sources of data and research methods to study a social phenomenon (Berg and Lune, 2004). All the articles appended to this thesis have incorporated to varying degrees elements of triangulation. For example, in conducting interviews for Articles 3, 4 and 5 at least two researchers have been involved, which gave room for different perspectives and depth during the discussions. These 
researchers and also project participants have different academic backgrounds (e.g. engineering, social and natural sciences) and competencies, which provided the possibility for wider and alternative interpretations of the empirical data and enriched the conclusions with interdisciplinarity. In addition, the overall thesis is based on different research methods such as surveys, document analysis and interviews to gather empirical data on the export of environmental technologies. Furthermore, data has been gathered from different sources, including government reports, employees of companies which have been involved in export, companies which have not been involved in export and company documentation. Different theoretical backgrounds such as the diffusion of innovations, market failures related to export, business models, and internationalisation have been used to understand and analyse the topic of environmental technology export.

\section{Transferability}

Given that qualitative research typically entails the intensive study of a group, or individuals with a (dis)similar characteristic, depth is often achieved within a given breadth. Thus, the issue of whether findings from this thesis are valid in some other contexts, or even in the same context at some other time is particularly relevant. As a recognition of the challenges with generalising qualitative studies, and in particular case studies, researchers are encouraged to give a detailed and rich account of the phenomenon which they have studied, which can serve as an input for others to judge the possibility of transferring the findings to their context (Bryman, 2015). The discussion on transferability varies between the credibility in making assumptions about entire populations based on measurements on samples - statistical generalisations (Field, 2013), and argumentations for the uniqueness of each case as an example within a broader group (see Yin, 2008).

In this thesis, Sweden served as the empirical context for operationalisation of the research aim and questions. Even though I recognise some specific characteristics of the environmental technology sector in Sweden (e.g. the important role of municipally owned companies), other characteristics such as the dominance of SMEs are applicable to other sectors and countries as well - e.g., between 80 and $90 \%$ of all enterprises in the EU are SMEs (Institute for Prospective Technological Studies, 2004). An underlining objective in writing the thesis is to develop knowledge that is relevant for a wider scientific and practitioner audience based on the Swedish context. Thus, several of the findings from this thesis could be relevant in other contexts given appropriate abstraction and contextualisation.

In Article 1, the study covers governmental export promotion initiatives from eight selected countries in Asia, Europe, and North America. Though this coverage is relatively wide, I acknowledge that other forms of export promotion initiatives could have been detected in different contexts. For example, issues outside the scope of this thesis, such as import substitution, trade and economic policy which advocates for replacing foreign imports with local production in the view of weak exporting prospects, and currency devaluation, have been identified in some countries (Volpe Martincus and Carballo, 2010).

Regarding the main findings reported in Article 2 on the perceived effectiveness of export promotion initiatives among Swedish environmental technology firms, some similarities can be 
found in studies among firms in Turkey (Kumcu et al., 1995), where firms did not directly see the benefits of governmental export promotion initiatives.

For Article 3, some of the institutional conditions within which municipal companies (e.g. the monopolistic right to household waste management within their municipality) operate are unique to Sweden or the European context. Thus, some obstacles and drivers for export, e.g. environmental improvements and strengthening city and company brand, are directly related to their unique situation. However, other obstacles (e.g. resource limitations) and drivers (e.g. owner directives) have been identified in other countries, even among SMEs (see Leonidou, 1995; Suarez-Ortega, 2003).

In Article 4, the actual use of international city networks by municipally owned companies would differ based on the relationship between the owner cities/municipalities and these companies in different contexts. However, the benefits of belonging to international city networks in general that were mentioned in Article 4 do not necessarily depend on geographical or political conditions, but rather are inherent to networks and the way they function.

Even though the components of business concepts synthesised in Article 5 are based on characteristics of environmental technologies in general (identified from the cases and also corroborated with the literature), these characteristics are influenced by the cases selected such as district heating, renewable energy and waste management systems. Thus, if other types of environmental technologies were to be selected, less or more emphasis could have been placed on the proposed components with the possibility for additional business concept components.

\section{Dependability}

To assess the quality of a research study in terms of dependability (yielding compatible results in another study given similar methods), Guba and Lincoln (1994) propose that the researcher should adopt an auditing approach. In this approach, the researcher should ensure that all records are kept along all phases of the research process from problem formulation, selection of participants, interview transcripts, and data analysis to conclusions. In this manner, peers would act as auditors, possibly in the course of the research and more so at the end, to establish how proper procedures have been followed. In view of the fact that central topics addressed in this thesis such as governmental export promotion initiatives, membership in international city networks and business concepts are dynamic and do change with time, it can be challenging to reproduce compatible results unless guided by the timeframe and empirical data upon which this thesis is based. The research reported in this thesis has gone through several dependability enhancement procedures. First, respondent validation and triangulation approaches as discussed above have been used to enhance the dependability of the results. In addition, during the course of the research, preliminary results have been presented at international scientific conferences for feedback and comments on the empirical data and analysis approaches adopted. Finally, all five articles appended to this thesis have been subjected to scientific peer review before acceptance for publication as journal articles. In this process, each of the manuscripts, including the complete set of empirical data, detailed description of research methods and conclusions have been subjected to critical review by at least two (sometimes three) experts in the field and have undergone at least two revisions before acceptance for publication. 


\section{Confirmability}

While absolute objectivity is challenging to establish in social science research, the researcher should take steps to ensure that personal values or theoretical inclinations do not sway the conduct of the research and the findings from it (Guba and Lincoln, 1994). Absolute objectivity is challenging because, among other things researchers often affect their study through case selection, funding applications, and research designs. As Bryman (2015) suggests, establishing confirmability should be one of the responsibilities of reviewers, and thus I have tried in all the articles to provide a detailed account of the empirical data, methods and conclusions for reviewers to judge the quality of the contributions. Despite the encouragement for objectivity, sometimes researchers are also encouraged to establish their position when relevant (Patton, 2002). I have reflected upon some personal positions in the next subchapter, where I problematise technological solutions and governmental export promotion initiatives as part of several approaches to tackle global environmental challenges. More so, I acknowledge that the thesis puts environmental technology suppliers at the centre of the analysis and that if other actors such as technology adopters were given central focus, potentially different aspects of export could be emphasised or overlooked.

\subsection{Reflexivity and Problematisation}

In this subchapter, I will critique some of the key methods and theories guiding this thesis. The objective is first to depict my awareness of different research methods which could have been used to address the aim and research questions and second to reflect on some potential outcomes if this thesis had been framed in other relevant theoretical backgrounds. I acknowledge that there are several alternative methods and theories that could in one way or another be applied to address the aim and research questions guiding this thesis, however I have chosen to discuss those methods and theories which have been used by other scholars and/or suggested as particularly relevant for diffusion and export studies. As Alvesson and Sandberg (2011) recommend, reflexivity is only possible after presenting key literature related to a certain topic and highlighting their core assumptions as has been done in the theoretical background chapter.

\subsubsection{Implications of Research Design and Methods}

The combination of qualitative and quantitative data has formed a basis for this thesis to explore "how" and "what" types of questions (see Yin, 2008). A combination of such approaches benefits from the synergies between the two methodological approaches, giving room for both coarse overviews and fine-grained empirical data collection and analysis. This approach further offered the flexibility needed to investigate questions that might not be possible to investigate exclusively with either quantitative or qualitative methods covering up for the inherent limitations of either approach. However, as with any scientific research method, there are inherent limitations which a researcher needs to be aware of and take steps to minimise the effects of (Bryman, 2015).

The analysis of survey results is particularly applicable to establish general relations and overviews about a particular sample or population (Field, 2013). The analyses of the surveys conducted in this thesis have been mostly descriptive. An alternative analysis, in which potential generalisations towards the entire population are made based on measurements on a sample, could be inferential. 
Despite the perceived robustness affiliated with such inferential analysis, they suffer from uncertainties introduced by generalisations about entire populations based on measurements from a sample (Field, 2013). During the later stages of my Ph.D. research education, I began to apply some inferential analysis to new survey data (e.g. regression, analysis of variance and correlations). Even though by doing so I have gained other insights, there are some challenges particularly related to the export of environmental technologies from Sweden. First, the Swedish environmental goods and services sector is relatively small, up to around 16,000 companies as of 2015 (See Table 1), a sub-set of which are interested and engage in the export activities of environmental technologies. This situation suggests that high survey response rates are needed for statistically significant analysis and robust generalisations to emerge without overfitting the data (Field, 2013). Second, inferential analyses such as the determination of statistically significant differences and correlations can induce all-or-nothing thinking into data analysis. All-or-nothing thinking misses on important contextual issues which might be important as the researcher is actively seeking statistically significant or insignificant relations. I also observe that, when the diffusion studies focus on technology adopters, and particularly end users, the population size may be larger compared to technology suppliers (which increases the probability of a higher response rate) and can particularly benefit from robust inferential analysis judging purely from the availability of data. Nonetheless, it is important to combine both descriptive and inferential analysis of survey data as this leads to a better understanding of and knowledge development on a phenomena (Onwuegbuzie et al., 2009).

Regarding interviews, a challenge identified with their use in diffusion studies is what Rogers (2003) refers to as the recall problem where interviewees depend on their memories to recall their experiences of the diffusion process. In addition to the approaches used in this thesis to minimise this effect such as sending interview questions to interviewees before actual interviews, triangulation and respondent validation, another approach could have been to conduct a longitudinal study in which interviews, observations, documentation studies and even participation can be combined. In fact, as mentioned in the preface, I have been involved in one implementation project over a four-year period, even though more as a participant than a researcher. However, the time frame and financing structure of research projects sometimes dictates that they have a limited time horizon, which does not always facilitate longitudinal studies which can be time and cost intensive (Bryman, 2015).

\subsubsection{Reflection on some key Assumptions and Theories}

The suggestion that the export of environmental technologies can contribute to tackling global environmental challenges needs to be reflected upon. First, the environmental performance of a given technology is not necessarily an inherent property of the technology, but rather dependent on how the technology is developed and applied throughout its life cycle (OECD, 2009). Thus, environmental technologies may not guarantee an absolutely better environmental performance but have the potential to deliver such benefits depending on their lifecycle development and application. In addition, governmental intervention to promote certain types of technologies or even entire sectors does not guarantee the export of the "right" technologies for environmental sustainability either. In some instances, governmental initiatives have been criticised for crowding out other beneficial technologies, picking the winners and even promoting suboptimal solutions leading to government failure (Carrillo-Hermosilla et al., 2009). 
Furthermore, as with many diffusion research studies, there is the inherent bias that a given technology should be widely diffused and rapidly adopted by all potential adopters in a social system given potential benefits without re-invention, adaptation and/or rejection (Rogers, 2003). And even though this thesis discusses the subject of stimulating the diffusion of environmental technologies through export, it is not a panacea for the diffusion of such innovations at all costs (e.g. in conflict with social aspects of sustainability such as access to basic education and gender empowerment), and neither does the thesis advocate a technological solution to all kinds of environmental problems. My understanding is that environmental technological change is one of several strategies to address environmental problems. Indeed uncontrolled widespread diffusion of "environmental technologies" can have rebound effects and other consequences on the environment e.g. encouraging waste generation and incineration instead of waste prevention (Corvellec et al., 2013).

To add to this, export in itself can be problematised for being traditionally unidirectional and hindering the development of technologies and capabilities in target markets. Nonetheless, it is increasingly evident that the export of the environmental technologies types addressed in this thesis without bidirectional interactions and learning, and capacity building of potential customers often lead to failed implementation or discontinuations in usage due to misalignment and disruptions in existing systems (Mejía-Dugand et al., 2013). Thus, export can contribute to the development of local capacities through contextual applications, adaption to fit local conditions and co-creation with customers.

With regard to the theoretical background for the entire thesis, there are several potential alternative theories and disciplines that could be used to analyse environmental technological change (i.e. invention, innovation and diffusion) in general and export in particular. For environmental technology change in general, these alternative theories and disciplines include environmental economics (Jaffe et al., 2002), technological innovation systems (Bergek et al., 2008), a multi-level perspective (Geels and Schot, 2010), and evolutionary economics (Rennings, 1998). For environmental technology export, the lead market framework (Beise and Rennings, 2005), is of direct relevance (Del Río, 2009). If this thesis were anchored in any of these alternative theories or disciplines, there could have been more emphasis on the impacts of national policy on export for a lead market perspective, path dependencies and lock-ins (or lockouts) for promoting different environmental technologies for an evolutionary economics perspective, and interactions between system components (technologies, actors, networks and institutions) that drive or hinder diffusion for an innovation systems perspective. Though this thesis is situated in the diffusion of innovations and international business literature, the focal points have potential synergies with some of the alternative theories and disciplines discussed above. This includes the focus on technology policies in export promotion initiatives as compared to policy emphasis in environmental economics and lead markets frameworks. 


\section{The Appended Articles}

This chapter presents the scientific articles which are appended to this thesis. The presentation is purposively focused on the results of each article, which are directly relevant for discussing the research questions guiding the thesis. Other aspects of the articles, such as theoretical background and research methods, contribute to their respective chapters in the thesis.

For clarity of presentation and to minimise repetition, each scientific article is presented according to the following aspects (i) background of the article, (ii) results relevant for the research question(s) and (iii) my contribution to the article.

\subsection{Article 1}

Title: Promoting the export of environmental technologies: An analysis of governmental initiatives from eight countries

Authors: Wisdom Kanda, Olof Hjelm, and Santiago Mejía-Dugand

Journal: Environmental Development 17 (2016): 73-87.

http://dx.doi.org/10.1016/j.envdev.2015.09.009

Status: Published

\section{Background of the article}

The idea for this article emerged as part of the Megatech project, which focused on cities as arenas for the diffusion of environmental technologies. Even though the Megatech project focused mainly on the adopter context, i.e. megacities, concluding insight from the project suggested the importance of environmental technology suppliers and their challenges in export. Specifically, technology suppliers often highlighted the different and "better" government support their counterparts from other countries received to participate in export. After reviewing the related literature on trade and government policy, to the best of my knowledge there were no articles which dealt with export promotion for environmental technologies. However, there were several contributions on export promotion in general on the firm and national levels (e.g. Kumcu et al., 1995; Lederman et al., 2010). On the other hand, in the diffusion of technology literature government promotion is identified as an important element for diffusion studies (Montalvo and Kemp, 2008) but to the best of my knowledge, no detailed accounts of governmental promotion initiatives to promote environmental technology export were available in the literature. These gaps in the trade and policy literature and in the technology diffusion literature motivated the writing of Article 1.

\section{How governments promote the export of environmental technology}

Article 1 analysed governmental initiatives aimed at promoting the export of environmental technologies from eight selected countries - Austria, Denmark, Finland, Germany, Japan, Norway, Sweden and the USA. Governmental initiatives to promote export are often unique, based on national idiosyncrasies (Leonidou et al., 2011). Despite these expected differences, a common overreaching aim of governmental export promotion initiatives is to enhance export. To serve as a basis for analysing Research Question 1 (How do governments promote environmental technology export, and what is the perceived effectiveness of such initiatives among private environmental technology 
companies?), the different initiatives available for environmental technology providers are identified and synthesised as depicted in Figure 3.

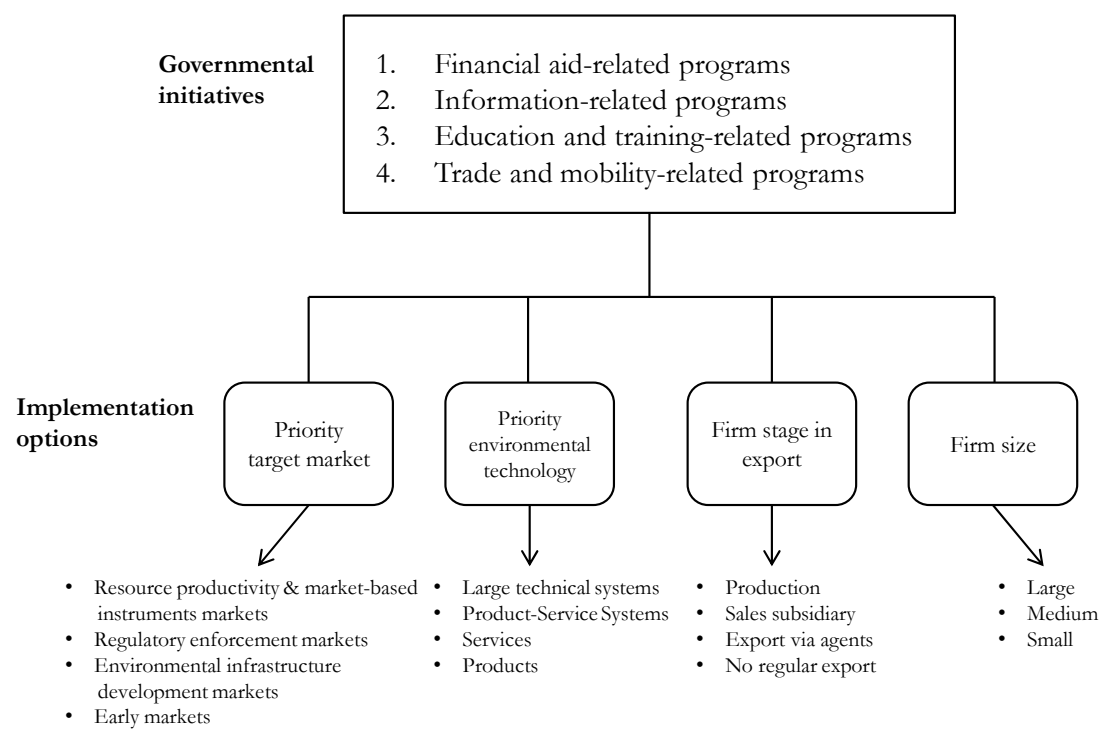

Figure 3: Governmental initiatives and implementation options for promoting environmental technology export (Kanda et al., 2016b).

The four categories of governmental initiatives were adopted from the previous literature (Leonidou et al., 2011), as they provided a concise categorisation for describing these governmental initiatives. The various implementation options are also in some instances adopted from previous literature, e.g. categorisations used to describe the maturity of various environmental technology markets (DEFTRA, 2002), the stage model of internationalisation (Johanson and Vahlne, 1977) and corroboration with our empirical data. The governmental initiatives are discussed under these four categories to minimise repetition. For a detailed country-by-country presentation of governmental export promotion initiatives to support environmental technology suppliers, refer to Kanda et al. (2012).

\section{Financial aid-related programs}

In all eight countries, there was a dedicated government agency - an "export credit agency" responsible for providing financial support and related advice to exporters. The portfolio of financial aid-related programs included guarantees against buyer default, credit guarantees and loans to facilitate export. This financial support was available for exporters in general, including environmental technology exporters. Despite this general financial support for all exporters in most of the studied countries, there were certain financial schemes tailored specifically for environmental technology providers. For example in Denmark, the export credit agency Eksport Kredit Fonden (EKF) provided tailored financial support for environmental technology exporters. This financial support incorporated buyer defaults, which can occur based on the particular characteristics of environmental technologies (e.g. utility costs savings, failure to issue carbon 
credits, and financing energy service companies), as well as risks related to economic and political default. This particular support offered to Danish environmental technology exporters extended beyond the initial sale of environmental technologies into the use phase, where potential environmental benefits and buyer default risks might accrue.

\section{Information provision-related programmes}

In all the studied countries, there were dedicated government agencies for export promotion activities in general - "export promotion agencies". These agencies mainly focused on other export promotion initiatives apart from export financing. Information provision-related programs to support exporters covered the provision of information both to technology suppliers and customers regarding market and technology trends, export regulations, sector characteristics, consumer preferences, laws, and regulations, both in the home and target markets. Specific information, often directed at environmental technology suppliers, covered policy and regulations in target markets due to its influence on the adoption of environmental technologies (particularly end-of-pipe technologies). Such information provision took place during trade fairs, marketing campaigns, and trade missions. Other arenas used for information sharing included virtual networks, technology clusters, industry publications and journals. Information from target markets is gathered by embassies and consulates together with export promotion agencies and provided to companies either at a fee or for free.

\section{Education and training-related programs}

The export business is more challenging for companies than doing business in the domestic market, particularly due to market differences and resource challenges (Fillis, 2002). In this regard, exporters need education and training on export management such as documentation, logistics, language, and export sales (Leonidou et al., 2011). Several of the selected countries had education and training initiatives for exporters and those interested in commencing export in general, but no education and training programs exclusively tailored for exporters of environmental technologies and their characteristics were detected. This training and education support may consist of workshops, seminars, conferences on export planning, foreign market identification and export logistics. Representatives from both the target and host markets, including technology suppliers and potential adopters could be educated to increase the familiarity with each other's technologies and to promote potential export.

\section{Trade mobility-related programs}

Trade mobility-related support for technology exporters connects largely to information provision between the home and target market, with the potential for direct contacts between technology suppliers and potential adopters. The programs included support to enable companies to participate in trade fairs and exhibitions, trade delegations and foreign visits. The initiatives from export promotion agencies provided financial support for exporters to invite potential customers to their home market, or to organise business delegations to visit the target market to explore export opportunities. Additional trade mobility-related support included financial support offered to firms to enable them to establish initial contacts with customers, and prepare trade visits, using the help from the government's trade offices in the target market. Trade and mobility support also focused on information sharing regarding e.g. market and technology trends, export 
regulations, sector characteristics, consumer preferences, laws and regulations, as well as demonstration activities both in the home and target markets.

Even though the governmental export promotion initiatives are presented as though categorically distinct, in practise there are synergies and sometimes conflicts between these categories and their responsible agencies. For example, information-related programs are strongly connected to trade and mobility, which in turn can be facilitated by financial support programs. As depicted in Figure 3, the four categories of governmental initiatives are implemented using different combinations of implementation options across the studied countries.

\section{Implementation options for export promotion}

As depicted in Figure 3, export promotion initiatives in the studied countries were implemented according to different priorities, namely (i) target markets, (ii) environmental technology types, (iii) firm stage in export, and (iv) firm size. Many of the studied countries had priority target markets and environmental technology types for which they focus their promotion initiatives (see Table 3, Article 1 for an overview). For example, in Austria, environmental technology export promotion initiatives were focused on Central and Eastern Europe, Asia and Africa as target priority markets with wastewater treatment, solid waste treatment, recycling and water supply. In Denmark, focus was placed on the USA, Brazil, Russia, India and China as priority markets to

promote energy efficiency, wind energy, biomass, and waste management. In Finland, priority environmental technology areas include renewable energy, recycling of materials, resource-saving processes, energy-saving technologies, and water treatment with no specifically selected priority target markets. Priority focus areas defined in Sweden were sustainable building, transport, energy, and water management targeted at Baltic countries, Russia, Western Europe, North America, Brazil, India and China. Despite these differences between countries with regard to priority target markets, and technology types, a commonality was that most countries focused export promotion initiatives on SMEs, and supported both exporters and non-exporters.

\section{My contribution to the article}

I was responsible for collecting and analysing the empirical data used to write Article 1. I also wrote major parts of the manuscript and was mainly responsible for the revisions during the publication process. Olof Hjelm contributed with critical feedback, comments and ideas on each version of the manuscript throughout its development. Santiago Mejía-Dugand also contributed through feedback and comments on several versions of the manuscript, as well as contributed with some empirical data in the final review process before publication. 


\subsection{Article 2}

Title: Governmental export promotion initiatives: awareness, participation, and perceived effectiveness among Swedish environmental technology firms

Authors: Wisdom Kanda, Santiago Mejía-Dugand, and Olof Hjelm

Journal: Journal of Cleaner Production 98(2015): 222-228.

http://dx.doi.org/10.1016/i.jclepro.2013.11.013

Status: Published

\section{Background of the article}

Article 2 was written as a direct follow-up to Article 1. After reviewing and analysing how different governments promote the export of environmental technologies, an interest emerged about evaluating the effectiveness of such initiatives as a potential basis for policy action. This interest was explored from the perspective of the targeted recipients and participants in governmental export promotion initiatives through a survey among Swedish environmental technology providers. An investigation of the perceived effectiveness is important because not only does the success of export promotion depend on the program formulation, but also its implementation and perceived effectiveness among recipients. The article was first presented as a conference paper at the 2012 Greening of Industry Network Conference in Linköping, Sweden before being further developed for publication as a journal article.

\section{Firms' perceived effectiveness of governmental export promotion initiatives}

Article 2 focuses specifically on Swedish environmental technology providers and how they perceive the effectiveness of governmental export promotion initiatives. This empirical data provides input for answering the second part of Research Question 1 (How do governments promote environmental technology export, and what is the perceived effectiveness of such initiatives among private environmental technology companies?). To address perceived effectiveness, the survey results cover the awareness and participation in export promotion initiatives among the respondent companies as depicted in, Figure 4 below.

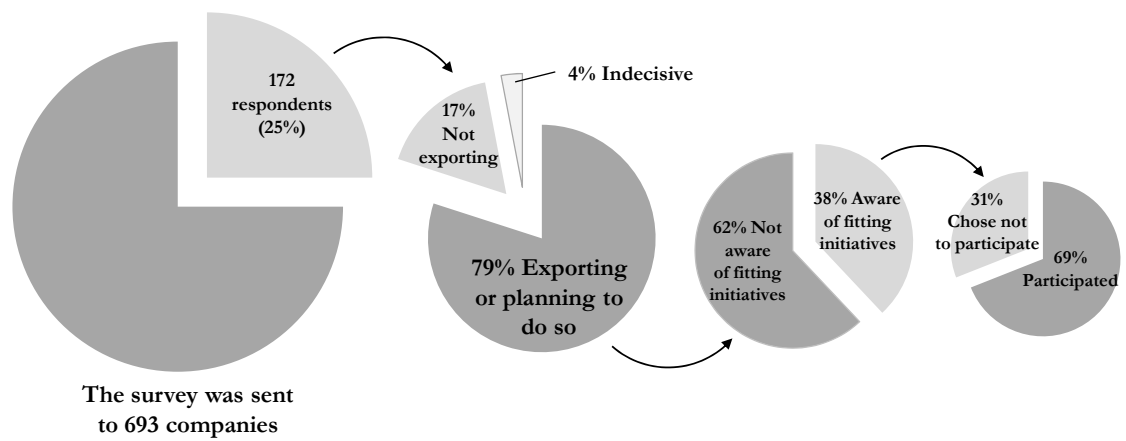

Figure 4: Awareness, participation and perceived effectiveness of governmental initiatives (Kanda et al., 2015b). 
As depicted in Figure 4, 172 companies out of the total 693 emailed recipients responded to the survey (approximately a 25\% response rate). Since the survey was conducted anonymously, we could not track the non-respondent companies further. Out of the 172 firms that responded, $79 \%$ of them indicated they were currently exporting or planning to do so in the near future (up to 5 years from the survey date), $17 \%$ of them indicated they were not exporting or planning to do so in the near future, and the remaining $4 \%$ were indecisive about their export ambitions. Those companies that were not exporting their environmental technologies indicated that they had a local niche market, so export was not their core business (e.g. being suppliers to a larger company in the domestic market), or they had limited capacity and resources to export (e.g. a micro company with limited financial and human resources). The large share of the respondents who were exporting or planning to do so in the near future (i.e. $79 \%$ ) gave an indication of the relevance of their response on the perceived effectiveness of governmental export promotion initiatives as they had first-hand experience with export or export planning and its related challenges.

Among the firms that were currently exporting or planning to do so, the next survey question explored if they were aware of governmental initiatives that could address their export needs and if they had participated in such programs. A large share $(62 \%)$ of those exporting or planning to do so were not aware of governmental programs that could fit their export needs as shown in Figure 4. The remaining (38\%) of the firms exporting or planning to export could identify governmental initiatives that fit their export needs.

Of the firms that could identify governmental initiatives that could address their export needs, the survey further investigated whether they participated in such initiatives. As shown in Figure 4, $31 \%$ of these firms did (could) not participate in such governmental programs. Reasons given for non-participation in governmental export promotion included difficulty to access governmental initiatives (e.g. expensive to access, too bureaucratic for small companies, and unclear benefits of participation). Other non-participants indicated the lack of needed resources to participate such as time and staff. Denied applications, especially in relation to financial support and future ambitions to participate, were also among other reasons given for non-participation in governmental initiatives to promote the export of environmental technology. Finally, as can be seen in Figure 4, 69\% of those firms that identified programs fitting to their export needs participated in them.

The last survey question addressed which types of governmental initiatives firms accessed, and whether these companies perceived these initiatives as contributing to export realisation. Of the export-oriented respondents that participated in governmental initiatives, 32\% of them could relate their participation to export success, but $68 \%$ could not relate the initiatives in which they participated to successful export business. It was evident from the survey results that many of those companies which responded to have participated in only one type of governmental support (e.g. information-related support) could not relate their participation to successful business abroad. On the other hand, those companies that reported to have participated in a combination of more than one type of government support (especially including financial support) reported positive outcomes. Furthermore, when comparing participation between the four categories of government support identified in Article 1, companies that had participated in financial aid programs appreciated this kind of support as a catalyst for their export business. 


\section{My contribution to the article}

The initial idea to assess governmental export promotion initiatives after reviewing such initiatives from different countries, as presented in Article 1, was jointly developed by me and my co-author, Santiago Mejía-Dugand. The survey data collection, analysis and writing of the manuscript were joint activities between me and my co-author, Santiago Mejía-Dugand. Olof Hjelm contributed with critical feedback, comments and improvement ideas on each version of the manuscript throughout the publication process.

\subsection{Article 3}

Title: Export of environmental technologies by publicly owned companies: approaches, drivers and obstacles among Swedish municipal companies

Authors: Wisdom Kanda, Olof Hjelm, Kajsa Kairento and Marcus Nygårds

Journal: European Planning Studies, 24 no. 12 (2016):2175-2196

http://dx.doi.org/10.1080/09654313.2016.1251881

Status: Published

\section{Background of the article}

Article 3 was developed based on insights which emerged from a three-year research project titled BMEX - "Business models for market expansion of Swedish Municipal Companies". The overall aim of the project was to develop knowledge on how to design business models for export of environmental technologies by municipally owned companies. The idea for Article 3 emerged after the realisation that municipally owned companies are different in certain dimensions from privately owned companies, may experience different obstacles and drivers, and use different approaches to export. In addition, since municipally owned companies play a significant role in the environmental technology sector in Sweden, the article sought a complementary view to the focus on small and medium-sized enterprises presented in Article 2.

\section{Obstacles to and drivers for environmental technology export among municipally owned companies}

Article 3 analysed the obstacles to and drivers for the export of environmental technologies among Swedish municipally owned companies. The empirical data provided in Article 3 provides a basis for discussing Research Question 2 (What are the obstacles to and drivers for environmental technology export among municipally owned companies?). An understanding of the obstacles to and drivers for export is important for stimulating export of environmental technologies, as mechanisms can be formulated both to tackle the obstacles and encourage the drivers.

Obstacles to export refer both to factors which companies perceive as challenging with the export process, and those factors which prevent some companies from initiating export. The different challenges to export mentioned by the exporting companies are presented in Figure 5. 


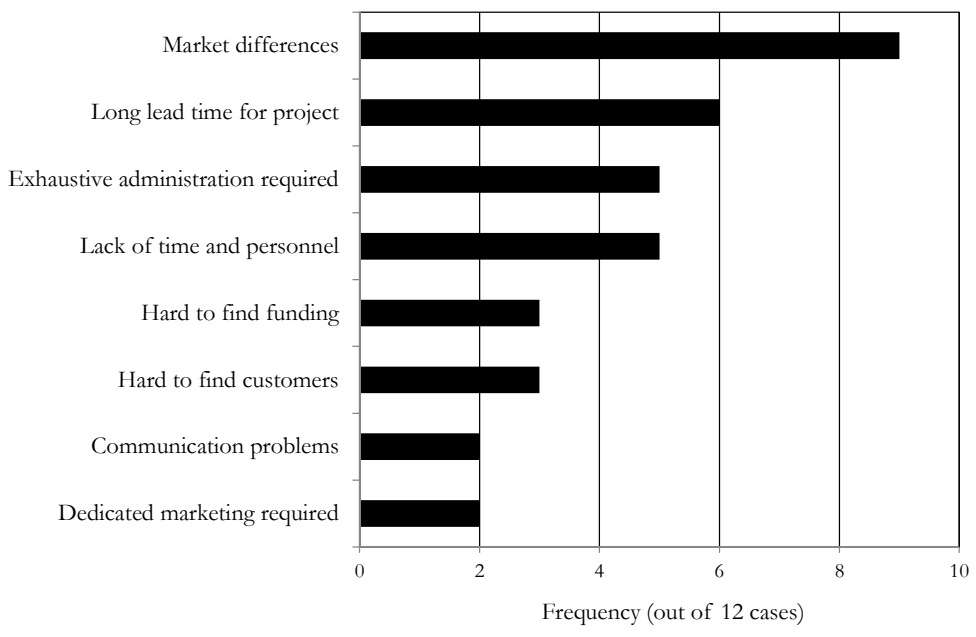

Figure 5: Frequency of mentioned challenges in export (Kanda et al., 2016a).

The most frequently mentioned challenge among exporters was market differences, which largely refer to differences in business culture (e.g. decision-making procedures, hierarchical structures) and political systems (e.g. financial independence and autonomy of cities) between the Swedish municipality and foreign markets. These often led to a difficulty in securing financing and approval on the side of the customer with regard to export projects. Other challenges relate to the Swedish municipally owned companies themselves including limited resources such as time, personnel and finance committed to export activities as compared to their local obligations. This limited resource commitment also amplified other challenges in export such as export planning, for example administrative procedures, long project lead times and export financing.

However, for those municipally owned companies which do not currently export, they mentioned a variety of related and different barriers which prevented them from initiating export. These included institutional barriers, particularly relating to how the political owners of the municipal companies viewed export. Some municipalities viewed exporting as a high-risk activity due to several factors including customer defaults, failure in project realisations and the competition with local priorities. Thus, their municipal companies mentioned their owner directives as preventing them from engaging in export. Other barriers mentioned which are quite similar to the challenges mentioned by municipally owned companies exporting include lack of resources, reorganisation of company activities, prioritisation of domestic obligations, exporting not permitted by municipal legislation, exporting not supported by the administrative board of the municipal company, overwhelming market activities involved and lack of incentives to export. 
Drivers for export refer to incentives to engage in export as well as perceived or realised gains. From the 12 Swedish municipally owned companies interviewed, their drivers for engaging in export and the frequency of each driver are presented in Figure 6 below. Since some companies mentioned more than one driver for export, the total sum of drivers is more than the number of companies interviewed.

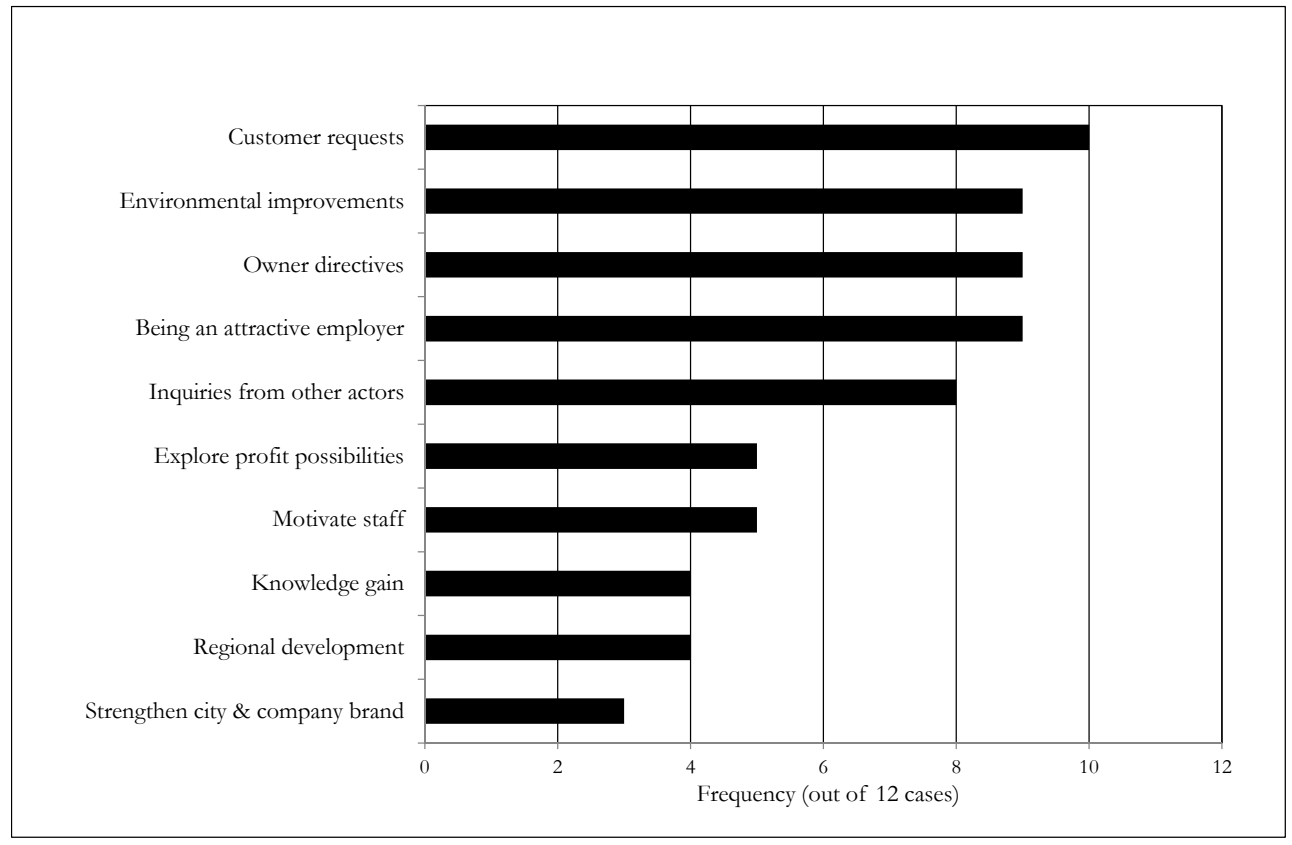

Figure 6: Frequency of mentioned drivers for export (Kanda et al., 2016a).

The most frequently mentioned driver for participating in export was foreign customer requests, as seen in Figure 6 above. Most often, these customer requests were inspired by visiting foreign delegations to and from Sweden (e.g. politicians, companies, academics) that come into contact with municipally owned companies and the technologies they develop. Other externally motivated drivers included contribution to global environmental sustainability, strengthening the city and company brand, and regional development. Drivers for export, which are largely internally motivated, include becoming an attractive employer, motivating current employees, exploring possibilities for extra income and knowledge gain.

\section{My contribution to the article}

This article is based on a master's thesis written by my co-authors Kajsa Kairento and Marcus Nygards, who were responsible for collecting the empirical data under my supervision and the examination of Olof Hjelm. I was mainly responsible for writing the entire manuscript. Before writing the first draft, I had an extensive discussion and brainstorming session with my co-author Olof Hjelm about the structure, content and contribution of the manuscript. I was also responsible to rewriting the manuscript after receiving comments from two reviewers during the 
publication process. Olof Hjelm assisted in the review process by giving feedback and comments on the revised manuscript and also reading all draft versions of the manuscript.

\subsection{Article 4}

Title: Analyzing international city networks for sustainability: a study of five major Swedish cities Authors: Santiago Mejía-Dugand, Wisdom Kanda, and Olof Hjelm

Journal: Journal of Cleaner Production 134 (2016):61-69

http://dx.doi.org/10.1016/i.jclepro.2015.09.093

Status: Published

\section{Background of the article}

The idea for Article 4 emerged as a follow-up to the BMEX project, which produced Article 3. After understanding the obstacles to and drivers for export among municipally owned companies, including the types of environmental technologies they offered, Article 4 sought to discuss international city networks as arenas for export of environmental technologies. This was inspired by the potential customers of municipally owned companies, which are often other municipalities and/or cities, and the forums from which they seek solutions to their challenges. An initial version of this article was presented at the 17th European Roundtable on Sustainable Consumption and Production (ERSCP 2014) in Portorož, Slovenia before being developed further for publication as a journal article.

\section{Using international city networks for environmental technology export}

The main argument in Article 4 is that by understanding and taking advantage of the positioning of a city or a group of cities in a network, the process of environmental technology export can be facilitated. By becoming part of international city networks, cities can have access to knowledge that is collectively supported, nurtured, and shared. Thus, Article 4 discusses how municipal companies can benefit from their city's memberships in international networks when it comes to the export of environmental technologies.

Each of the five studied cities (Stockholm, Gothenburg, Malmö, Uppsala and Linköping) belonged to at least one international city network, with the number of memberships ranging from six to almost seventy. A general trend observed was that the larger cities had memberships in more city networks than the smaller cities, with the exception of Uppsala compared to Linköping; see Table 1 in Article 4 for basic information about the studied cities and a summary of the data found about their memberships. As discussed by the interviewees, one of the main challenges regarding participation in international city networks was monitoring and assessment of the benefits such membership brought to the city. This is challenging because of the difficulty of establishing cause and effect between membership and outcomes. Nonetheless, cities analysed advantages and disadvantages of their membership in international city networks using proxies such as resource input (e.g. membership fees, human resource commitments, travel, and reporting) vs. the perceived benefits of membership. With regard to perceived benefits, finding funding for the development of local projects, attraction of international companies, talents and even tourism were commonly mentioned by many interviewees. More importantly, most cities 
recognised the potential of city networks in giving visibility to their cities and knowledge abroad, creating milieus where they can contribute solutions to common problems, providing important opportunities for benchmarking, and allowing members to learn from each other.

The focus of the international city networks and the geographical spread of memberships have potential implications on its relevance for export. The two largest cities, Stockholm and Gothenburg, have a wider geographical span (e.g. membership in global networks) through their networks compared to the other cities. Their position as larger cities gave them the resources and visibility to engage with special types of networks outside the reach of smaller cities. Most of the cities reported an interest in participating in networks with broader foci, e.g. networks dealing with environmental, economic and social issues, as several issues could be tackled efficiently concurrently. For example, networks for sustainability were regarded as broad and appropriate milieus where bidirectional information and experiences can be shared about environmental technologies, and where cities can both learn from the solutions of other cities and promote their own solutions.

Identifying direct benefits for municipal companies from their owner city's participation in international networks is challenging to establish, according to the interviewees. This can be attributed to the challenges with monitoring and evaluation methods, and also the fact that municipalities and their cities are engaged in numerous activities outside international city networks, and that the quantification of a given benefit may not always be possible. However, perceived benefits for municipal companies mentioned by the interviewees included gaining access to multi-directional information flows, receiving funding for specific export projects, and attracting attention from foreign politicians and potential customers.

\section{My contribution to the article}

The initial idea to analyse international city networks as potential arenas for export was jointly developed by me and my co-author, Santiago Mejía-Dugand. I jointly participated with Santiago Mejía-Dugand in interviewing the studied cities and collecting data on city networks, in addition to writing and reviewing the article during the publication process. Olof Hjelm contributed with feedback, comments and suggestions for improvement during the development of the manuscript.

\subsection{Article 5}

Title: Components of business concepts for the diffusion of large scaled environmental technology systems

Authors: Wisdom Kanda, Tomohiko Sakao, and Olof Hjelm

Journal: Journal of Cleaner Production 128 (2016): 156-167

http://dx.doi.org/10.1016/i.jclepro.2015.10.040

Status: Published

\section{Background of the article}

The idea for Article 5 emerged at the end of the BMEX - "Business models for market expansion of Swedish Municipal Companies" research project, which had the objective to 
develop knowledge on how to design business models for export of environmental technologies by municipally owned companies. In hindsight, this article builds upon understanding gained from Articles 1, 2, 3, and 4 about environmental technology export. In particular, we wanted to develop business concepts that were relevant for both municipally owned and privately owned companies, considering the specific characteristics of environmental technologies which could potentially enhance their export activities.

\section{Export business development activities of environmental technology suppliers}

Article 5 provides a basis for discussing Research Question 4 (Which components could be considered in business concepts for environmental technology export?). Developing such business concepts was based on empirical data and also insights from the scientific literature on business models (already presented in Chapter 2, theoretical background). The empirical findings regarding how the studied companies conducted export business is presented case-by-case below.

\section{Usitall AB}

Usitall AB (currently inactive) was established in 2008 with the primary objective to export knowhow related to the development of waste-to-energy systems (particularly incineration with heat recovery and electricity generation). Usitall $\mathrm{AB}$ was a subsidiary of the municipally owned company, Tekniska verken i Linköping $\mathrm{AB}$, which is locally active in many areas including household waste management, biogas production, broadband internet, electricity production and distribution, district heating and cooling, water supply, and waste-water treatment. Their selected target markets for export of technical knowledge regarding the development of waste-to-energy systems were Central and Eastern Europe based on (i) a projected availability of raw materials, (ii) a commercial market for heat and electricity, (iii) the non-existence of strong competitors on the market, (iv) existing district heating infrastructure, and (v) EU legislation on landfilling. The company's export business consisted of four phases (i) establishment, (ii) secure sponsor, (iii) secure financing, and (iv) construction, each with different sub-activities.

The focus in the establishment phase was to understand the business context in the target market including legislations, laws, and business culture, and more importantly to establish contacts with key decision makers such as city mayors and politicians. The firm also conducts technical feasibility studies on key parameters such as the generation and characterisation of solid waste. The final component of the establishment phase was to secure contracts for both raw material (waste) and end-products (heat and electricity) from the waste-to-energy system. During the secure-sponsor phase, a paying customer (e.g. a private energy company or a local municipal authority) was sought for the waste-to-energy project. This paying customer subsequently secures financing before the construction of the waste to energy facility. Due to the municipal ownership of Usitall $\mathrm{AB}$ which restricts risk-taking in foreign markets, the company's plan was to hand over the export project to the paying customer and withdraw before the construction phase. On the average, it can take from seven to ten years from the first agreement for a waste-to-energy project to complete construction of such a waste-to-energy facility. The nature of municipal solid waste as well as the potential heat and electricity generation from this export business imply that, Usitall $\mathrm{AB}$ had to deal with different types of markets. These different markets included waste-asmaterial where access to waste as a raw material is negotiated, a technical market where different 
waste treatment options are discussed, and a commercial market for the end products. These different markets are also embedded in the socio-economic and political system. Usitall AB thus has to meet both formal and informal expectations of different actors and institutions to conduct successful export business.

\section{Swedish Biogas International}

Swedish Biogas International (SBI) is a privately owned company established in 2006 that specialises in building and operating biogas production facilities. Their export activities have targeted South Korea and some states in the USA. At the time of the studies, their international activities in South Korea had been terminated partly because of market differences (e.g. differences in customer preferences, business culture, laws, and regulations between the home and target markets). The engagement of Swedish Biogas International in the USA and South Korea was facilitated primarily by the availability of secured funding to undertake biogas export projects. For example, SBI entered the USA market through a grant agreement between the Michigan Economic Development Agency and the Swedish government. Other international export activities of the company have targeted Poland and the Baltic countries because of a projected demand for biological treatment of farm residues and run-off threatening the Baltic Sea. The company engages in active export marketing through participation in conferences, advertisements, and exhibitions and by organising site visits for potential customers. The potential customers of SBI range from farmers, industries to municipalities. Their export business is tailored according to differences in raw material amounts and characterisation, regulations, customer preferences, and biogas use. As these dimensions differ between different markets and customers, the company has to be aware of the related actors, regulations and expectations and how they influence the design and operation of their biogas facilities, including their export business.

\section{VafabMiljö}

VafabMiljö is a municipally owned company with over 30 years' experience in waste management, particularly biogas production and material recycling. The company has been engaged in different international projects, mainly in developing countries like Botswana, Southern Africa. In their approach, the parent municipality company dedicates some employees to lead export activities on a project basis. They seek financing from international developmentoriented organisations such as the Swedish International Development Cooperation Agency (SIDA) to enable the company to engage in export activities. Thus, the costs related to developing export business such as working time and travel are pre-financed before the company's involvement. Their international activities are also facilitated by their owner municipality's engagement in networking and sister city relation with potential customers which the company can use as arenas for export. The socio-technical nature of such waste management systems and their potential customers (often cities) requires functioning waste management regulations, the compliance of citizens to regulations through for example proper waste sorting, and potential markets for end-products. Thus, the company collaborates with actors such as policy makers, research institutions, private companies and citizen groups in their target markets to undertake the development of waste management systems. 


\section{Svensk Biogas}

Svensk Biogas specialises in biogas production, distribution and use as vehicle fuel. The company's research and development unit focuses on developing knowledge and competence for optimizing the biogas production process which, is at the centre of Svensk Biogas' export activities. The company uses a combination of different approaches such as licensing, using city networks, and participation in government-funded projects to engage in export. However, their main export activity has been through a licensing agreement with Kemira, a private chemical manufacturing company headquartered in Finland and operating throughout Europe in the waste-intensive industries. Svensk Biogas has developed an additive for optimising the biogas production process which is part of a product sold by Kemira. Thus, through this licensing agreement, Svensk Biogas receives a fee from Kemira based on the total sales of this product. In addition, the company has been involved in consultancy services to optimise biogas production processes in existing facilities in for example Malta and Estonia, where they received payments based on man-hours and the delivery of technical reports. Apart from licensing, the company markets its offerings by attending industrial conferences and participating in its owner city's international networking activities. Through the use of city networking activities, the company gets access to foreign market information, interacts with potential customers and gains legitimacy from other cities that can relate more to the solutions and challenges of their peer cities. Future market expansion ambitions are targeted at the United Kingdom and Eastern Europe, partly due to the high concentration of biogas facilities, which suggests a potential market for technical competence on biogas production processes and optimisation.

As presented in the theoretical background, different business model approaches can serve as a basis for synthesising components of business concepts for the export of environmental technologies. As depicted in Step 1 in Figure 7, those business models reviewed in this thesis were purposely selected to cover general business offerings (Osterwalder and Pigneur, 2010), products (Mason and Spring, 2011), combined product-service offerings (Lay et al., 2009) and large technical systems (Okkonen and Suhonen, 2010). From these previous literatures, six basic components are synthesised as relevant components of business concepts for the export of environmental technologies. These are (i) market, (ii) finance, (iii) resources, (iv) activities, (v) partnerships, and (vi) ownership and responsibility. 


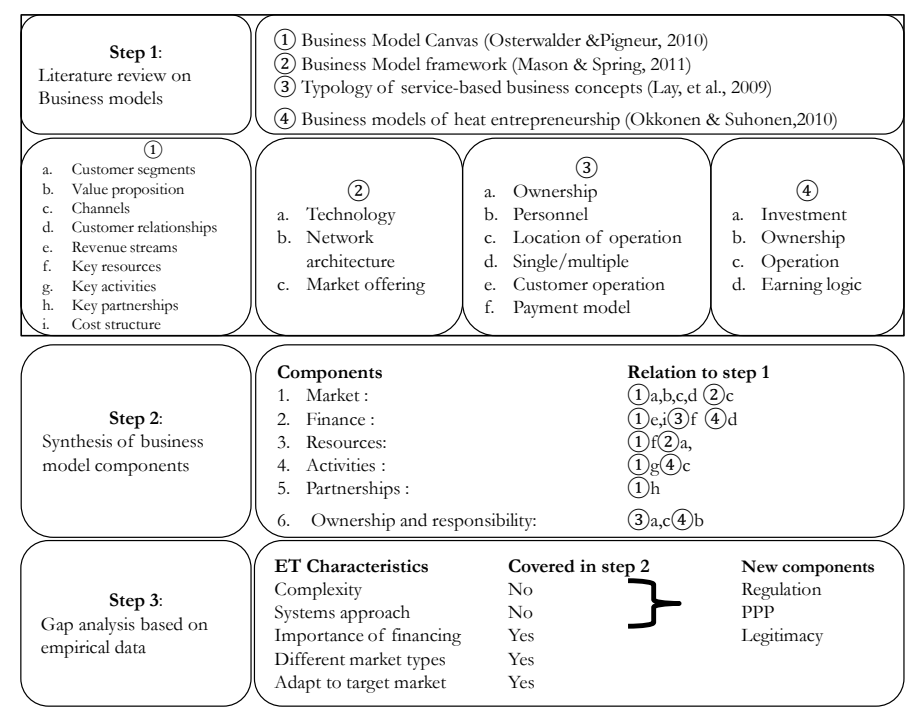

Figure 7: Synthesis of components of business concepts for environmental technology export (Kanda et al., 2016d).

From the empirical cases presented under Article 5, certain characteristics of environmental technologies which potentially influence their export were identified as depicted above in Step 3 of Figure 7. The implicit consideration of some of these specific characteristics of environmental technologies (particularly their complexity and systems approach) by previous business model approaches led to the addition of three components, that is "regulation", "private-public partnership" and "legitimacy", as particularly pronounced in the export of environmental technologies. The reasoning behind the addition of these components and their relevance in environmental technology export are discussed in the next chapter.

\section{My contribution to the article}

I was mainly responsible for collecting and analysing the empirical data upon which this article is based. I was also responsible for writing sections of the article which focus on components of business concepts for environmental technology export, and took the lead in the revision of the manuscript after major comments from reviewers during the publication process. My co-author, Tomohiko Sakao, wrote parts of this article which focused on the expansion of ecodesign and Product-Service Systems design. Olof Hjelm gave critical feedback, comments and ideas for improvement throughout the writing of the manuscript. Sahar Sadri wrote her master's thesis as part of the BMEX project "Business models for market expansion of Swedish Municipal Companies", and by that participated in conducting the interviews and their initial analysis but did not participate in the article writing. 


\section{Discussions and Conclusions}

This chapter addresses the research questions guiding this thesis by discussing the results presented in the previous chapter, with reference to the theoretical background. The chapter is structured according to the four research questions guiding the thesis.

\subsection{Governmental Export Promotion Initiatives and their Perceived Effectiveness}

In principle, the identified governmental export promotion initiatives for environmental technology suppliers are largely similar to export promotion initiatives for exporters in general. This means that environmental technology suppliers often have to compete for and access export promotion initiatives similar in content for all kinds of exporters. These initiatives include financial aid, information provision, education and training, and trade and mobility-related programs, as described in the previous chapter. However, there were some dedicated export promotion initiatives targeted mainly at environmental technology suppliers in several of the studied countries (Article 1, Article 2). Even though, these initiatives are dedicated for environmental technology suppliers, the contents of these dedicated initiatives were largely similar to those for exporters in general. Thus, these dedicated initiatives do not explicitly reflect the pronounced characteristics of environmental technologies such as externalities and the importance of regulations and their environmental performance, as highlighted in the theoretical background. Finally, as presented in the previous chapter, in very few cases, for example in Denmark, there was export promotion initiatives with content tailored specifically to reflect some pronounced characteristics of environmental technologies. These content-tailored initiatives extend into the use phase of the technologies, where environmental benefits and buyer defaults might accrue (Article 1).

Even though there are isolated cases of content-tailored export promotion initiatives for environmental technology providers, the dominant approach to supporting such firms in export is to provide similar services for all kinds of exporters. This generic approach to governmental export promotion initiatives could be linked to several underlining reasons. Theoretically, this observation could be linked to the use of externalities, free rider problems and market failures in export as the basis for all kinds of governmental interventions to promote export (cf. Lederman et al., 2010). Furthermore, governmental policy intervention in markets is based on the notion of intervening to tackle market and system failures (Bleda and Del Río, 2013). This suggests a complementary role of governmental interventions to market initiatives, and thus governmental export promotion is not intended to distort market initiatives. In this regard, governmental export promotion initiatives may not be expected to fulfil every market and system need, but rather to complement and intervene where there are failures to create fair conditions for competition (European Commission, 2007).

With the ambition for resource effectiveness and the need to support different sectors, an efficient way to offer governmental export promotion initiatives could be to offer generic support (see Lederman et al., 2010). Thus, support is often targeted at SMEs as a homogenous group, with few content-tailored initiatives for certain sectors and technologies (Article 1). Furthermore, environmental technologies have several similarities with "other" technologies. 
Similarly, environmental technology suppliers experience several similar challenges and barriers reported in the literature for exporters in general (cf. Leonidou, 1995). With these commonalities, governmental export promotion agencies may choose to ignore, or even lack the required competence to incorporate, the pronounced attributes of environmental technologies such as externalities, the importance of regulations and their environmental performance in their export promotion initiatives.

Also, with regard to the content of export promotion initiatives, there is a dominating focus on providing financial support to firms, as can be inferred from a dedicated export credit agency in each of the studied countries. Though financial aid programs reflect the genuine need for export credits, guarantees against political and economic risks of default, they can also be prevalent since firms often express the need for and appreciate such support (as indicated by survey results presented in Article 2). Furthermore, financial aid is relatively easier to administer and monitor compared to other types of support such as information provision, trade delegations and education. However, financial support cannot be a substitute for internal firm resources, capabilities and competencies, as discussed in the resource-based view of the firm. Governmental export promotion initiatives which overly rely on providing financial support to exporters are bound to face challenges from uncommitted exporters, particularly when such support is withdrawn. Thus, in addition to providing financial support to firms, other forms of support such as education and training, and information provision which can assist firms to develop their internal resources, capabilities and competencies are equally important in government support, as stressed by the resource-based view of the firm.

The implementation of governmental export promotion initiatives also influences their effectiveness (Kumcu et al., 1995; Volpe Martincus and Carballo, 2010). In connection with implementation, there are important differences between the studied countries with regard to choice of (i) target markets, (ii) environmental technology types, (iii) firm stage in export, and (iv) firm size, as shown in Figure 3 in the previous chapter. These differences could be linked to the idiosyncrasies of particular countries in terms of their competitive advantages, technological competence, economic, cultural, historical and political ties (see Leonidou et al., 2011). These different implementation options are expected to have an influence on the effectiveness of export promotion initiatives. For example, though there are projected needs for environmental technologies in emerging markets such as many parts of Africa and Southeast Asia (e.g. Vietnam), the environmental markets are underdeveloped in many of the countries, as markets are characterised by command and control policies, weak implementation of regulations, and limited investments in environmental sustainability, with preference for end-of-pipe environmental technologies under regulatory pressure (DEFRA and DTI, 2002). Though governmental export promotion initiatives are attempts to steer export, companies also have access to market initiatives and thus might approach export differently, e.g. with regard to target markets and priority technologies, than stipulated in official export promotion initiatives.

The perception of the effectiveness of governmental initiatives among target firms is important, since it influences the decision of firms' to participate in governmental initiatives and also the potential benefits they attain from participation (Kumcu et al., 1995). In this regard, when analysing the results from the survey among Swedish environmental technology suppliers presented in Article 2, discussions could relate to their awareness, participation and the perceived 
effectiveness of governmental export promotion initiatives. As indicated in Figure 4 in the previous chapter, $62 \%$ of export-oriented firms (exporting or planning to do so in the next five years) that responded to the survey were not aware of fitting (i.e. initiatives which could assist firms to tackle their challenges in export) governmental export promotion initiatives. This lack of awareness of fitting initiatives could be linked to the structure of governmental support actors and their initiatives. In this regard, the environmental technology sector has been selected as a priority sector by the Swedish government for export promotion (Swentec, 2008b; The Swedish Government, 2013), and thus there are several governmental agencies and initiatives to support firms, which can be difficult for firms to navigate.

Even though these governmental initiatives are intended to complement each other, in reality there might be very weak interactions, tensions and even conflicts between agencies and their initiatives, underpinned by the political economy of policy-making (Howlett et al., 2017). In this regard, certain groups of actors may promote certain public support policies without consideration of their potential implications on other elements and actors in the public support policy mix. For example, certain export promotion initiatives target emerging markets where there are considerable environmental problems, while private companies may avoid such markets due to financially constrained customers and lax environmental regulations. The difficulty in navigating the governmental export promotion initiatives can even be complicated, given the characteristics of SMEs such as relatively limited finance and personnel committed to accessing governmental support. In tackling navigation-related challenges, governmental agencies have a crucial task in both better communicating about their support activities and how it differs from the activities of other agencies, and in more importantly guiding firms to the "right" governmental agencies and initiatives irrespective of their first point of call. This would require an overview understanding of the various governmental agencies by each other, co-ordination between various actors and their initiatives, and even decommissioning duplicative actors and initiatives. In fact, empirical studies show that the success of public policy in supporting environmental technologies does not only depend on the specific type of instrument, but equally on their design, implementation and co-ordination and framework conditions such as stability and transparency in public policy (Del Río et al., 2010). However, the responsibility for improving the navigation and communication about the export promotion initiatives does not only rest with the governmental agencies; it is also a responsibility of firms to dedicate time and resources to actively scan and participate in programs relevant for their export needs.

Establishing a causal relationship between the participation of firms in export promotion and export outcomes is difficult mainly, due to the use of firm-level perception, the numerous factors at play and the time delay between participation in export promotion and export realisation. As indicated in the previous chapter under Article 2, of those firms participating in governmental export promotion initiatives, $32 \%$ could relate their participation to export success, while $68 \%$ could not relate their participation to successful export business. Even though such questions on perceived effectiveness induce yes or no thinking, i.e. successful or not successful, it is even more compelling to discuss which kinds of promotion initiatives are perceived to lead to export realisation. In this regard, firms that participated in more than one type of governmental initiative (particularly including financial aid programs) could relate their participation to successful export cases, compared to those who participated in only one type of support (e.g. information 
provision). Volpe Martincus and Carballo (2010) reported similar findings from their study of Colombian exporters, where they concluded that firm participation in bundled export promotion services worked better in realising export than participating in single programs. Although firms appreciate financial support as the results suggest, it is also clear that the challenges in export are not only financial, but include other types of challenges related to differences in markets, information and resources which can be tackled with a bundle of support services.

Among those firms that could not relate their participation in export promotion to successful export cases, different explanations could be inferred. The source of perceived failure could be based on the content of the governmental initiatives that do not incorporate particular challenges of environmental technology suppliers and their technologies. As conceptualised in the Uppsala Internationalization Model (Johanson and Vahlne, 1977; Johanson and Vahlne, 2009), there are different stages in the internationalisation of a firm, and different studies (e.g. Kanda et al., 2016c; Smith et al., 2006; Suarez-Ortega, 2003) have concluded on the changing perception of export challenges along the export development stages. This suggests that the lumped and generic export promotion initiatives, where exporters are considered as a homogenous group, might be insensitive to the potential differences among exporters relating to their challenges and drivers. Governmental agencies thus need to understand the dynamic nature of export challenges and develop initiatives which are able to support such dynamic export development trajectory. Other bases of the perceived ineffectiveness could be procedural regarding how the export promotion initiatives are implemented. Relevant questions in this regard relate to which firms are chosen for support, what are their competencies and how is their export readiness. Are governmental export promotion initiatives favouring the potentially successful exporters, the weak ones or attempting to create framework conditions for all kinds of exporters to succeed? In certain instances, failure in realising export could be attributed to the firm's attributes, such as lack of knowledge about foreign markets and committing limited resources to export.

Conclusions on Research Question 1: How do governments promote environmental technology export and what is the perceived effectiveness of such initiatives among private environmental technology companies?

Governmental export promotion initiatives for environmental technology providers can be grouped into financial aid, information, education and training, and trade and mobility-related programs. In principle, these initiatives are generic for all kinds of exporters and even in cases in which support is dedicated to environmental technology suppliers, the content is still similar to the generic initiatives. However, there are a few cases of content-tailored export promotion initiatives which incorporate specific characteristics of environmental technologies. With regard to the perceived effectiveness of export promotion initiatives among firms, the discussions of the results suggest that participating in bundled export promotion initiatives such as information programs, education and training, and trade and mobility including financing support was perceived as more effective, since companies encounter a mix of different challenges. This suggests a need for a combination of generic export promotion initiatives, together with dedicated and content-tailored support which incorporates specific attributes of environmental technologies and their suppliers as they internationalise. 


\subsection{Obstacles to and Drivers for Environmental Technology Export among Municipally Owned Companies}

As indicated by the results presented from Article 3, municipally owned companies have different stakeholder objectives and institutional conditions compared to typical privately owned companies, which suggests that they somehow experience different challenges, barriers, and drivers for export.

Obstacles to export include attitudinal, structural and operational issues that deter a company from initiating, expanding or sustaining international activities (Smith et al., 2006). Thus obstacles relate to both challenges encountered by currently exporting companies and barriers which deter non-exporters from commencing export (Suarez-Ortega, 2003). As indicated in the previous chapter, Figure 5 depicts that the most frequently mentioned challenge among municipally owned exporting companies were differences between the home and target markets, particularly regarding the decision-making structure of adopters and the political systems within which they operate. As a consequence, in some export cases, decision-making regarding the adoption of environmental technologies can be highly bureaucratic due to hierarchical decision making structures. For example, in some export cases, it was realised that even though the adoption of the environmental technology was a decision of the city council, financial support for the project was a decision to be considered in the national budget which involved several stakeholders and their different requirements and expectations, thus making the adoption decision more complex. In addition, environmental regulations within the context of the potential technology adopter have significant influence on their adoption of environmental technologies (cf. Del Río, 2005; Del Río et al., 2016). Thus, a difference between the home market and the target market regarding the stringency and implementation of environmental regulations implies that, in certain export cases, municipal companies face financially uncommitted customers, particularly in relation to technologies whose adoption is perceived as additional costs.

Even though some of the challenges experienced by municipally owned companies relate to the target market and potential adopters, there are also internal challenges relating to their commitments towards international markets. Municipally owned companies experience resource constraints (financial, personnel and time) in connection with exports, since many of these companies regard their local obligations as their priority and thus are not always willing to commit extensive resources to exports. Indeed, smaller municipal companies even expressed stronger resource constraints for export compared to larger municipal companies, an observation which is in line with previous contributions which concluded that company size dictates which barriers and how strongly they are experienced in export (Smith et al., 2006). This lack of resources to engage in export consequently manifests itself in other export challenges such as finding export financing, finding customers and export planning, as depicted in Figure 5. As theorised in the resource-based view of the firm, this lack of internal resources, capabilities and competence to engage in export can be an important competitive disadvantage, and thus the root of the different challenges encountered by municipally owned companies in the export.

However, some of the barriers which prevent municipally owned companies from initiating export can be attributed to their municipal ownership and the institutional contexts of rights and obligations within which they operate (see Thomasson, 2009). There could be different 
entrepreneurial ambitions between the politically appointed board members and the citizens they represent and the management of the company, which can restrict export activities. In fact, several municipalities consider export a risky activity, and thus their municipal companies are only allowed to export know-how and services regarding environmental technologies (Kairento and Nygårds, 2014). Furthermore, the monopoly many of these municipally owned companies have regarding the management of household waste within the boundaries of their local municipalities can sometimes reduce their interest in international markets. However, as discussed in the theoretical background, this monopolistic context within which these municipally owned companies operate is not static but rather dynamic, and under contention with several legal issues (Corvellec and Bramryd, 2012). This could mean that in the future, municipally owned companies could need to be more active on markets outside their locality, due to increasing competition on their domestic market.

With regard to the drivers among municipal companies for export, unsolicited customer requests were most frequently mentioned (see Figure 6). Though unsolicited customer requests are an important driver for export even among private companies (Leonidou et al., 2007), it suggests an ad hoc reactive approach to export which can suffer from different challenges due to lack of strategic export planning (Czinkota and Ronkainen, 2006). The dominance of this reactive approach among municipally owned companies can be linked to their monopolistic position, which to some extent guarantees their access to their home market (see Corvellec et al., 2012) and thus no pressing need of international activities.

A driver for export detected among the municipally owned companies which is not often pronounced in the literature is the desire to contribute to the public good, such as environmental sustainability and regional development. The desire to contribute to global environmental sustainability could be linked to the public ownership of these companies and their long experience of taking care of the environmental pressure from their inhabitants. The stakeholders of municipally owned companies could value issues such as contributing to environmental sustainability more than in the case of privately owned companies, whose activities are typically profit-driven due to externalities and free-rider problems (cf. Turnheim and Geels, 2012). Even though municipally owned companies also face free-rider problems and externalities, they increasingly see their opportunity to contribute to significant environmental sustainability as global compared to incremental improvements in their localities. This desire can be part of their responsibility to society and even be stipulated in their owner directives as a public company. The desire of publicly owned companies to work with public goods such as environmental sustainability and regional development makes them an important actor, particularly in regard to externality-generating activities such as gathering foreign market information related to customer preferences, laws, regulations and business opportunities, establishing links to foreign markets, and information gathering associated with export. However, municipally owned companies cannot be solely responsible for such positive spillover-generating activities and need the support from privately owned companies. As discussed in the theoretical background, the subjection of environmental technologies to externalities and free-rider problems (see Turnheim and Geels, 2012) makes it even more vital that municipally owned companies are engaged with and interested in the export of such technology export, since private initiatives alone may not be sufficient. 
Nonetheless, the opportunity to explore the possibilities for extra income also emerged as a driver for export among the municipal companies. This driver is relatively weak as compared to the importance it bears in the export activities of privately owned companies (cf. Leonidou et al., 2007). Since export is often regarded as secondary compared to the primary obligations of municipally owned companies, the drivers for extra income are explicably low among exporters (cf. Figure 6). For example, many of the municipal companies expressed the need for their costs to be covered rather than actively seeking extra income from their international activities. This approach to export means that many of the export activities in which Swedish municipally owned companies are involved are pre-financed by international developmental aid organisations and only in some cases have customers been required to pay themselves for consulting activities and process optimisations (Kairento and Nygårds, 2014).

Conclusion on Research Question 2: What are the obstacles to and drivers for environmental technology export among municipally owned companies?

The institutional conditions under which municipally owned companies operate, including their municipal ownership, the environmental technology types they offer, and their target markets, induces barriers which prevent some of these companies from initiating export and also challenges to those already exporting. The most pronounced obstacle to export relates to differences in decision making and the political system between the home market and the target market. Furthermore, the focus of many municipal companies on fulfilling their local obligations means that they do not commit extensive resources to international markets, which suggests that they might even aggravate some of their export challenges and barriers. One particular driver among such companies to engage in export is their ambition to contribute to the public good, such as global environmental sustainability and regional development. This attribute makes municipally owned companies important actors in the export of environmental technologies particularly in situations where positive spillovers may be generated such as market information gathering and investments to establish linkages with foreign markets. Furthermore, their longterm experience, functioning proof-of-concept, municipal ownership and systemic approach (involved in the entire value chain of the technology e.g. from waste collection to transportation, end treatment and selling the commercial product and governance) gives them legitimacy, especially when potential customers are also other cities or municipalities, something which might be challenging for privately owned SMEs to achieve.

\subsection{Using International City Networks for Export}

The results from appended article 4 indicate that membership and participation in international city networks through knowledge and experience exchanges, co-creating solutions and applications, and supporting each other continuously represent potential benefits of such international city networks which could facilitate the export of environmental technologies. In this context, the barriers and challenges experienced by municipally owned companies in export deserve close attention. As discussed in response to the Research Question 3 above, the differences between the home and target market regarding decision-making structure and the political context is the most frequent challenge that the studied municipally owned companies experience in export. Other challenges included the lack of resources (finance, personnel and time) to participate in export, and these resource limitations also manifest themselves in other 
challenges such as the difficulty of finding customers and export planning. Furthermore, international city networks are not only relevant for fostering export because of the challenges experienced by municipally owned companies. More so, international city networks are relevant because of the potential customers of municipally owned companies, which are often other cities, or municipalities who can relate to their peers, and also the milieu from which they seek solutions to their challenges.

Despite the potential benefits that have been reported in the innovation diffusion literature (see e.g. Batten, 1995; Cooke et al., 2002) and the empirical results that emanate from participation in international city networks, not all export barriers and challenges experienced by municipally owned companies can be tackled by the participation in city networks by their owner municipalities or cities. Furthermore, access to city networks cannot substitute the need for firms to develop internal resources, capabilities and competencies needed for export and also to effectively participate, contribute to and benefit from international city networks. On the limits of international city networks, challenges in export such as differences between the home and target markets regarding decision making and political context can be regarded as a given condition for exporters to work with. However, participation in international city networks can provide an appropriate arena to exchange information, learn and develop deep understanding about these market differences, which can facilitate export. Furthermore, participation in city networks provides the platform for municipalities to share their experiences and approaches to problems (including technologies) and showcase their local competence and expertise to potential customers. In particular, international city networks provide platforms for two-way communication and information sharing between and among members. Gathering foreign market information on customer preferences, laws, regulations, and business opportunities can help municipally owned companies in the export of environmental technologies. As pointed out in the theoretical justification for export promotion, the gathering of foreign market information involves some positive spillovers, as information gathered can benefit competitors who do not directly invest in gathering such information themselves, and thus companies, especially privately owned, might be hesitant to undertake such activities (Lederman et al., 2010).

City networks, particularly those with a defined thematic focus area such as sustainability, provide potentially detailed information about different markets as there is direct interaction between decision makers and key stakeholders from different cities and municipalities. In addition to information sharing, participating in city networks contributes to building legitimacy as members can be regarded as committing resources to and being actively engaged with a thematic area such as energy or the environment. Legitimacy refers to social acceptance and compliance with relevant institutions and regulations, including the ability to meet formal and informal expectations (Bergek et al., 2008). Members of international city networks (especially those with a defined thematic focus area) share common goals and facilitate the development of legitimacy through the development of their competencies related to the achievement of these collective goals. Such legitimacy can be relevant for municipally owned companies, particularly for export of environmental technologies, as they have to convince potential adopters of their technologies and meet the expectations of different stakeholders. Svensk Biogas participated in city networking activities on the request of their home city, which resulted in some export realisations (Article 5). In this case, the use of such city networks helped the company to gain access to 
foreign market information, gain international attention and build legitimacy from relevant stakeholders, since such large technical systems for biogas production are often owned by other cities, which can relate more to the challenges and solutions of other cities. Such legitimacy is important for resources to be mobilised and markets to form around a particular technology (Bergek et al., 2008), and in particular to overcome liability of foreignness and newness associated with export (Johanson and Vahlne, 1977; Johanson and Vahlne, 2009).

However, outside the boundaries of international city networks, companies and cities are also involved in bilateral relations with other cities, often labelled as sister cities. These bilateral relations can have more concrete objectives compared to international city networks (Article 4). One such case in described in appended Article 5, where the international activities of VafabMiljö to develop a waste-to-energy facility for municipal solid waste management were facilitated by the sister-city relation between their owner city Västerås, in Sweden and Gaborone, in Botswana. Activities in bilateral sister city relations are easier to manage due to fewer cities involvement and also to track due to oftentimes concrete outcomes such as projects. Even though such initiatives can also contribute to two-way information and knowledge flows, they are limited in scope since they involve fewer cities. The geographical spread (which can also suggest diversity) and size of international city networks is particularly relevant for export (Mejía-Dugand, 2015b). As discussed in the theoretical background, such interactions and communications between heterogeneous actors (e.g. lead users and laggards), even though they pose more challenges, can further the diffusion of innovations beyond close-knit networks (Rogers, 2003). On the other hand, within a homogenous group, certain commonalities such as culture, language, and status of economic development, facilitate the spread of technological innovations, something MejíaDugand et al. (2013) observes as they trace the spread of Bus Rapid Transit Systems in Latin America.

As indicated in the results from appended Article 4, the studied cities had access to members around the world through their city networks, especially the larger cities of Stockholm and Gothenburg. Access to a wider variety of members might be beneficial for cities, given the challenges of globalisation, the pool of knowledge that can be shared and the potential diversity in technological developments and solutions. Considering the exchanges between members in these networks, and the positive spillovers of belonging to city networks, cities with a wider geographic outreach through their membership may find more opportunities for export for their local companies as the potential audience is also broader. As indicated in the theoretical background, communication between diverse units is expected to further the diffusion process across groups more than communication limited to members who are similar within a group (Rogers, 2003). However, participating and maintaining membership in international city networks requires resource commitment since it involves responsibilities such as attending meetings, paying fees, information sharing and a particular challenge may relate to assessing the effectiveness of membership in such networks as their direct benefits may be difficult to quantify (Mejía-Dugand et al., 2016). 
Conclusions on Research Question 3: How could municipally owned companies use international city networks to facilitate environmental technology export?

Though international city networks may not address all the challenges faced by environmental technology exporters, they are particularly relevant for building legitimacy, bilateral information and knowledge exchanges, which are relevant for environmental technology export. Though the provision of market information to exporters is a common governmental export promotion service, international city networks represent an arena for sharing even more detailed market information, particularly in networks with a chosen thematic focus such as sustainability. Despite these potential benefits from participation in networks, they demand time, personnel and financial resources to administer, and their benefits might be diffused and difficult to quantify. Cities which belong to diverse, geographically wide-reaching networks stand to benefit as they can use these networks to showcase their technologies to a potentially wider and diverse audience beyond closely-knit networks which is relevant for broadening the scope of diffusion. However, municipalities and cities that have access to such international networks may not only use them for the direct benefit of their own companies; they can also use their membership in such networks to indirectly connect to other actors, such as privately owned companies which might find it challenging to access such city networks.

\subsection{Components of Business Concepts for Environmental Technology Export}

To be able to synthesise components of business concepts for the diffusion of environmental technologies, it was necessary to connect to previous literature on business models, and to identify specific characteristics of environmental technologies that influence their export. As discussed in the theoretical background, there are business modelling approaches in the literature which are of relevance for Research Question 4, since environmental technologies and their suppliers share certain attributes with "other" technologies and exporters in general (see Sections 2.1 and 2.2). The analysis purposively focuses on business "concepts", since the studied companies were in their initial stages of export and thus had no functioning business models to describe based on facts.

From a review of some previous literature on the business model canvas (Osterwalder and Pigneur, 2010), business model framework for products (Mason and Spring, 2011), typology of service-based business concepts (Lay et al., 2009) and business models for large technical systems (Okkonen and Suhonen, 2010), six components were synthesised as basic components of business concepts for export business development. These six components are (i) market, (ii) finance, (iii) resources, (iv) activities (v) partnerships and (vi) ownership and responsibility. Of course, it is possible to synthesise additional components based on the objective of a particular study and the reviewed business model literature. These six components proved sufficient, however, since this study aimed at synthesising components of business concepts that can be used for strategic discussions during export development. The available information at the early stages of export development limited the possibility for further detail. The composition of each of these six main components is provided in Figure 7 and can be used to further describe and discuss business concepts, subject to available information. 
After synthesising such components from the previous literature, specific characteristics of environmental technologies, which influence their export, were identified from the empirical cases presented in the previous chapter (export business development of environmental technology suppliers under appended Article 5). Table 3 below summarises the characteristics on the left-hand side, based on the empirical findings and their corroborations from previous scientific literature.

Table 3: Pronounced characteristics of environmental technologies which could influence its export.

\begin{tabular}{|c|c|}
\hline Characteristics from the studied cases & Reference/relation to literature \\
\hline $\begin{array}{l}\text { Complexity with several technical } \\
\text { components, actors and institutions } \\
\text { (interviews, Usitall AB; Swedish Biogas } \\
\text { International; and Svensk Biogas). }\end{array}$ & $\begin{array}{l}\text { Complexity exhibited by some environmental } \\
\text { technology types requires additional training } \\
\text { for workforce upon adoption (Del Río, 2009). } \\
\text { Businesses based on industrial ecosystem } \\
\text { thinking, such as biofuel businesses } \\
\text { representing complex systems from rather } \\
\text { stable subsystems and requiring a variety of } \\
\text { actors to work together (Tsvetkova and } \\
\text { Gustafsson, 2012). }\end{array}$ \\
\hline $\begin{array}{l}\text { Importance of financing (interviews, Usitall } \\
\text { AB; Svensk Biogas; VafabMiljö). }\end{array}$ & High initial investment (Del Río, 2009). \\
\hline $\begin{array}{l}\text { Need to address different market types } \\
\text { (interviews, Usitall AB; and Swedish Biogas } \\
\text { International). }\end{array}$ & $\begin{array}{l}\text { Environmental technology companies have to } \\
\text { compete and meet expectation and } \\
\text { requirements in different kinds of markets } \\
\text { (Corvellec and Bramryd, 2012). }\end{array}$ \\
\hline $\begin{array}{l}\text { Need to adapt to the target market, including } \\
\text { regulations (interviews Swedish Biogas } \\
\text { International; and Usitall } \mathrm{AB} \text { ). }\end{array}$ & $\begin{array}{l}\text { Environmental technologies need to be } \\
\text { compatible with, flexible and adaptive, to local } \\
\text { systems and conditions (Mejía-Dugand, 2015b). }\end{array}$ \\
\hline $\begin{array}{l}\text { Relevance of a systems approach } \\
\text { considering economic, environmental and } \\
\text { social aspects (interviews, VafabMiljö; Usitall } \\
\text { AB). }\end{array}$ & $\begin{array}{l}\text { "Sustainability-driven innovations" require } \\
\text { multiple organizations to act in an orchestrated } \\
\text { fashion (Rohrbeck et al., 2013). } \\
\text { Environmental technology change should } \\
\text { encompass non-technological aspects such as } \\
\text { culture, consumption, behaviour, lifestyles to } \\
\text { be able to deliver even wider environmental } \\
\text { change beyond technological improvements } \\
\text { (OECD, 2009). }\end{array}$ \\
\hline
\end{tabular}

After comparing the characteristics of environmental technologies identified in Table 3 above to the six basic components synthesised from the literature, three additional components were proposed. Particularly, characteristics of environmental technologies such as the need for a systems approach, and their complexity, which involves several actors and institutions, underlines the proposal of the three additional components (i) regulation as part of market, (ii) publicprivate partnership, and (iii) legitimacy. It should be stressed that the studied environmental technology types, i.e. district heating supply, waste management and renewable energy systems, influence the identified characteristics and consequently the additional components proposed. 
However, an attempt was made to abstract the characteristics of the studied cases, which are applicable to environmental technologies in general with some corroboration from the literature as presented in Table 3 above. Furthermore, in certain export cases and for some environmental technology types, certain characteristics can be more relevant than others - regulations, for example, are particularly important for the adoption of end-of-pipe technologies (Institute for Prospective Technological Studies, 2004).

The addition of "regulation" as a sub-component to market emphasises the important role regulation plays in the adoption of environmental technologies, particularly end-of-pipe technologies, an issue long identified in the literature (Del Río, 2009; Del Río et al., 2016). Particularly in markets where environmental sustainability agendas are still steered by command and control mechanisms, regulations are significant drivers for the adoption of environmental technologies. Even in environmentally mature markets driven by market incentives and resource productivity, regulations may still have important influence on the adoption of emerging environmental technologies (cf. DEFRA and DTI, 2002). Furthermore, regulations do not only determine adoption but can also influence the design of certain environmental technologies which goes a long way to influence their environmental performance (Carrillo-Hermosilla et al., 2010). A waste management company has to comply with foreign market regulations on raw material markets, technical markets and also commercial markets for the end-products of waste treatment to gain social acceptance and formal compliance (Article 5). Regulations can even influence what is regarded as waste, its compositions and how it should be treated, and thus influence the design of waste management systems (Taye et al., 2014). Information provision on regulation from target markets forms an integral part of the services provided by export promotion agencies and information sharing in city networks, and can contribute to uncovering both existing and forthcoming regulations relevant for environmental technology export.

The component "public-private partnership" is emphasised because of the systemic nature of environmental technology, which requires different actors and institutions to collaborate (see Tsvetkova and Gustafsson, 2012). These partnerships could also transcend national borders to include partnerships in international markets as facilitated through several international city networks, sister city partnerships and information communication technology. More so, the characteristics of the Swedish environmental technologies sector (the important role of municipally owned companies, and about $90 \%$ Small and medium-sized companies) including the environmental technology offerings as presented in the theoretical background makes publicprivate partnership even more compelling. Large technical systems such as district heating, renewable energy systems, and waste management systems require different actors to collaborate for proper functioning of the system, and thus different actors have different competencies with regard to export as well. For example, Swedish small and medium-sized environmental technology companies have struggled to meet customer demands as they outstrip their capacity (Frankelius et al., 2011). On the other hand, municipally owned companies have long experience of operating such large technical systems, have a functioning proof-of-concept and experience some different obstacles and drivers in export. Municipally owned companies stressed their ambitions to contribute to public goods such as environmental sustainability and regional development. As these companies are often system integrators (capable of working with the development of large technical systems based on technology from smaller suppliers), partnerships 
between municipally owned companies and privately owned companies which have the innovative capacity, competitiveness and relative flexibility could be particularly relevant for environmental technology export.

Legitimacy refers to the social acceptance and compliance with relevant institutions. The process of building legitimacy is complicated, takes time and competition from existing technologies. Building legitimacy can be approached using different strategies such as lobbying to change the rules of the game, choosing to follow existing norms and expectations, and influencing the creation of new institutional frameworks (Bergek et al., 2008). These approaches could even be more complicated in export since they cross national borders and might require more efforts beyond the capacity of companies, particularly SMEs. Thus, the support of other actors such as politicians, international city networks, and demonstration projects can offer bridges to the context of potential adopters (Mejía-Dugand, 2015b). The environmental technology provider, including the technology, needs legitimacy for resources to be mobilised for its adoption and to reach social acceptance and use. Legitimacy is not given but formed through actions by various organisations and individuals, which may eventually help the technology supplier and the environmental technology to overcome its liability of foreignness (Johanson and Vahlne, 2009) and newness (Zimmerman and Zeitz, 2002), most importantly among potential adopters (Rogers, 2003). The environmental technology supplier could work toward social acceptance through the showcasing of long-term track records, functioning proof-of-concept and demonstration projects. Another approach as discussed in relation to international city networks is for technology suppliers to connect to and utilise international city networks which have thematic focus areas as an indication of actively engaging with and working with those thematic issues. This is particularly relevant when the technology under discussion is a large technical system and the customer is another city or municipality, since cities can relate to the solutions and challenges of their peer cities.

Conclusions on Research Question 4: Which components could be considered in business concepts for environmental technology export?

From a study of export activities of municipally and privately owned companies, three components - regulation, private-public partnership and legitimacy - are proposed as particularly important for the export of environmental technologies. Out of these three proposed components, public-private partnerships are within the direct action scope of companies. Furthermore, private-public partnerships can offer a bridge to building legitimacy and gathering information about current and forthcoming regulations. Legitimation is not given but rather an outcome of continuous activities of several organisations and individuals including policy actors. Regulations, especially in foreign markets, may be difficult to influence by exporters and thus represent a given contextual condition to work with. Public-private partnerships are even more important due to externalities, which characterise environmental technologies, which in turn suggest that private companies sometimes have limited incentives to engage with them. Furthermore, spillovers in export, such as gathering foreign market information, makes publicly owned companies even more relevant as they can have stakeholder objectives for positive spillover-generating activities. However, publicly owned companies cannot be expected to be solely responsible for environmental technology export, and face their respective challenges and barriers. A public-private partnership can thus be synergistic with public companies providing 
legitimacy, long-term experience, functioning proof-of-concept and system integration. Private companies can supply technological innovations, competitiveness and agility. Such partnerships can be particularly relevant in the export of large technical systems, which encompass both technological and non-technological dimensions building on the complementary competencies of both private and public companies. However, such public-private partnerships involve trade-offs between independence and efficiency, require reciprocal commitments and managers will have to devise new strategies to maintain a balance between network strategies and internal competencies. 


\section{Synthesis}

In this chapter, I address the overarching aim of the thesis by drawing insights from the conclusions to each of the research questions in an attempt to further the discourse on the export of environmental technologies.

The overarching aim of this thesis is to analyse how to stimulate the diffusion of environmental technologies through export. This overreaching aim is explored through four research questions which focus on governmental export promotion initiatives and their perceived effectiveness among private environmental technology suppliers, obstacles to and drivers for export among municipally owned companies, the use of international city networks as arenas for the export of environmental technologies and components of business concepts for the export of environmental technologies.

To provide a basis for the analysis of the overarching aim, five elements were synthesised from the literature (e.g. Fichter and Clausen, 2016; Rogers, 2003; Wejnert, 2002) as particularly relevant for the diffusion of technological innovations. These five elements, as compiled in Table 4 are (i) the technology, (ii) technology suppliers, (iii) technology adopters, (iv) communication channels, and (v) the diffusion context. The empirical results presented in Chapter 4 and discussed in Chapter 5, offer conclusions which can be used to further conceptualise these five main elements, particularly with a focus on the export of environmental technologies.

This conceptualisation of the export of environmental technologies is undertaken from the perspective of an analyst, i.e. an individual or organisation (e.g. policy makers, business manager national agencies, and researchers) interested in the overall discussion on stimulating the export of environmental technologies. The conceptualisation adopts a parsimonious approach to depict the central elements of the export of environmental technologies, and not to replicate a complex reality (cf. Johanson and Vahlne, 2009). Thus, the objective of the conceptual model is to depict the complex phenomenon of the diffusion of environmental technologies through export in a coherent way, which will enable the analyst to adopt a comprehensive approach to the topic and focus on the main elements.

Furthermore, there are potential gaps that this conceptualisation addresses in the diffusion of innovations and international business literature. Specifically, in the diffusion of innovations literature, technology adopters and their characterisation have been the focus of extensive research, while technology suppliers have received relatively little attention. On the other hand, in the international business literature, the dominant unit of analysis has been technology suppliers, i.e. firms and their characteristics in export with no explicit attention to potential adopters. Both streams of literature adopt an actor perspective (i.e. technology suppliers or adopters), with some consideration of the contextual issues such as technology policies and the particular characteristics of environmental technologies (e.g. externalities, the role of regulations and environmental performance as discussed in the theoretical background) and how they influence export. Of course, discourse in other literature such as environmental economics (e.g. Beise and Rennings, 2005) considers some of these elements though they are often on an aggregate level (e.g. national regulation) with limited discussions on the actor perspectives. These potential gaps in the literature motivate the conceptualisation presented. 


\subsection{An attempt to Conceptualise the Diffusion of Environmental Technologies through Export}

Starting with the problematisation presented on the previous page, an attempt is made to conceptualise the diffusion of environmental technologies through export. This conceptualisation, which is depicted in Figure 8, encompasses both aggregate and actor-level perspectives. In this regard, diffusion through export is conceived to occur primarily between technology suppliers in a host country and potential adopters in a target market. These two types of actors are linked together by communication channels. As recent research suggests, diffusion of environmental technologies through export is not a unidirectional activity from technology suppliers to adopters; rather, it is increasingly a bidirectional activity where potential customers are actively involved in seeking technologies and suppliers, adaptation, redesigning, and even cocreating technologies to fit local contexts (see e.g. Mejía-Dugand, 2015b). This is depicted by the bidirectional arrow between the suppliers and adopters in Figure 8.

Information about environmental technologies is thus carried through various communication channels between these two actors. The diffusion of innovation literature identifies different types of communication channels, which are influenced by the characteristics of the technology, the information source, the target recipient, and the information as presented in the theoretical background. Though there are different communication channels, international city networks are particularly relevant for large technical systems with cities and municipalities as potential customers.

In totality, these actors (i.e. technology suppliers and adopters) do not exist in a vacuum, but are influenced by and influence contextual issues such as policies, competing and complementing technologies, market structure, geographic conditions and culture. Technology suppliers are heterogeneous and have different characteristics with regard to export business development as well as different obstacles to and drivers for export (Article 3 and Article 5). Similarly, for environmental technology adopters, recent research has also conceptualised them as a heterogeneous group with different drivers for and barriers to adoption (Mignon, 2016).

More so, as depicted in Figure 8, technology suppliers and adopters do not always exist as individual entities, but are involved in different business networks and partnerships both locally and internationally for different reasons, including technology export and adoption. The entire phenomenon under study is a dynamic process where conditions in the context change and technology suppliers gain knowledge and experience of export activities, and thus perceive barriers and drivers differently, and also where adopters can change their status regarding previous adoption or rejection of a technology. Furthermore, the technology is not static but continues to be adapted, redesigned and changed over time with influence from the diffusion context, including the home and target markets.

The conclusions from this thesis also synthesise pronounced characteristics of environmental technologies which influence their export - that is, externalities, adaptability to different markets, systems approach, and functioning proof-of-concept (see Table 4). These characteristics of environmental technologies complement characteristics of technological innovations in general which influence their adoption - i.e., relative advantage, compatibility, complexity, trialability and 
observability (cf. Rogers, 2003). Thus, this conceptual model could be used by analysts to identify key elements to analyse in the export of environmental technologies and to formulate action plans to stimulate their diffusion. Finally, it should be stressed that any concept, which aims for general applicability cannot consider all kinds of detail, and thus other elements, in addition to those presented in the conceptualisation, might occasionally be relevant in different export cases of environmental technologies.

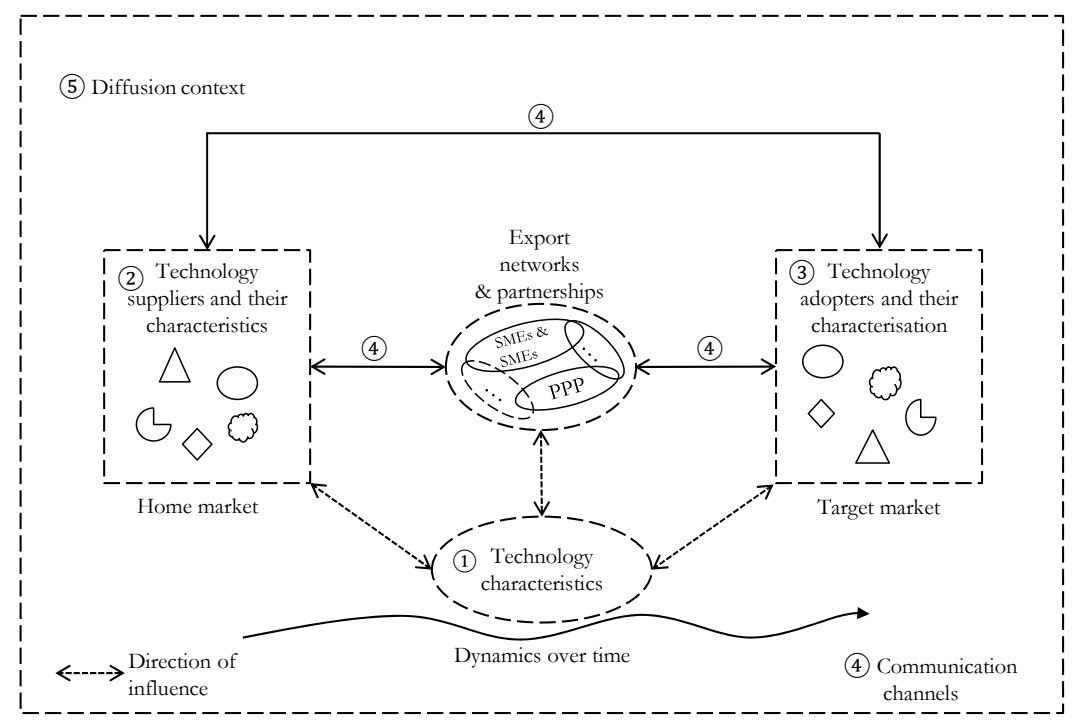

Figure 8: A conceptual model of the diffusion of environmental technologies through export.

In Table 4 below, a brief explanation regarding the use of the five main elements in the context of this thesis is provided. Furthermore, specific attributes of each of the five main elements, with a focus on the export of environmental technologies, are also presented.

Table 4: Main elements in the diffusion of environmental technologies through export.

\begin{tabular}{|c|c|c|}
\hline Main elements & $\begin{array}{l}\text { Explanation of main } \\
\text { elements }\end{array}$ & $\begin{array}{l}\text { Subcategories of main elements and } \\
\text { references to the literature }\end{array}$ \\
\hline 1. The technology & $\begin{array}{l}\text { Technology incorporates both } \\
\text { hardware (e.g. products, tools } \\
\text { and machines) and software } \\
\text { (e.g. procedures/processes and } \\
\text { digital protocols) that can be } \\
\text { used to solve real-world } \\
\text { problems. }\end{array}$ & 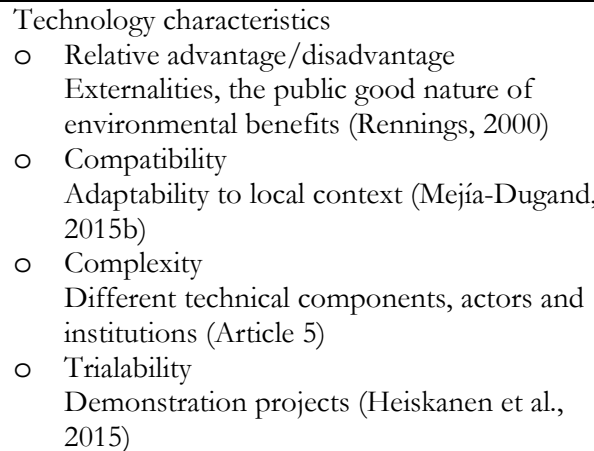 \\
\hline
\end{tabular}




\begin{tabular}{|c|c|c|}
\hline & & $\begin{array}{ll} & \text { Observability } \\
& \text { Functioning proof-of-concept (Article 5) }\end{array}$ \\
\hline $\begin{array}{l}\text { 2. } \\
\text { sechnology } \\
\text { suppliers }\end{array}$ & $\begin{array}{l}\text { An actor in contact with } \\
\text { potential technology adopters } \\
\text { with an intention to persuade } \\
\text { them to adopt a particular } \\
\text { technology or technologies. }\end{array}$ & $\begin{array}{ll}\text { Supplier characteristics } \\
\circ & \text { Business concepts (Article 5) } \\
\circ & \text { Obstacles to export (Article 3) } \\
\circ & \text { Drivers for export (Article 3) } \\
\circ & \text { Resources, capabilities and competences, e.g. } \\
\text { knowledge of target markets, financial } \\
\text { reserves, human resources, top management } \\
\text { commitment (Article 3) }\end{array}$ \\
\hline $\begin{array}{l}\text { 3. Technology } \\
\text { adopters }\end{array}$ & $\begin{array}{l}\text { Actors in a social system who } \\
\text { adopt (may also reject) a } \\
\text { technology. }\end{array}$ & $\begin{array}{ll}\text { Adopter categorisation } \\
\circ & \text { Innovativeness (Rogers, 2003) } \\
\circ & \text { Challenges in adoption (Mignon, 2016) } \\
\circ & \text { Drivers for adoption (Mignon, 2016) } \\
\circ & \text { Resources, capabilities and competencies e.g. } \\
& \text { technological competence, financial reserves, } \\
& \text { human resources (Del Río, 2005) }\end{array}$ \\
\hline $\begin{array}{l}\text { 4. Communication } \\
\text { channels }\end{array}$ & $\begin{array}{l}\text { The means by which } \\
\text { information about a particular } \\
\text { technology gets from one unit } \\
\text { to another. }\end{array}$ & $\begin{array}{ll} & \text { International city networks (Article 4) } \\
\circ & \text { Personal networks } \\
\circ & \text { Mass media channels, e.g. radio, television, } \\
& \text { newspapers, internet (Rogers, 2003) }\end{array}$ \\
\hline $\begin{array}{l}\text { 5. Diffusion } \\
\text { context }\end{array}$ & $\begin{array}{l}\text { Structures and factors within a } \\
\text { social system that interact with } \\
\text { the diffusion of a particular } \\
\text { technology. }\end{array}$ & $\begin{array}{ll}\text { O Technological context, e.g. complementing } \\
\text { or competing technologies } \\
\text { Political context } \\
\text { Technology policy, e.g. export promotion } \\
\text { (Article } 1 \text { and Article 2) } \\
\text { Environmental policy (Jaffe et al., 2002) } \\
\text { Cultural context, e.g. adopter norms, } \\
\text { behaviour (Mejiá-Dugand, 2015b) } \\
\text { Geographical context, e.g. climate } \\
\text { conditions, endowments of natural } \\
\text { resources, various kinds of waste (Heiskanen } \\
\text { and Matschoss, 2017) } \\
\text { Market structure, e.g. market availability of } \\
\text { technologies, cost and quality of design, } \\
\text { competing and complementary technologies } \\
\text { (Heiskanen and Matschoss, 2017) }\end{array}$ \\
\hline
\end{tabular}

References to the literature are used to support some of the attributes of these five elements, though the main objective is to show aspects which this thesis and its appended articles contribute with. Thus, the reference list is not exhaustive and neither are the specific subcategories. Finally, this conceptualisation does not claim absolute novelty, as it builds upon previous conceptualisations in the literature (e.g. Fichter and Clausen, 2016; Johanson and Vahlne, 2009; Rogers, 2003; Wejnert, 2002) as presented in the theoretical background. However, a potential distinctive aspect of the conceptualisation presented in this thesis is the combination of the complementarities between the diffusion of innovations and the international business literature. Specifically, distinctive attention is given to the actor level - technology suppliers, adopters, and the characteristics of environmental technologies, - and the aggregate level - the dynamic aspect of the export phenomenon and public policy. 
From this synthesis, recommendations are provided in the next chapter for policy makers, business managers and researchers, suggesting actions they can take to further the discourse on stimulating the diffusion of environmental technologies through export. 


\section{Implications}

In this chapter, the implications of the conclusions and synthesis from this thesis for policy making, business, and further research are presented.

\subsection{Implications for Policy Making}

The conclusions drawn from this thesis have potential implications for policy making, in particular governmental organisations tasked with the responsibility to promote the export of environmental technologies. As concluded in this thesis, export promotion initiatives seem to be relevant for the export of environmental technologies and their exporters, but their often generic and static nature contributes to their perceived ineffectiveness among environmental technology exporters.

Export promotion initiatives could thus become more effective by incorporating specific content-tailored export promotion initiatives into existing generic support measures. This recommendation reflects the understanding that, though environmental technologies and their suppliers have certain pronounced attributes which can influence their export as discussed throughout the thesis, they also face general challenges and barriers to export as experienced by technologies and exporters in general. Thus, a dynamic combination of generic and contenttailored support could be necessary for policy making. The recognition and incorporation of the specific attributes of environmental technologies and their exporters into export promotion initiatives is emerging, though not mainstream, as many initiatives continue to be generic or dedicated to the environmental technology sector but not tailored in content.

In striving for a balance between generic support and content-tailored support, other attributes which characterise the export of environmental technologies need to be incorporated. As conceptualised in the synthesis model in the previous chapter, environmental technology exporters are a heterogeneous group, and thus have different characteristics such as technology offerings, business concepts, drivers for and obstacles to export. Furthermore, these attributes do not remain static but change along with export business development. As pointed out in the synthesis conceptualisation, technologies are redesigned and adapted in the export process, exporters gain knowledge, and experience barriers to and drivers for export with different intensities and frequencies. Thus, a combination of generic and content tailored export promotion initiatives should also incorporate a dynamic aspect where initiatives are adapted in response to major signals from market trends, technological trajectories and the diffusion context in general.

From the four categories of governmental initiatives to promote the export of environmental technologies (financial aid, information provision, trade and mobility, and education and training programs), content-tailored financial support which enables technology suppliers to deliver their environmental technologies and also tackle potential risks of default along the life-cycle of technologies is more likely to represent an opportunity for more ambitious export promotion initiatives. This is because the analysis shows the appreciation of financial support among exporters and its relevance in perceived effectiveness of governmental export promotion initiatives. Furthermore, environmental technologies have potential environmental benefits not 
only at the point of adoption, but more so throughout their life cycle, and suppliers risk defaults even at those phases. In addition, the externalities and free-rider problems associated with environmental technologies suggest that special types of financing may be appropriate to internalise some of the benefits from the adoption of environmental technologies. Without such technology-specific support to complement current generic support, promising but currently uncompetitive technologies (e.g. in cost, performance) will not gain the support needed to become competitive and thus mainly incremental technologies might be chosen by the market (Azar and Sandén, 2011).

However, due to the need for resource effectiveness of governmental export promotion initiatives, resource allocation between competing sectors, the risks of government failure by "picking the wrong winners", and the complementary role of governmental intervention to market initiatives, governmental export promotion initiatives cannot be always expected to be tailored to the specific needs of individual companies or technologies (cf. Azar and Sandén, 2011). Furthermore, governmental initiatives are not self-sufficient, but rather complement market initiatives. Other avenues, such as the private market, and international city networks, could complement certain activities of governmental intervention such as gathering and disseminating market information, building legitimacy for technologies and their suppliers, and networking between technology suppliers and potential adopters.

Furthermore, the importance of policy instruments, in particular regulations in the adoption of environmental technologies, suggests that policy formulations (e.g. technology policies) to promote the export of environmental technologies should not be approached in isolation but with interaction from other influential policies (e.g. environmental policies). In particular, policymakers need to be aware of the potential interactions and interdependencies between their policies to promote the export of environmental technologies and other policies which could influence their initiatives, both in the home and target markets. For example, the importance of regulations on different markets such as the raw material market, technical markets, electricity, and heat market influence the potential export of waste management technologies, and thus policies formulated to promote their export must be aware of and anticipate interactions, consequences and counter effects from other relevant policies.

For governmental export promotion initiatives to be effective, in addition to their formulated content, their implementation also requires equal attention. Particularly, emphasis could be put on improving how target firms navigate the export promotion support system by reducing the degree of overlapping actors and their initiatives, tailoring access procedures to certain needs (e.g. application procedures for financial support could be less bureaucratic for small and micro enterprises) and directing firms between various agencies based on best available support. However, this suggestion might require other kinds of actors (e.g. intermediaries), who can bridge between various agencies and initiatives, and who have an overview of the export promotion system to foster more interactive learning and promotion activities. More so, the suggestion for improved interactions could be challenged by competition for clients and resources between various governmental agencies and their initiatives. 


\subsection{Implications for Business}

For managers of businesses interested in the export of environmental technologies, the components of business concepts synthesised in this thesis could serve as input for strategic discussions during export development.

In particular, the three components - regulation, legitimacy and public-private partnership - are relevant as this thesis demonstrates their importance for the diffusion of environmental technologies through export. Among these three components, partnerships seem to be within the direct action space of companies and can directly or indirectly contribute to building legitimacy and also gathering foreign market information including regulations.

At least two types of partnerships are suggested as potentially important for the export of environmental technologies. This is based on the notion that different types of companies such as municipally owned companies, privately owned large-sized companies, and small and mediumsized enterprises have complementary roles in the export of environmental technologies. These two types of partnerships are private-public partnerships and partnerships between incumbentsnew entrants in export.

Public-private partnerships are particularly important for stimulating the export of environmental technologies for different reasons. First, the public good nature of environmental benefits sometimes disincentives private firms from undertaking certain activities due to market failures and free-rider problems, which could hamper export activities. Furthermore, in export, there are externalities regarding gathering foreign market information, establishing contacts and distribution links to new markets, which private firms are hesitant to undertake entirely by themselves knowing that their competitors can benefit from such activities without bearing the total costs. Juxtaposing these challenges with some attributes of municipally owned companies, it is evident that municipally owned companies sometimes have different business logic in export which are not always profit-driven but could be inclined towards generating positive spillovers such as regional development, establishing linkages to foreign markets and strengthening the city brand, which could yield export opportunities for private firms.

As legitimacy is important to overcome liabilities of foreignness and newness in export, municipally owned companies have long-term experience in developing and operating large technical systems, have functioning proof-of-concept, are system integrators (including both the hard technical parts and the non-technological dimensions such as the governance and regulations) and have access to international networks, which private companies might struggle to establish. On the other hand, privately owned SMEs do supply hard technology to some municipally owned companies and thus could be the technological sources of such partnership, while municipally owned companies integrate the different actors, technical components and aspects (e.g. governance, regulations) of the technologies.

A complement to public-private partnerships for environmental technology export is partnerships between incumbents and new entrants in export. Incumbents in export e.g. SCANIA, are important for such export partnerships because they are often large-sized companies which have extensive export experience, international networks including local partners and subsidiaries, and a broader reach due to their established presence on different 
markets, and are also capable of taking higher financial risks in export (cf. Hockerts and Wüstenhagen, 2010). Incumbents often tackle systemic challenges such as city waste management or transportation, which presents opportunities for often small-sized, relatively new exporters, with relatively small international networks and market presence - "new entrants" - to partner with such incumbents in export. By forming such partnerships with incumbents, new entrants eventually internationalise. These new entrants can thus become even more specialised and deliver customised technologies while tackling particular challenges related to their size and export experience, such as liabilities of smallness and foreignness (cf. Johanson and Vahlne, 2009). Through such partnerships, firms could overcome the inherent limitations of size, export experience and ownership, and achieve the efficiencies required to compete on foreign markets. Specifically, smaller firms could be sheltered within their networks from harsh competition between the larger and more efficient networks (Etemad et al., 2001). Smaller firms can also specialise more and achieve economies of scale, while larger companies can also gain flexibility and access to technological innovations through such partnerships. Despite the potential benefits of such partnerships, they involve trade-offs between independence and efficiency, require trust and mutual commitment, and take time and resources to establish (Johanson and Vahlne, 2009). Thus, managers will have to devise new strategies to maintain network capabilities in addition to their internal competencies. 


\subsection{Implications for Further Research}

The conclusions and synthesis drawn in this thesis lead to several other questions which could further expand the discourse on environmental technology export.

First, this thesis has mainly focused on the export of environmental technologies, which is regarded as one approach to diffusion. Diffusion is one dimension of environmental technological change, which also encompasses invention and innovation (Del Río, 2009). An interesting extension to this thesis could be to analyse the interaction between the invention and innovation phase of environmental technologies and how that potentially influences export. This could include how to design and implement policy interventions, which would not only support invention but also innovation and diffusion. On the firm level, detailed attention could be given to how the export ambitions of companies influence their invention and innovation processes. Early intervention mechanisms could be formulated to encourage firms to develop "global" technologies right from the onset and escape from the idiosyncrasies of their home markets.

Second, an important question which emerges from this thesis is when and under which conditions environmental technologies and their suppliers should receive content-tailored support in combination with generic support. Specifically, four categories of export promotion initiatives are synthesised in this thesis as financial aid, information provision, education and training, and trade and mobility-related programs. How could policies related to these four categories be formulated to strive for a dynamic balance between generic and content-tailored support initiatives for environmental technology exporters? A complementary perspective could focus on the challenges of implementing such generic and content-tailored support from the perspective of export promotion and export credit agencies.

In this thesis, environmental technology has been analysed as a homogenous set of technologies, even though the cases presented in the articles already indicate differences between suppliers. This homogenous conceptualisation has been adopted particularly to reflect how governmental export promotion initiatives are organised in practise. However, the literature also acknowledges that different types of environmental technologies have different factors which influence their adoption (Fichter and Clausen, 2016; Institute for Prospective Technological Studies, 2004). Further research which disintegrates this homogenous conceptualisation of environmental technology into specific sub-sectors (e.g. renewable energy, waste management, air pollution control; or process vs. product environmental technologies) and how each sub-sector experiences export could provide direct input for supporting such sub-sectors, even though such an analysis could be conceptually challenging given that several environmental technology types cut across different sectors.

Finally, the attempt to conceptualise the diffusion of environmental technologies through export presented in this thesis beckons new research questions. The conceptualisation presents the opportunity for further interaction between the fields of international business and diffusion of innovation, drawing upon their complementary strengths and weaknesses, which is more likely to result in a comprehensive understanding of and approach to the export of environmental technologies than using either of the two fields alone. Furthermore, the conceptualisation consists of five main elements which could be further explored. How do these elements interact 
with each other in the export of environmental technologies? How could the interaction between the different elements influence the policies mix formulated to support the export of environmental technologies? Which additional elements could be considered in an analysis of the export of environmental technologies? Such a dynamic and interactive approach to the export of environmental technologies is more likely to foster their international diffusion and potential contributions to global sustainability. 


\section{References}

Albaum, G.S., Albaum, G., Duerr, E., 2008. International marketing and export management. Pearson Education, Harlow.

Alvesson, M., Sandberg, J., 2011. Generating research questions through problematization. Academy of Management Review 36, 247-271.

Amit, R., Zott, C., 2001. Value creation in e-business. Strategic management journal 22, 493-520.

Andersson, S., 2003. Innovative Internationalisation in New firms: Born Globals-the Swedish Case. Journal of International Entreprenuership, 249-276.

Andersson, S., 2004. Internationalization in different industrial contexts. Journal of Business Venturing 19, 851-875.

Andersson, S., Wictor, I., 2003. Innovative internationalisation in new firms: born globals-the Swedish case. Journal of International Entrepreneurship 1, 249-275.

Azar, C., Sandén, B.A., 2011. The elusive quest for technology-neutral policies. Environmental Innovation and Societal Transitions 1, 135-139.

Baas, L., 2007. To make zero emissions technologies and strategies become a reality, the lessons learned of cleaner production dissemination have to be known. Journal of Cleaner Production 15, 1205-1216.

Babbie, E.R., 2013. The basics of social research. Wadsworth Cengage Learning, Australia.

Baptista, R., 2001. Geographical Clusters and Innovation Diffusion. Technological Forecasting and Social Change 66, 31-46.

Barney, J.B., 1986. Organizational culture: can it be a source of sustained competitive advantage? Academy of Management Review 11, 656-665.

Batten, D.F., 1995. Network cities: creative urban agglomerations for the 21 st century. Urban studies 32, 313-327.

Beise, M., Rennings, K., 2005. Lead markets and regulation: a framework for analyzing the international diffusion of environmental innovations. Ecological Economics 52, 5-17.

Bell, J., McNaughton, R., Young, S., Crick, D., 2003. Towards an integrative model of small firm internationalisation. Journal of International Entrepreneurship 1, 339-362.

Berg, B.L., Lune, H., 2004. Qualitative research methods for the social sciences. Pearson, Boston.

Bergek, A., Jacobsson, S., Carlsson, B., Lindmark, S., Rickne, A., 2008. Analyzing the functional dynamics of technological innovation systems: A scheme of analysis. Research policy 37 , 407-429.

Bleda, M., Del Río, P., 2013. The market failure and the systemic failure rationales in technological innovation systems. Research policy 42, 1039-1052.

Boons, F., Montalvo, C., Quist, J., Wagner, M., 2013. Sustainable innovation, business models and economic performance: an overview. Journal of Cleaner Production 45, 1-8.

Bryman, A., 2015. Social research methods. Oxford university press, Oxford.

Canabal, A., White, G.O., 2008. Entry mode research: Past and future. International Business Review 17, 267-284.

Carrillo-Hermosilla, J., Del Río González, P., Könnöla, T., 2009. Eco-innovation: when sustainability and competitiveness shake hands. Palgrave Macmillan Hampshire.

Carrillo-Hermosilla, J., Del Río, P., Könnölä, T., 2010. Diversity of eco-innovations: Reflections from selected case studies. Journal of Cleaner Production 18, 1073-1083.

Cerin, P., Axelsson, U., Ekengren, Ö., 2007. Research, Development and Demonstration Strategies on Environmental Technology - Suggested foundations for a Formas-Vinnova strategy. IVL, Stockholm.

Chertow, M.R., 2000a. Accelerating Commercialization of Environmental Technology in the United States: Theory and Case Studies. PhD Thesis, Yale University.

Chertow, M.R., 2000b. The IPAT equation and its variants. Journal of Industrial Ecology 4, 1329. 
Chetty, S., Holm, D.B., 2000. Internationalisation of small to medium-sized manufacturing firms: a network approach. International Business Review 9, 77-93.

Cooke, P., Davies, C., Wilson, R., 2002. Innovation advantages of cities: from knowledge to equity in five basic steps. European Planning Studies 10, 233-250.

Corvellec, H., Bramryd, T., 2012. The multiple market-exposure of waste management companies: A case study of two Swedish municipally owned companies. Waste management 32, 1722-1727.

Corvellec, H., Bramryd, T., Hultman, J., 2012. The business model of solid waste management in Sweden-a case study of two municipally-owned companies. Waste Management \& Research 30, 512-518.

Corvellec, H., Zapata Campos, M.J., Zapata, P., 2013. Infrastructures, lock-in, and sustainable urban development: the case of waste incineration in the Göteborg Metropolitan Area. Journal of Cleaner Production 50, 32-39.

Czinkota, M., Ronkainen, I., 2006. International marketing. The Dryden Press, Hinsdale.

Dean, T.J., McMullen, J.S., 2007. Toward a theory of sustainable entrepreneurship: Reducing environmental degradation through entrepreneurial action. Journal of Business Venturing 22, 50-76.

DEFRA, DTI, 2002. Global Environmental Markets and the UK Environmental Industry: Opportuinities to 2010, in: Department for Environment, F.a.R.A., Industry, D.f.T.a. (Eds.).

Del Río, P., 2005. Analysing the factors influencing clean technology adoption: a study of the Spanish pulp and paper industry. Business strategy and the environment 14, 20-37.

Del Río, P., 2009. The empirical analysis of the determinants of technologicall change: A research agenda. Journal of ecological economics, 861-878.

Del Río, P., Carrillo-Hermosilla, J., Könnölä, T., 2010. Policy Strategies to promote ecoinnovation: An Integrated Framework. Journal of Industrial Ecology 14, 541-557.

Del Río, P., Peñasco, C., Romero-Jordán, D., 2016. What drives eco-innovators? A critical review of the empirical literature based on econometric methods. Journal of Cleaner Production 112, Part 4, 2158-2170.

Dentchev, N., Baumgartner, R., Dieleman, H., Jóhannsdóttir, L., Jonker, J., Nyberg, T., Rauter, R., Rosano, M., Snihur, Y., Tang, X., 2015. Embracing the variety of sustainable business models: social entrepreneurship, corporate intrapreneurship, creativity, innovation, and other approaches to sustainability challenges. Journal of Cleaner Production.

Dunning, J.H., 1988. The eclectic paradigm of international production: A restatement and some possible extensions. Journal of international business studies 19, 1-31.

Estrin, S., 2012. The Internationalization of State Owned Enterprises: The Impact of Political Economy and Institutions. London Business School. Available at http://personal.lse.ac.uk/estrin/Publication $\% 20 \mathrm{PDF} \% 27 \mathrm{~s} /$ Internationalization $\% 20 \mathrm{of} \%$ 20SOEs.pdf [Last accessed 2017-08-08].

Etemad, H., Wright, R.W., Dana, L.P., 2001. Symbiotic international business networks: collaboration between small and large firms. Thunderbird International Business Review 43, 481-499.

European Commision, 2016. Closing the loop - New circular economy package., European Parliamentary Research Service. PE 573.899.

European Commission, 2007. Supporting the internationalisation of SMEs - Final report of the expert group., p. 38.

Fichter, K., Clausen, J., 2016. Diffusion Dynamics of Sustainable Innovation-Insights on Diffusion Patterns Based on the Analysis of 100 Sustainable Product and Service Innovations. Journal of Innovation Management 4, 30-67.

Field, A., 2013. Discovering statistics using IBM SPSS statistics. Sage, Los Angeles. 
Fillis, I., 2002. Barriers to internationalisation-An investigation of the craft microenterprise. European Journal of Marketing, 912-927.

Finnveden, G., 2000. On the limitations of life cycle assessment and environmental systems analysis tools in general. The International Journal of Life Cycle Assessment 5, 229-238.

Fletcher, R., 2001. A holistic approach to internationalisation. International Business Review 10, 25-49.

Font Vivanco, D., Kemp, R., van der Voet, E., 2015. The relativity of eco-innovation: environmental rebound effects from past transport innovations in Europe. Journal of Cleaner Production 101, 71-85.

Frankelius, P., 2009. Questioning two myths in innovation literature. The Journal of High Technology Management Research 20, 40-51.

Frankelius, P., Hultman, C., Linton, G., Johanzon, C., Gunnarsson, C., 2011. The cleantech mystery: new theoretical model for understanding export capabilities in small and medium-sized innovative cleantech companies, The R\&D Management Conference 2011. $\mathrm{R} \& \mathrm{D}$, Sustainability \& Innovation, the need for new ideas, initiatives and alliances, Norrköping, Sweden 28-30 June.

Furlong, K., 2015. Water and the entrepreneurial city: The territorial expansion of public utility companies from Colombia and the Netherlands. Geoforum 58, 195-207.

Furlong, K., 2016. The public shareholder: The commercialization and internationalization of publicly owned utility corporations. Utilities Policy 40, 104-106.

Geels, F.W., Schot, J., 2010. The dynamics of transitions: a socio-technical perspective, in: Grin J., Rotmas, J., Schot, J., Transitions to sustaibable development: New directions in the study of long term transformative change. Routledge, New York.

Grin, J., Rotmans, J., Schot, J., 2010. Transitions to sustainable development. New Directions in the Study of Long Term Tansformative Change, New York.

Guba, E.G., Lincoln, Y.S., 1994. Competing paradigms in qualitative research. Handbook of qualitative research $2,105$.

Guziana, B., 2011. Is the Swedish environmental technology sector 'green'? Journal of Cleaner Production 19, 827-835.

Heiskanen, E., Matschoss, K., 2017. Understanding the uneven diffusion of building-scale renewable energy systems: A review of household, local and country level factors in diverse European countries. Renewable and Sustainable Energy Reviews 75, 580-591.

Heiskanen, E., Nissilä, H., Lovio, R., 2015. Demonstration buildings as protected spaces for clean energy solutions-the case of solar building integration in Finland. Journal of Cleaner Production 109, 347-356.

Hockerts, K., Wüstenhagen, R., 2010. Greening Goliaths versus emerging Davids-Theorizing about the role of incumbents and new entrants in sustainable entrepreneurship. Journal of Business Venturing 25, 481-492.

Howlett, M., Vince, J., del Río, P., 2017. Policy Integration and Multi-Level Governance: Dealing with the Vertical Dimension of Policy Mix Designs. Politics and Governance 5, 69-78.

Institute for Prospective Technological Studies, 2004. Promoting environmental technologies: Sectoral analyses, barriers and measures, Sevilla (Spain).

ITPS, 2008. Svensk miljöteknik - En Kartläggning av Aktörer, Marknader och Konkurrenter [Swedish Environmental Technology - A Map of Actors, Markets and Competititors]. Institutet för tillväxpolitiska studier (ITPS), Report A2008:009.

Jackson, T., 2009. Prosperity without growth: Economics for a finite planet. Earthscan, UK.

Jacobsson, S., Johnson, A., 2000. The diffusion of renewable energy technology: an analytical framework and key issues for research. Energy Policy 28, 625-640.

Jaffe, A.B., Newell, R.G., Stavins, R.N., 2002. Environmental policy and technological change. Environmental and resource economics 22, 41-70. 
Jaffe, A.B., Newell, R.G., Stavins, R.N., 2005. A tale of two market failures: Technology and environmental policy. Ecological Economics 54, 164-174.

Jaffe, A.B., Stavins, R.N., 1995. Dynamic Incentives of Environmental Regulations: The Effects of Alternative Policy Instruments on Technology Diffusion. Journal of Environmental Economics and Management 29, S43-S63.

Johanson, J., Mattsson, L.G., 2015. Internationalisation in industrial systems-a network approach, Knowledge, Networks and Power. Springer, pp. 111-132.

Johanson, J., Vahlne, J.E., 1977. The internationalization process of the firm-a model of knowledge development and increasing foreign market commitments. Journal of international business studies, 23-32.

Johanson, J., Vahlne, J.E., 2009. The Uppsala internationalization process model revisited: From liability of foreignness to liability of outsidership. Journal of international business studies 40, 1411-1431.

Kairento, K., Nygårds, M., 2014. Export of municipal environmental technology knowledge : An analysis of previous activities and incentives. Masters thesis LIU-IEI-TEK-A-14/01823-SE, Linköping University.

Kanda, W., Hjelm, O., Kairento, K., Nygårds, M., 2016a. Export of environmental technologies by publicly owned companies: approaches, drivers and obstacles among Swedish municipal companies. European Planning Studies 24, 2175-2196.

Kanda, W., Hjelm, O., Mejiá-Dugand, S., 2012. Environmental technology export promotion: A review of governmental initiatives in selected countries. LIU-IEI-R, 12:005, 2012, Linköping University, Linköping, p. 42.

Kanda, W., Hjelm, O., Mejía-Dugand, S., 2016b. Promoting the export of environmental technologies: An analysis of governmental initiatives from eight countries. Environmental Development 17, 73-87.

Kanda, W., Mejía-Dugand, S., Hjelm, O., 2015a. Environmental technology exports: Analyzing Swedish government and firms' initiatives, Greening of Industry Network Conference 2012, Linköping, p. 15.

Kanda, W., Mejía-Dugand, S., Hjelm, O., 2015b. Governmental export promotion initiatives: awareness, participation, and perceived effectiveness among Swedish environmental technology firms. Journal of Cleaner Production 98, 222-228.

Kanda, W., Olof, H., Bienkowska, D., 2016c. Internationaliastion among Swedish biogas companies - Drivers, Barriers and Business models, Biogas Research Center Annual Meeting, Linköping.

Kanda, W., Sakao, T., Hjelm, O., 2016d. Components of business concepts for the diffusion of large scaled environmental technology systems. Journal of Cleaner Production 128, $156-$ 167.

Kanda, W., Tomohiko Sakao, Olof Hjelm, 2013. Business models for market expansion of Swedish municipal environmental technologies, Linköping University, p. 24.

Karakaya, E., Hidalgo, A., Nuur, C., 2014. Diffusion of eco-innovations: A review. Renewable and Sustainable Energy Reviews 33, 392-399.

Keiner, M., Kim, A., 2007. Transnational city networks for sustainability. European Planning Studies 15, 1369-1395.

Kemp, R., Volpi, M., 2008. The diffusion of clean technologies: a review with suggestions for future diffusion analysis. Journal of Cleaner Production 16, S14-S21.

Kivimaa, P., 2014. Government-affiliated intermediary organisations as actors in system-level transitions. Research policy 43, 1370-1380.

Kraaijenbrink, J., Spender, J.C., Groen, A.J., 2010. The resource-based view: a review and assessment of its critiques. Journal of management 36, 349-372. 
Kumcu, E., Harcar, T., Kumcu, M.E., 1995. Managerial perceptions of the adequacy of export incentive programs: Implications for export-led economic development policy. Journal of Business Research 32, 163-174.

Lay, G., Schroeter, M., Biege, S., 2009. Service-based business concepts: A typology for businessto-business markets. European Management Journal 27, 442-455.

Lederman, D., Olarreaga, M., Payton, L., 2010. Export promotion agencies: Do they work? Journal of Development Economics 91, 257-265.

Leonidou, L.C., 1995. Empirical research on export barriers: review, assessment, and synthesis. Journal of International Marketing, 29-43.

Leonidou, L.C., Fotiadis, T.A., Christodoulides, P., Spyropoulou, S., Katsikeas, C.S., 2015. Environmentally friendly export business strategy: Its determinants and effects on competitive advantage and performance. International Business Review 24, 798-811.

Leonidou, L.C., Katsikeas, C.S., Palihawadana, D., Spyropoulou, S., 2007. An analytical review of the factors stimulating smaller firms to export: Implications for policy-makers. International Marketing Review 24, 735-770.

Leonidou, L.C., Palihawadana, D., Theodosiou, M., 2011. National export-promotion programs as drivers of organizational resources and capabilities: effects on strategy, competitive advantage, and performance. Journal of International Marketing 19, 1-29.

Lieberherr, E., Truffer, B., 2015. The impact of privatization on sustainability transitions: A comparative analysis of dynamic capabilities in three water utilities. Environmental Innovation and Societal Transitions 15, 101-122.

Magretta, J., 2002. Why business models matter. Havard Business Review 80 (5), 86-92.

Mason, J., 1996. Qualitative researching. Sage, London.

Mason, K., Spring, M., 2011. The sites and practices of business models. Industrial Marketing Management 40, 1032-1041.

Meade, N., Islam, T., 2006. Modelling and forecasting the diffusion of innovation - A 25-year review. International Journal of Forecasting 22, 519-545.

Mejía-Dugand, S., 2013. Diffusion of Environmental Technology in a Megacity - A case study of Mexico City. Licentiate Thesis No. 1574, Linköping University Electronic Press, Linköping, p. 73.

Mejía-Dugand, S., 2015a. A city's utility company as an axis for its sustainable development: A case study of EPM of Medellín, Colombia.

Mejía-Dugand, S., 2015b. Environmental Technology and its Role in the Search for Urban Environmental Sustainability: The Dynamics of Adaptation. PhD Thesis No. 1659, Linköping University Electronic Press.

Mejía-Dugand, S., Hjelm, O., Baas, L., Ríos, R.A., 2013. Lessons from the spread of bus rapid transit in Latin America. Journal of Cleaner Production 50, 82-90.

Mejía-Dugand, S., Kanda, W., Hjelm, O., 2014. Analyzing city networks for the diffusion of environmental innovations: A study of five major Swedish cities, 17th European Roundtable on Sustainable Consumption and Production (ERSCP 2014), 14-16 October 2014, Portoroz, Slovenia. Nigrad dd, pp. 197-206.

Mejía-Dugand, S., Kanda, W., Hjelm, O., 2016. Analyzing international city networks for sustainability: a study of five major Swedish cities. Journal of Cleaner Production 134, Part A, 61-69.

Mignon, I., 2016. Inducing large-scale diffusion of innovation: An integrated actor-and systemlevel approach. PhD Thesis No. 1777, Linköping University Electronic Press.

Mignon, I., Bergek, A., 2016. System-and actor-level challenges for diffusion of renewable electricity technologies: an international comparison. Journal of Cleaner Production 128, 105-115.

Montalvo, C., Kemp, R., 2008. Cleaner technology diffusion: case studies, modeling and policy. Journal of Cleaner Production 16, S1-S6. 
Norrman, C., 2008. Entrepreneurship Policy : Public Support for Technology-Based Ventures. PhD Thesis No. 1175, Linköping University Electronic Press, Linköping, p. 112.

OECD, 2009. Eco-Innovation in Industry:Enabling green growth. OECD publishing, France.

Okkonen, L., Suhonen, N., 2010. Business models of heat entrepreneurship in Finland. Energy Policy 38, 3443-3452.

Onwuegbuzie, A.J., Johnson, R.B., Collins, K.M., 2009. Call for mixed analysis: A philosophical framework for combining qualitative and quantitative approaches. International journal of multiple research approaches 3, 114-139.

Osland, G.E., Taylor, C.R., Zou, S., 2001. Selecting international modes of entry and expansion. Marketing intelligence \& planning 19, 153-161.

Osterwalder, A., Pigneur, Y., 2010. Business model generation: a handbook for visionaries, game changers, and challengers. John Wiley \& Sons.

Patton, Q.M., 2002. Qualitative research and evaluation methods. Sage Publications Inc, California.

Peñasco, C., del Río, P., Romero-Jordán, D., 2017. Analysing the role of international drivers for eco-innovators. Journal of International Management 23, 56-71.

Peng, M.W., 2001. The resource-based view and international business. Journal of management 27, 803-829.

Rennings, K., 1998. Towards a theory and policy of eco-innovation-Neoclassical and (Co-) Evolutionary Perspectives. ZEW Discussion Papers.

Rennings, K., 2000. Redefining innovation-eco-innovation research and the contribution from ecological economics. Ecological Economics 32, 319-332.

Rennings, K., 2014. Introduction: Global diffusion of environmental innovations. Environmental Innovation and Societal Transitions 10, 1-3.

Rogers, E.M., 2003. Diffusion of innovations. The Free Press, Simon and Schuster, New York.

Rohrbeck, R., Konnertz, L., Knab, S., 2013. Collaborative business modelling for systemic and sustainability innovations. International Journal of Technology Management 63, 4-23.

Saeedi, M.R., 2017. Pluripotent Dynamic Capabilities in the Internationalization of Firms: Focus on Learning, Innovating and Networking in SMEs from Sweden. PhD Thesis No. 1800, Linköping University Electronic Press.

Sarkar, J., 1998. Technological diffusion: alternative theories and historical evidence. Journal of economic surveys 12, 131-176.

SFS, 1991:900. Kommunallag. Stockholm: Ministry of Justice.

SFS, 2009:47. Lag om vissa kommunala befogenheter. Stockholm: Ministry of Justice.

Simmie, J., 2003. Innovation and Urban Regions as National and International Nodes for the Transfer and Sharing of Knowledge. Regional Studies 37, 607-620.

SKL, 2013a. 150 år av självstyrelse $[150$ years of self-government]. Available: http://www.skl.se/kommuner_och_landsting/darfor_ar_sjalvstyrelse_bra/vad_ar_kom munal_sjalvstyrelse [Acessed 2013-12-03].

SKL, 2013b. Så styrs en kommun. Available: http://www.skl.se/kommuner_och_landsting/sa_styrs_en_kommun [Acessed 2013-1203].

Smith, D., Gregoire, P., Lu, M., 2006. Managers' perceptions of export barriers: a cross-cultural perspective of service firms. Journal of Transnational Management 12, 51-68.

Statistics Sweden, 2015. Environmental accounts - SEK 220 billion turnover in environmental sector.

Statistics Sweden, 2016. Environmental Accounts MIR 2015:6, Creating statistics about environmental technology (clean tech).

Suarez-Ortega, S., 2003. Export barriers: insights from small and medium-sized firms. International Small Business Journal 21, 403-419.

Swentec, 2008a. Action Plan for Swedish Cleantech. 
Swentec, 2008b. Swedish strategies and initiatives for promotion of environmental technology-A national roadmap for the implementation of the EU Action Plan for Environmental Technology, ETAP.

Taye, M., Kanda, W., Krook, J., Lindahl, M., 2014. E-Waste in Gaborone, Botswana-Assessing The Generation, Handling Practices, and Strategies For Improvement. The Journal of Solid Waste Technology and Management 40, 349-356.

The Swedish Government, 2011. Strategi för utveckling och export av miljöteknik 2011-2014 [Strategy for development and export of environmental technology 2011-2014]. The Swedish Government, Sweden. Available at www.regeringen.se/sb/d/14218/a/174071.

[Accessed 2012-05-27].

The Swedish Government, 2013. Environental Technology - 13 Swedish solutions, Västerås. The Swedish Ministry of the Environment, 2005. Environmental Technology. Available at http://www.government.se/sb/d/5400/a/43595 [Accessed 2014-12-04]

Thomasson, A., 2009. Navigating in the landscape of ambiguity: A stakeholder approach to the governance and management of hybrid organisations. Lund University.

Tsvetkova, A., Gustafsson, M., 2012. Business models for industrial ecosystems: a modular approach. Journal of Cleaner Production 29, 246-254.

Turnheim, B., Geels, F.W., 2012. Regime destabilisation as the flipside of energy transitions: Lessons from the history of the British coal industry (1913-1997). Energy Policy 50, 3549.

UN General Assembly, 2015. Transforming Our World: The 2030 Agenda for Sustainable Development.

UNFCCC, 2009. Report of the Conference of Parties on its fifteenth session, held in Copenhagen from 7 to 19 December 2009.

UNFCCC, 2015. Adoption of the Paris Agreement. Report of the Conference of the Parties, held in Paris from 30 November to 11 December 2015.

Valente, T.W., Rogers, E.M., 1995. The origins and development of the diffusion of innovations paradigm as an example of scientific growth. Science communication 16, 242-273.

Wejnert, B., 2002. Integrating models of diffusion of innovations: A conceptual framework. Annual review of sociology, 297-326.

Wernerfelt, B., 1984. A resource-based view of the firm. Strategic management journal 5, 171180.

Volpe Martincus, C., Carballo, J., 2010. Export promotion: bundled services work better. The World Economy 33, 1718-1756.

WWF, 2012. Coming clean: The Global Cleantech Innovation Index 2012. Cleantech group LLC; WWF

WWF, 2014. The Global Cleantech Innovation Index 2014. Cleantech group LLC; WWF.

Yin, R.K., 2008. Case study research: Design and methods. SAGE Publications, Incorporated, USA.

Zimmerman, M.A., Zeitz, G.J., 2002. Beyond survival: Achieving new venture growth by building legitimacy. Academy of Management Review 27, 414-431.

Zou, S., Stan, S., 1998. The determinants of export performance: a review of the empirical literature between 1987 and 1997. International Marketing Review 15, 333-356.

Öhrwall Rönnbäck, A., 2010. Collaborative Innovation for Entering Emerging Markets, ISPIM Innovation Symposium-Managing the Art of Innovation: Turning Concepts into Reality, Quebec City, Canada, 12-15 December 12/12/2010-15/12/2010. 


\section{Papers}

The articles associated with this thesis have been removed for copyright reasons. For more details about these see:

http://urn.kb.se/resolve? urn:nbn:se:liu:diva-139979 